\title{
Recent Advances in the Synthesis of Heterocycles via Reactions Involving Elemental Sulfur
}

\author{
Thanh Binh Nguyen ${ }^{\text {a* }}$ \\ a Institut de Chimie des Substances Naturelles, CNRS UPR 2301 \\ Université Paris-Sud, Université Paris-Saclay \\ 1, avenue de la Terrasse, Gif-sur-Yvette, 91198, France
}

Dedicated to Dr. Gilles Dujardin on the occasion of his 63th birthday

Abstract. It is well known that heterocycles are among the
most significant molecules for everyday life, ranging from Keywords: Elemental sulfur; Heterocycle; Sulfur
natural products and bioactive substances to functional heterocycle; Nitrogen heterocycle; Thiophene
materials. This review will focus on the synthesis of
heterocycles by reactions involving elemental sulfur
published from 2017 until now.

\section{Introduction}

It is well known that heterocycles are among the most significant molecules for everyday life, ranging from natural products and bioactive substances to functional materials. The role played by modern organic chemistry is to develop cheaper, greener, more direct and more sustainable synthetic methods of these molecules while avoiding environmental problems and natural resource depletion.

As a waste produced by modern oil and gas refineries at 70 million tons per year, sulfur is an extremely cheap raw material. Its low toxicity along with its unique physical properties (stable, odorless, non-hygroscopic, free-flowing solid at rt) makes this substance a user-friendly synthetic tool ${ }^{[1]}$ of both sulfur-containing and sulfur-free heterocycles.

At the beginning of 2017, we have reviewed significant organic reactions involving elemental sulfur for the period 2000-2016. ${ }^{[2]}$ From 2017, reports on such reactions prospered thanks to its amazingly rich chemistry along with all the above-mentioned qualities of this element as a reagent. Since elemental sulfur is one of the central molecules of our research, we feel the need to prepare this short review to provide the readers with a detailed and comprehensive overview of development on the organic synthesis with this element from 2017 until now. However, reminders of reactions reported before this period will be given when necessary.

Due to the complexity of the reactivities of elemental sulfur, we arbitrarily divide its organic reactions into two main categories based on the presence or not of the starting sulfur in the final products. For the first category, sulfur is undeniably the best source of sulfur atoms in the formation of organosulfur. If sulfur is not incorporated in the final product, it can act as an oxidant, reductant or catalyst as a single component or in combination with other catalysts.

Sulfur is in general not very reactive under ambient conditions but can become highly reactive upon heating and/or in the presence of a base or a transition metal ion or complex. With appropriate choices of activating conditions, its reactivity could be strongly modified.

Thanh Binh Nguyen received his B. Sc. in chemistry from University of Natural Sciences in Hochiminh city, Vietnam in 2004. In 2005 he completed his M. Sc. in Université du Maine, Le Mans, France under the guidance of Pr. J. Mortier and Dr. A. S. Castanet. He pursued his Ph.D. studies in the same university under supervision of Dr. G.

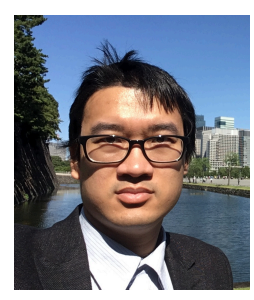
Dujardin, Pr. R. Dhal and Dr. A. Martel (2005-2008). After a postdoctoral stay in the laboratory of Dr. F. Guéritte and Dr. Q. Wang at Institut de Chimie des Substances Naturelles - Gif-sur-Yvette, France (2009-2011), he became a researcher of the CNRS, working with Dr. A. Almourabit in the same institute. He started his independent career as a principle investigator in 2017. His research interests focus on the exploration of new reactivity and application of elemental sulfur, molecular iodine and iron in organic synthesis, as well as photochemistry in solid and suspension state with a strong interest in bioactive molecules and sulfurcontaining functional materials. 
Throughout the review, while elemental sulfur is indicated as cyclooctasulfur $\mathrm{S}_{8}$ to respect its molecular structure, its equivalent number in a given reaction was based on atomic sulfur (32 mg.mmol ${ }^{-1}$ ).

\section{Elemental sulfur acting as a sulfur source}

\subsection{Thiophenes and thiophenes fused with a non aromatic system}

Acetophenone 1 was found to undergo a sulfurative dimerization when heated with elemental sulfur to provide thiophene 2 (Scheme 1). ${ }^{[3]}$ The reaction was catalyzed by both aniline and a strong Brønsted acid such as PTSA via formation of key scaffold but-2-en1 -one 3 or its imine derivative with aniline.

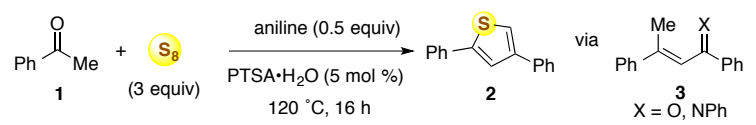

\section{Scheme 1}

Similar transformation was observed with cyclopentanone $\mathbf{4}$, leading to fused thiophene $\mathbf{5}$, whereas complex mixtures were obtained with higher cycloalkanones (cyclohexanone, cycloheptanone)

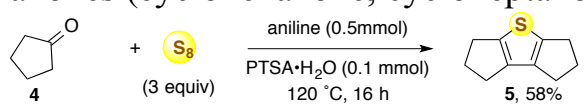

\section{Scheme 2}

The generation of the key scaffold but-2-en-1-one could be achieved in different manners. For example, Deng et al performed the condensation of phenylacetaldehyde 6 with 1,3-diketone (7, R = Alkyl) or $\beta$-ketoester $(7, \mathrm{R}=\mathrm{OAlkyl})$ with $\mathrm{K}_{2} \mathrm{CO}_{3} / \mathrm{KHCO}_{3}$ (3.5 equiv) as base catalysts in the presence of sulfur (Scheme 3). ${ }^{[4]}$ In this case, the initially formed but-2en-1-one 8 underwent an isomerization to its thermodynamically more stable regioisomers but-3en-1-one 9, which reacted with sulfur to produce thiophenes $\mathbf{1 0}$ in good yields.

$$
6 \text { (2 equiv) }
$$

\section{Scheme 3}

Alternatively, dihydrofuran $\mathbf{1 5}$, a synthetic equivalent of but-3-en-1-one 9, could react with elemental sulfur in the presence of morpholine catalyst in a similar manner (Scheme 4). This intermediate $\mathbf{1 5}$ could be generated by triethylamine catalyzed threecomponent reaction between penta-2,4-dione 11, benzaldehyde $\mathbf{1 2}$ and $\alpha$-pyridiniumacetophenone bromide 14 (generated from reaction between phenacyl bromide $\mathbf{1 3}$ and pyridine). ${ }^{[5]}$

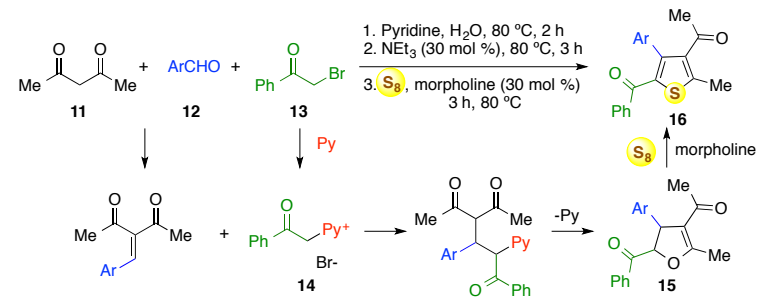

\section{Scheme 4}

Likewise, 1,3-diketo compounds such as 4hydroxycoumarine, ethyl acetoacetate, dimedone and cyclohexa-1,3-dione could be used in place of penta2,4-dione, whereas $p$-nitrobenzyl chloride displayed the same reactivity in this kind of multicomponent reactions. Selected examples were shown in Scheme 5.

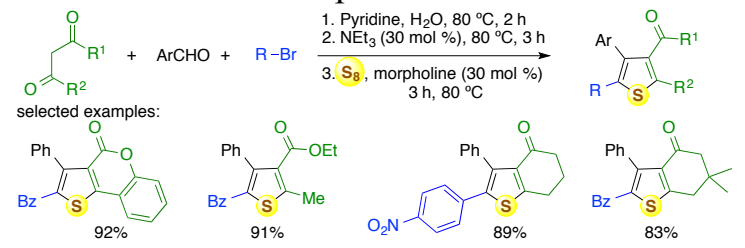

\section{Scheme 5}

The combination of aromatic aldehydes and phenacyl bromides could be replaced by chalcones $\mathbf{1 7}$ as a unique component (Scheme 6). ${ }^{[6]}$ In this case, the first step was a Michael addition of 1,3-diketone or $\beta$ ketoester 18 to chalcones 17 catalyzed by triethylamines whereas the second step followed exactly the same pathway.

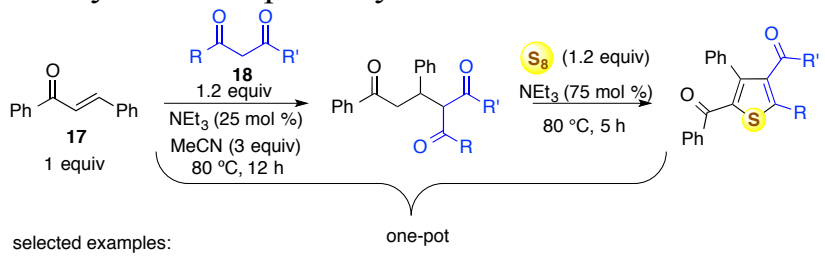

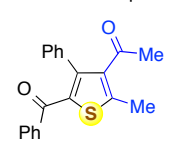

$84 \%$

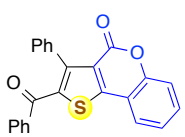

$83 \%$

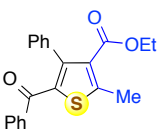

$80 \%$

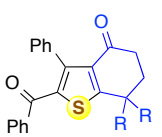

$90 \%$

\section{Scheme 6}

Conjugated butenyne or enyne system bearing a trifluoromethyl group such as $\mathbf{1 9}$ reacts in the same manner (Scheme 7). ${ }^{[]]}$Thiophene 21 was expected to be generated from the reaction of $\mathbf{1 9}$ with sulfur upon heating with $\mathrm{K}_{2} \mathrm{CO}_{3}$ in DMF was found to be further trapped by gaseous chlorodifluoromethane $\mathbf{2 0}$ via difluorocarbene to give 22. Similar reactivity was observed with elemental selenium.

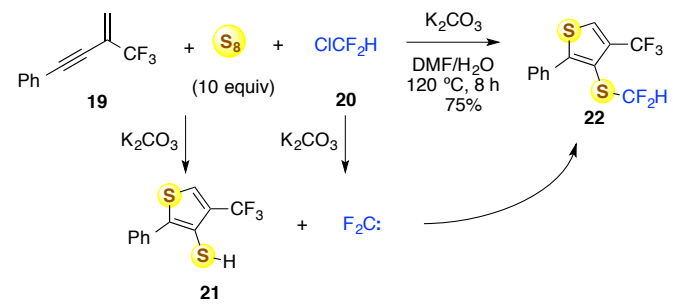

Scheme 7. 
Gewald reaction is unarguably one of the best methods to synthesize 2-aminothiophenes. ${ }^{[8]}$ One of its important version consists in a three-component assembly of ketones with acetonitriles substituted by a strong electron withdrawing group (such as ester, amide, nitrile) and elemental sulfur. Recently, the Gewald reaction condition was proven to be compatible to boronate substrates $\mathbf{2 3}$, leading to the corresponding 2-aminothiophenes $\mathbf{2 4}$ readily functionalized by known boron chemistry (Scheme 8). ${ }^{[9]}$

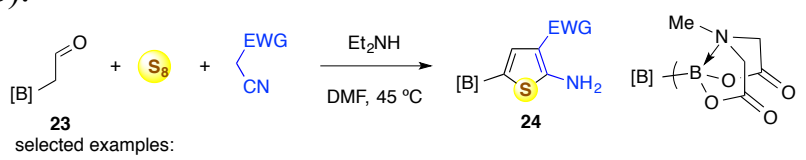

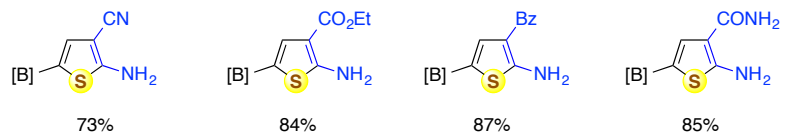

Scheme 8.

The Michael-Gewald four component reaction was developed to increase rapidly the molecular diversity ${ }^{[10]}$ For this purpose, the carbonyl components for the Gewald reaction $\mathbf{2 7}$ were formed by the conjugate addition of different indole derivatives 25 to $\alpha, \beta$-unsaturated aldehydes 26 (Scheme 9). This is followed by an in situ Gewald three-component reaction which results in the formation of compound 28 bearing an indole and a 2-aminothiophene moiety separated by one-carbon spacer.

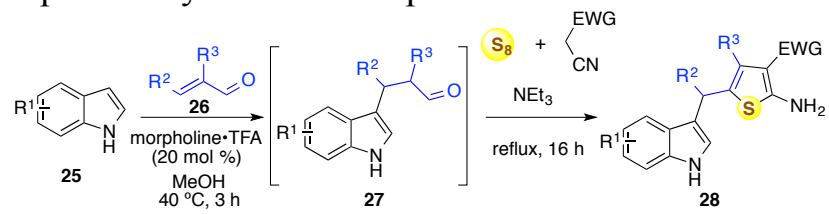

Scheme 9.

The carbonyl component in Gewald reaction could be replaced by a benzylidenemalononitrile 29, which could be easily generated by condensation of an aldehyde with malononitrile (Scheme 10). ${ }^{[1]}$ Alternatively, direct four-component reaction could be accomplished with proline catalyst.

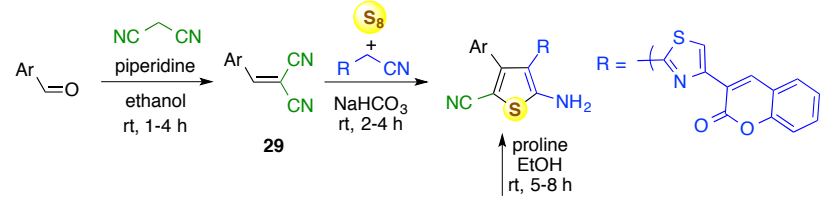

$$
\begin{aligned}
& \mathrm{S}_{8} \mathrm{R}_{\mathrm{CN}} \\
& { }_{\mathrm{NC}} \widehat{C}_{\mathrm{CN}}{ }^{\mathrm{Ar}}\llcorner=\mathrm{O}
\end{aligned}
$$

\section{Scheme 10.}

One of the limitations of Gewald reaction is the acetonitrile components should be substituted by a strong electron donating group. Moreover, chalcones were not previous known as the ketone component for this reaction. In view of this missing literature, we have developed a new version of Gewald reaction between chalcones 30, arylacetonitriles $\mathbf{3 1}$ and sulfur (Scheme 11). ${ }^{[12]}$

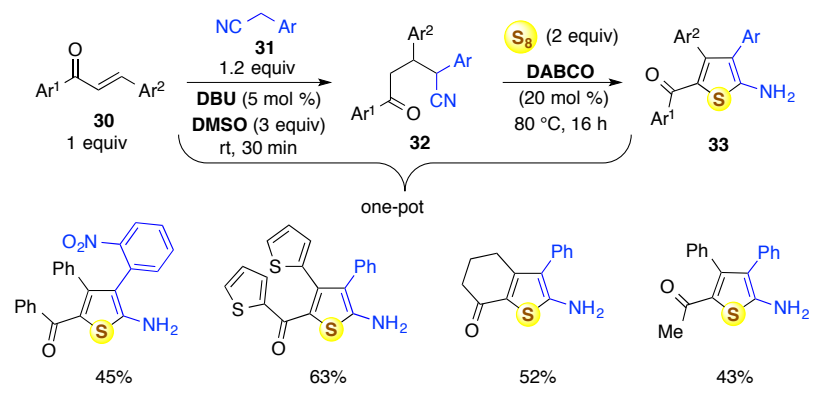

Scheme 11.

The first step of formation of Michael adduct 32 between chalcones and arylacetonitriles was efficiently performed with DBU as a strong organic base catalyst. These conditions led to the expected adduct $\mathbf{3 2}$ even at $\mathrm{rt}$ form less than $30 \mathrm{~min}$. On the other hand, DABCO was found to be particularly useful base catalyst for subsequent thienylation of 4-cyano-1-propanones 32, leading to a wide range of fully substituted 2aminothiophenes 33. Compared to classical Gewald reaction, our transformation consists in an additional oxidizing aromatization with $\mathrm{S}_{8} / \mathrm{DMSO}$. The strategy was successfully applied to a wide range of arylacetonitriles and chalcones and could also be extended to cyclohex-2-enone and benzalacetone, despite in lower yields.

When cyanoacetate $\mathbf{3 4}$ was submitted to the same conditions, the reaction stopped at the stage of formation of trans-dihydrothiophene adduct $\mathbf{3 5}$ without further aromatization (Scheme 12).

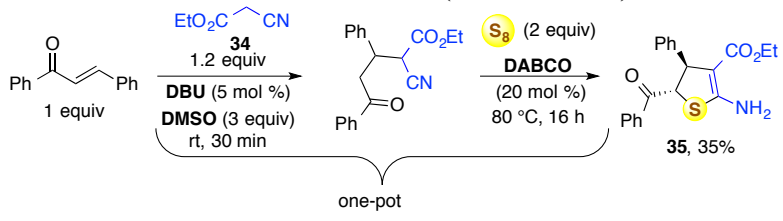

\section{Scheme 12.}

It was found that the low valent transition metalphosphine complexes systems genenated in situ from $[\mathrm{M}]-\mathrm{Ph}_{3} \mathrm{P}-\mathrm{Et}_{3} \mathrm{Al}(1: 2: 4)$ could catalyze thienylation of $N, N$-dimethylhept-2-yn-1-amine $\mathbf{3 6}$ to $\mathbf{3 7}$ along with the formation of thioamide 38 in various proportions (Scheme 13). ${ }^{[13]}$ Thiophene 37 was selectively formed in $58 \%$ yield when $\gamma-\mathrm{Al}_{2} \mathrm{O}_{3}$-supported $\mathrm{Co}(\mathrm{OAc})_{2}$ was used as Co catalyst precursor.

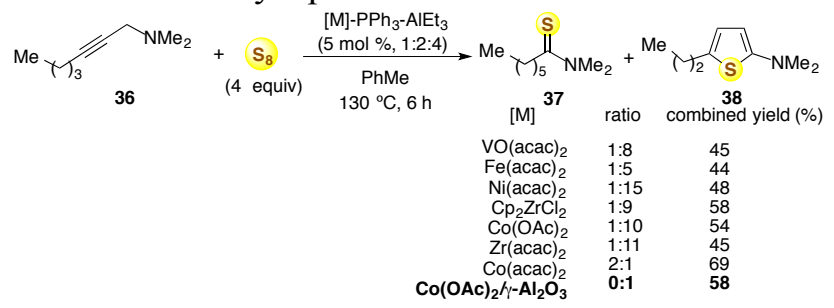

\section{Scheme 13.}

Interestingly, bis-thiophene $\mathbf{4 0}$ was formed exclusively from decadiynediamine $\mathbf{3 9}$ with elemental sulfur catalyzed by $\mathrm{Co}(\mathrm{acac})_{2}-\mathrm{PPh}_{3}-\mathrm{AlEt}_{3} \quad(1: 2: 4)$ (Scheme 14). 


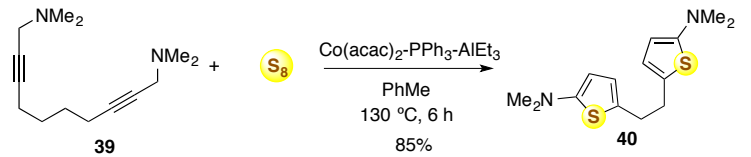

Scheme 14.

The diaryldiacetylene $\mathbf{4 1}$ system could be thienylated to $\mathbf{4 2}$ with elemental sulfur and a suitable base such as $\mathrm{NaSH}$ or $t$-BuONa even at $\mathrm{rt}$ (Scheme $15) \cdot{ }^{[14]}$

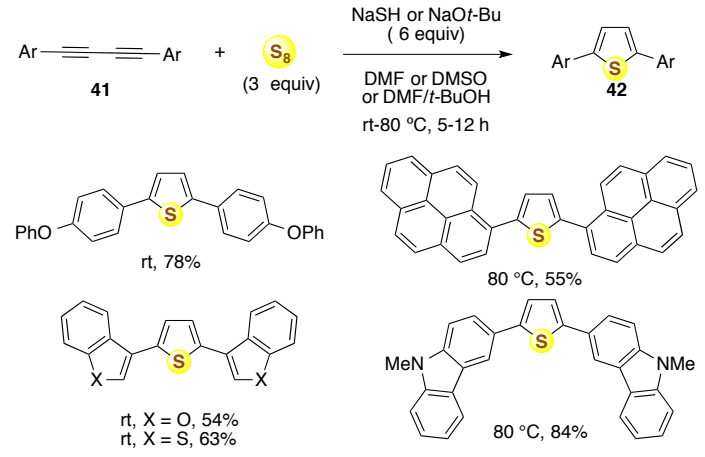

Scheme 15.

Heating was required for polyaromatic or heteroaromatic substrates. Theoretically, the transformation consists in a double addition of dihydrogen sulfide to two triple bonds.

Treatment of 43 with $\mathrm{NaSH}$ generated from the reduction of $\mathrm{S}_{8}$ with $\mathrm{NaBH}_{4}$ in DMF led to the corresponding sulfur heterocycles $\mathbf{4 4 - 4 5}$ in moderate yields (Scheme 16). ${ }^{[15]}$ The reaction followed as sequence of nucleophilic sulfuration and cyclization. When substituted by a phenyl group, the product exists as benzylidene form $\mathbf{4 5}$, whereas aromatic form $\mathbf{4 4}$ is exclusive for $t$-butyl derivative.
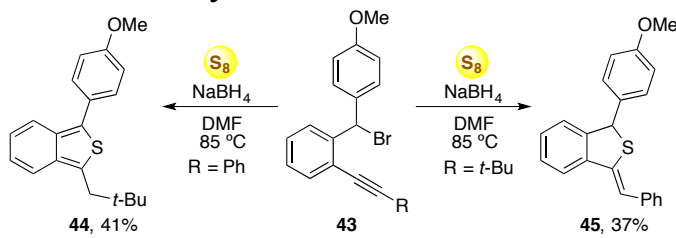

Scheme 16.

\subsection{Thiophenes fused with aromatic carbocycles}

\subsubsection{Benzothiophenes}

2-Nitrochalcones 46, readily obtained from classical Claisen-Schmidt condensation between $O$ nitrobenzaldehydes and acetophenones, could serve as excellent precursors for the synthesis of 2benzoylbenzothiophenes 47 (Scheme 17). ${ }^{[16]}$ When treated with sulfur in the presence of DIPEA or similar tertiary amines, chalcones $\mathbf{4 6}$ underwent a cascade of reactions of alkene sulfuration, aromatic sulfurative denitration and cyclization in the absence of transition metal catalyst. Later, this reaction was found to be operational even at $\mathrm{rt}$ when DMSO was used as additive. ${ }^{[17]}$ The reaction conditions tolerated in general many functional group, including halogen, which serve at starting point for further functionalization of benzothiophenes products. Notably, the sulfurative denitration was specific for ortho-nitro groups, while other meta and para-nitro groups remained untouched.

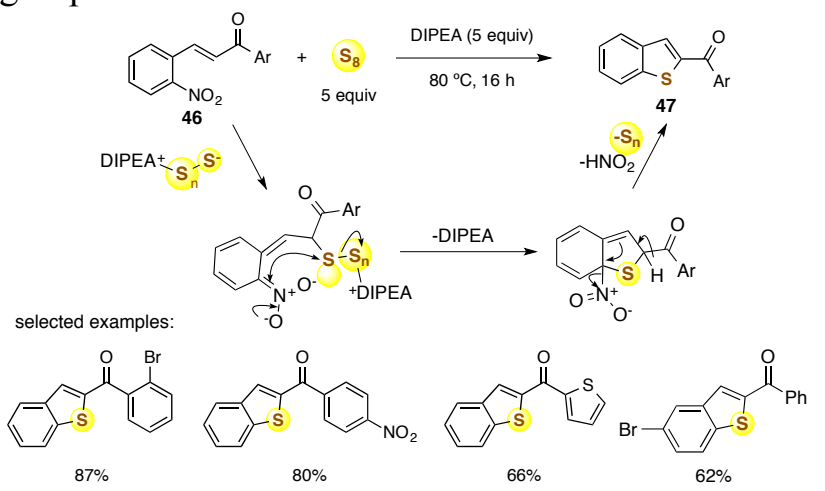

Scheme 17.

The strategy of sulfurative denitrative cyclization was further applied to $o$ '-nitrochalcones $\mathbf{4 8}$, leading consistently to thioaurones 49 (Scheme 18). This family of products, well known for their photochromic properties with application as photoswitch, was previously synthesized via multistep sequences involving malodorous thiol/sulfide precursors as well as strong bases. Interestingly, the reactions were found to proceed even at $\mathrm{rt}$ for substrates bearing electron withdrawing groups. With substrates which are substituted by strong and multiple electron donating groups or/and sterically demanding, the expected products could be formed at higher temperatures in satisfactory yields.

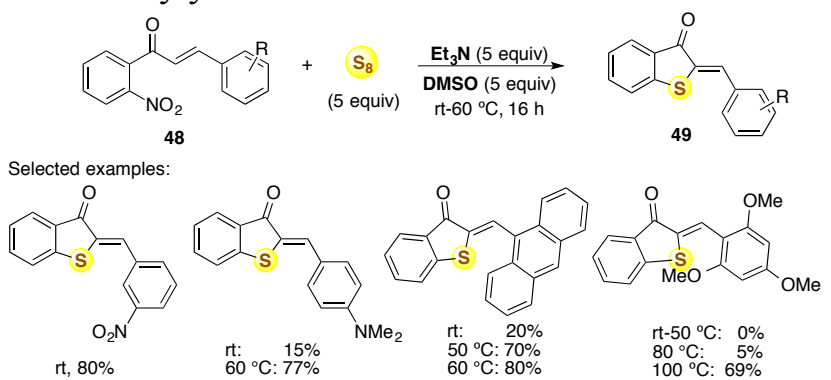

Scheme 18.

Very recently, Miura et al. proposed a synthesis of benzothiophene $\mathbf{5 2}$ by rhodium-catalyzed threecomponent coupling reaction of arylboronic acids 50, alkynes 52, and elemental sulfur with silver acetate as oxidant (Scheme 19). ${ }^{[18]}$ An interesting feature of this method is the formation of benzothiophenes 52a with high regioselectivity when non symmetrical alkynes were used. The reaction proceeded via a sequence of alkyne insertion, $\mathrm{C}-\mathrm{H}$ activation, and then sulfur atom transfer to the metallacycle intermediate.

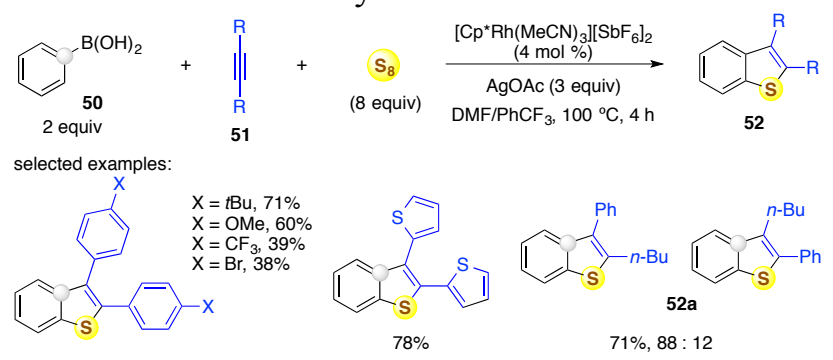

Scheme 19. 
Likewise, dibenzothiophenes 54 can be assembled from the parent biarylboronic acids 53 (Scheme 20). The reaction was found to proceed at $\mathrm{rt}$ with stoichiometric amount of silver acetate oxidant.

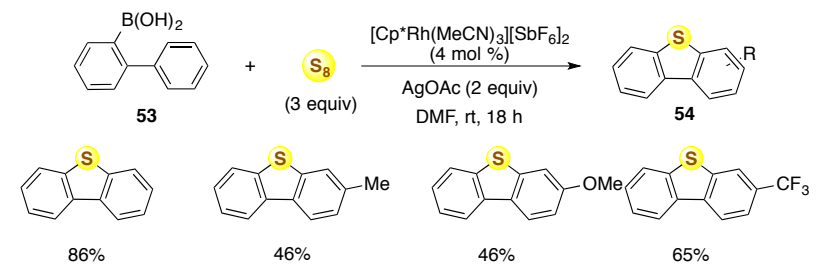

Scheme 20.

Yoshida et al found that the degree of annulative cyclization of 1,1-diphenylethylene $\mathbf{5 5}$ could be controlled by simply changing the quantity of iodine oxidant and reaction time (Scheme 21). ${ }^{[19]}$

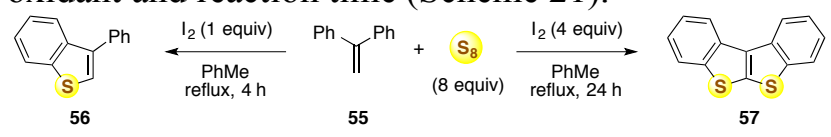

Scheme 21.

Disulfurative thienylation to $\mathbf{5 7}$ occurred upon prolonged heating excess molecular iodine, whereas shorter reaction time with stoichiometric amount of $\mathrm{I}_{2}$ led to 3-phenyl product $\mathbf{5 6}$.

Similar conditions applied to diphenylacetylene $\mathbf{5 8}$ produced both benzothiophenes 59 and $\mathbf{6 0}$ in low yields (Scheme 22). It should be noted that the reaction required sulfur and iodine in large excess.

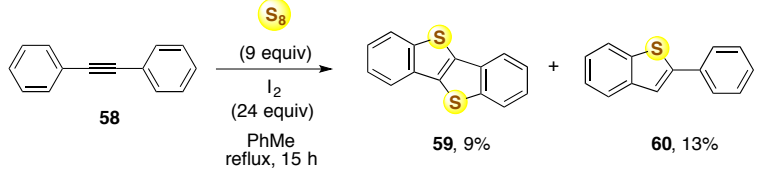

Scheme 22.

Non symmetrical $o, o$-lithiated diphenylacetylene $\mathbf{6 1}$ could be sulfurated with elemental sulfur to provide tetracyclic fused benzothiophenes 62a-b after oxidation with $\mathrm{K}_{3} \mathrm{Fe}(\mathrm{CN})_{6}$ in low yield as a mixture of both regioisomers (Scheme 23). ${ }^{[20]}$ Subsequent desulfuration with metallic copper led convergently to benzothienobenzothiophene $\mathbf{6 3}$ in excellent yield, despite high temperature of the process.

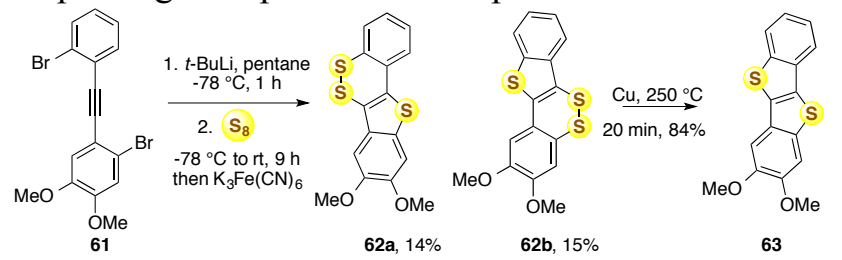

Scheme 23.

Nitro groups in a polycyclic aromatic system were known to be displaced by a sulfur group when heated with elemental sulfur. ${ }^{[21]}$ Recent exploitation of this unique chemistry was used to synthesize various molecules with interesting properties. ${ }^{[22]}$ For example, 1-nitroperylene 64 reacted with sulfur in $N$ methylpiperidone at $180{ }^{\circ} \mathrm{C}$ to provide fused thiophene 65 (Scheme 24). ${ }^{[23]}$

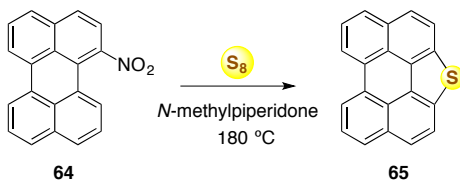

Scheme 24.

The reactions were found to be considerably facilitated in extensive fused aromatic system with electron withdrawing groups. Indeed, the reaction of mononitroperylene 66a with sulfur to produce thiophene 67 in good yield at $153^{\circ} \mathrm{C}$ (Scheme 25). ${ }^{[24]}$

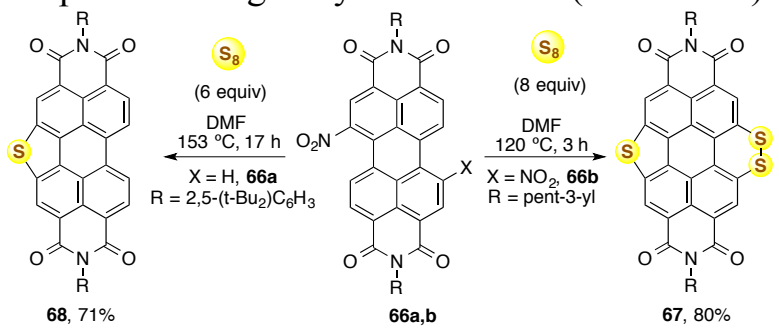

Scheme 25.

Notably, dinitroperylene $\mathbf{6 6 b}$ reacted with sulfur at lower temperature to provide thiophene product $\mathbf{6 8} .^{[25]}$ The degree of sulfuration seemed strongly dependent on the reaction temperature. This reaction was in agreement with the previous result observed with parent tetracarboxylic acid derivative. ${ }^{[26]}$

1-Ethynylanthaquinones 69 reacted readily when heated with a basic solution of sulfur in ethanol (Scheme 26). Both 2-H and 2-Cl substrates were competent substrates, leading to benzothiophenenaphthoquinone fused products $\mathbf{7 0}$ in good to excellent yields. ${ }^{[27]}$ It is obvious that the naphthoquinone facilitates this sulfurative annulation.

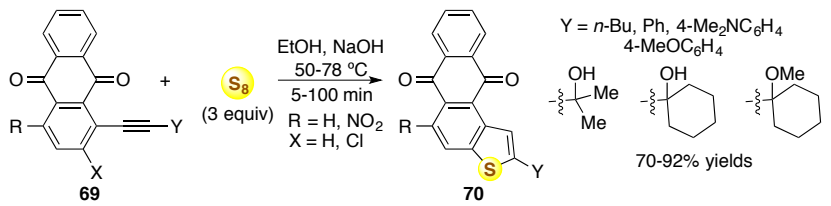

\section{Scheme 26.}

Naphthylphenylacetylene $\mathbf{7 1}$ reacted with sulfur at rt with $\mathrm{NaOH}$ as a base in DMF to provide fused thiophene $\mathbf{7 2}$ in low yield along with its dimer disulfide 73 (Scheme 27). ${ }^{[28]}$ When the reaction was performed at higher temperature with $\mathrm{NEt}_{3}$ as a base, the reaction resulted in thiophene $\mathbf{7 2}$ in excellent yield.
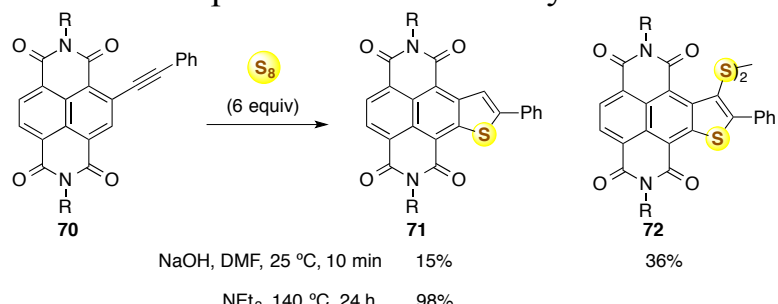

\section{Scheme 27.}

A fourfold thienylation of tetraethynylperylene $\mathbf{7 3}$ could be achieved via heating with large excess of sulfur upon prolonged heating in DMF (Scheme 28). ${ }^{[29]}$ 

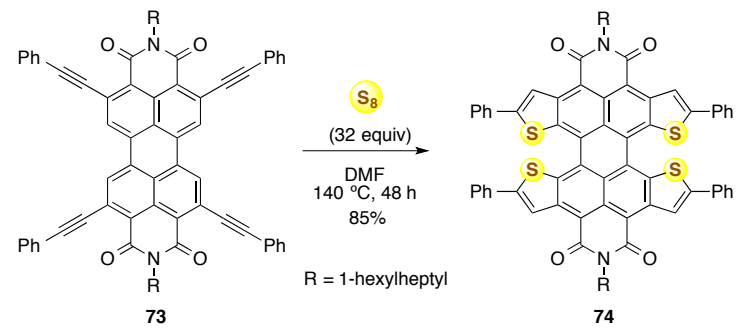

Scheme 28.

\subsection{Thiophene fused with azulene}

Thienylation of azulyl aryl acetylenes 75 could be achieved by heating with elemental sulfur in DMF (Scheme 29). ${ }^{[30]}$

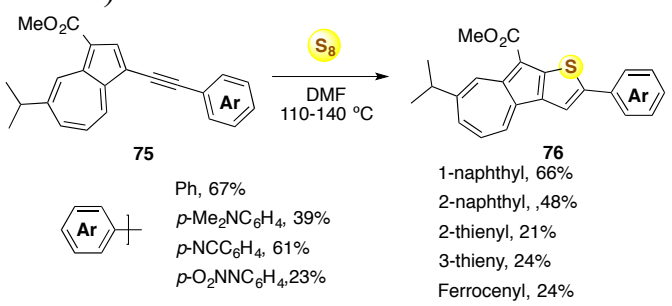

\section{Scheme 29.}

In view of the regiochemistry of this transformation, it is concluded that the azulene ring is more reactive than the benzene rings (substituted or not) as well as naphthalene, thiophene and ferrocene rings.

\subsection{Thiophene fused with heteroaromatic cycles}

\subsubsection{Thiophene fused with indole}

$\mathrm{N}$-Ethynylindole 77 could be cyclized into fused heterocycles $\mathbf{8 1}$ via a one-pot transformation including: (i) lithiation with strong base $n$-BuLi at low temperature to $\mathbf{7 8}$, (ii) sulfurative cyclization of $\mathbf{7 8}$ with elemental sulfur to $\mathbf{7 8}$ via $\mathbf{7 9}$, and (iii) $S$-alkylation of $\mathbf{8 0}$ with alkyl halides (Scheme 30 ). ${ }^{[31]}$ Contrary to the previous cases of sulfurative cyclization of aromatic ethynyl system, all the reactions of this approach occur at or below rt.

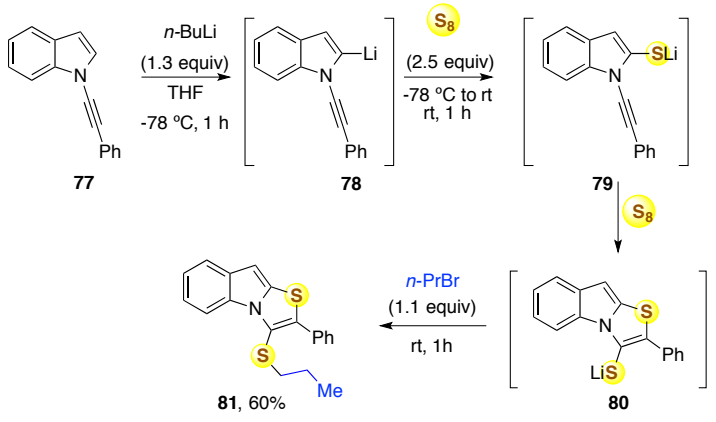

Scheme 30.

In 2019, Zhang et at reported as synthesis of $8 H$ thieno[2,3- $b$ ]indoles 83 via oxidative sulfuration of Friedel-Craft adducts $\mathbf{8 2}$ between indoles and chalcones (Scheme 31). The reaction occurred in DMSO at $120{ }^{\circ} \mathrm{C}$ in the presence of excess $\mathrm{NaO} t$-Bu and provided a wide range of fused heterocycles in good yields. ${ }^{[32]}$

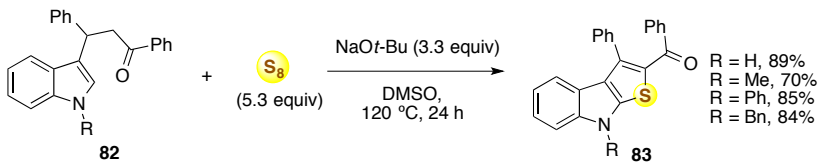

Scheme 31.

When the position 2 of the indole core is substituted as in 84, the thienylation proceeded on the phenyl ring, leading to bis-hetarene 85 in a moderate yield.
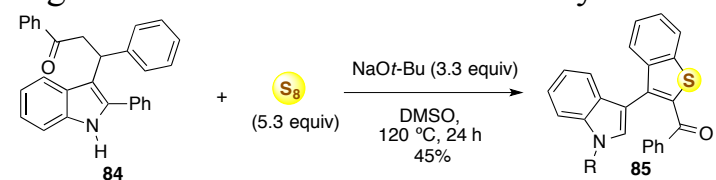

\section{Scheme 32.}

In 2017, Deng et al reported a regiodivergent threecomponent access to fused indole-thiophene heterocycles 87 or 89 by heating indoles with acetophenones and elemental sulfur (Scheme 33). ${ }^{[33]}$ In the presence of $\mathrm{HI}$ as a strong acidic promoter, the reaction proceeded via $\mathbf{8 6}$ as a result of a first step of Friedel-Craft reaction between indole and acetophenone followed by oxidative thienylation with elemental sulfur. On the other hand, when DMF was used as the solvent in the absence of the strong acid, the first step was as Willgerodt reaction of acetophenone with DMF, which acted as a high temperature dimethylamine source to provide $\mathbf{8 8}$. This step allowed migration of the electrophilic center to the end of acetophenone and reversed the regiochemistry of the reaction. ${ }^{[34]}$

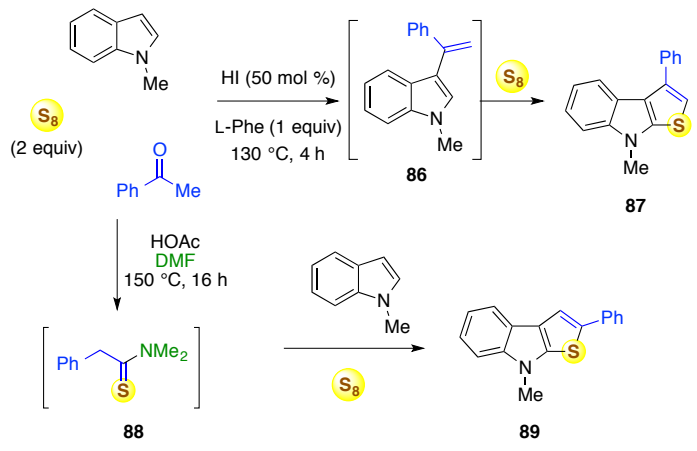

Scheme 33.

In a similar manner, cinnamic acid 91, which could involve in a decarboxylative Willgerodt pathway in DMF, displayed the same reactivity (Scheme 34$){ }^{[35]}$

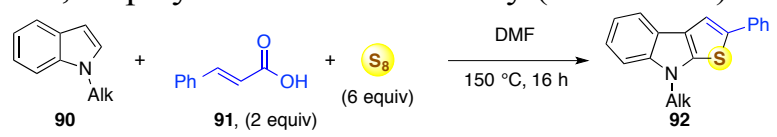

Scheme 34.

A similar set of conditions involving a stoichiometric amount of molecular iodine was applied to cyclohexanones 93 (Scheme 35). ${ }^{[36]}$ In this case, based on the regiochemistry of the final fused heterocycles when 4-substituted cyclohexanones were used, the formation of Friedel-Craft adducts 96 by the attack of C-3 of indoles 93 to the ketone function of cyclochexanones 94 was the first step. Iodine played an important role in this reaction, acting as both 
precursor for in situ generation of strongly acidic $\mathrm{HI}$ to catalyze the Friedel-Craft and as oxidant for sulfuration and aromatization.
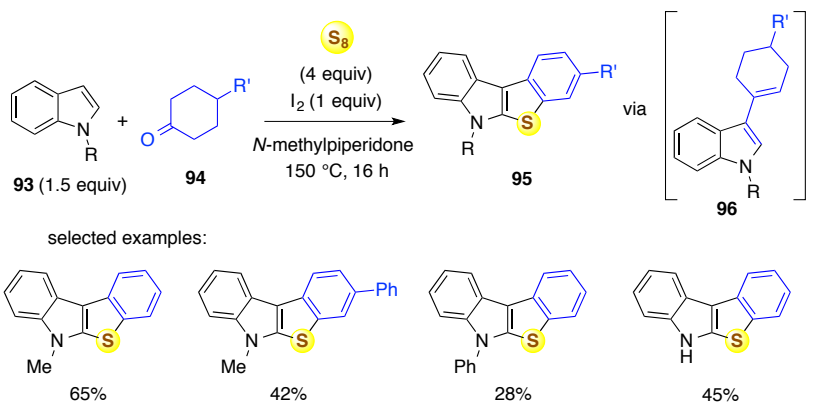

Scheme 35.

$\mathrm{Yu}$ et al reported a synthesis of $4 H$-thieno[3,2$b$ ]indole 98 via thermal sulfuration of 97 with elemental sulfur in HMPA (Scheme 36). ${ }^{[37]}$ Although the mechanism was not fully understood, the reaction involved scission of the triple bond with subsequent recombination of the benzylidyne group. When $\mathrm{Ar}^{1}$ is replaced by a methyl group, the reaction proceeded via a different pathway, leading to thieno[3,4-c]quinoline4(5H)-thione products $\mathbf{1 0 0}$ as a result of a cascade involving demethylation and disulfuration (see section 2.3.2).

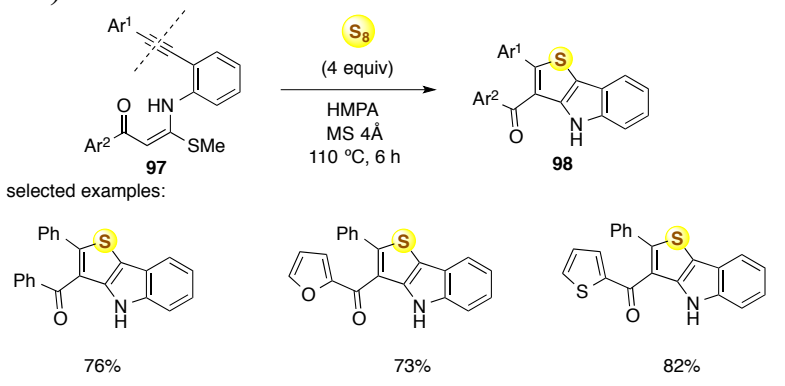

Scheme 36.

\subsubsection{Thiophenes fused with fused pyridines}

Construction of thieno[3,4-c]quinoline-4 $(5 H)$ thione $\mathbf{1 0 0}$ was accomplished by heating of 1phenylpropynes 99 with sulfur in HMPA (Scheme 37). ${ }^{[37]}$ The methyl group of the triple bond as well as methylthio were removed during this cascade of disulfuration.

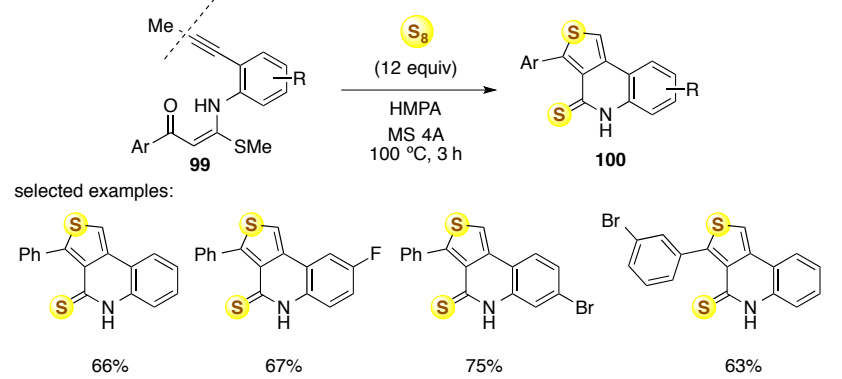

Scheme 37.

Khan et al developed a synthesis of 2benzoylthieno[2,3-b]quinolines $\mathbf{1 0 2}$ from 2-haloquinolinyl ketones 101 (Scheme 38) ${ }^{[38]}$ According to the proposed mechanism, the first step was a dehydrogenation of the propanone moiety to chalcone.
The presence of the pyridine would facilitate the subsequent displacement of the chloro by sulfur. While the reaction conditions were relatively complex with the involvement of copper-TEMPO-2,2'-bipyridine catalysts and tetrabutylammonium acetate as an ionic reaction medium, the reaction followed the same pathway as for the reaction of $o$-nitrochalcones with sulfur in the presence of a tertiary amine previously described by our group (Section 2.2.1). ${ }^{[16],[17]}$

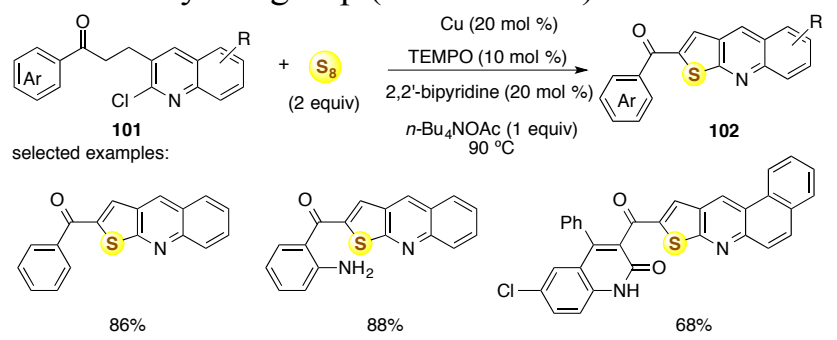

\section{Scheme 38.}

Huang et al reported a copper-catalyzed threecomponent access to a variety of benzo[4,5]thieno[3,2c] isoquinoline and thieno[3,2-c] isoquinoline $\mathbf{1 0 5}$ from methylketoxime acetates $\mathbf{1 0 3}, o$-halobenzaldehydes 104, and elemental sulfur (Scheme 39). ${ }^{[39]}$ It was postulated that 3-aminobenzothiophene would be formed from sulfuration of acetophenone oxime acetate.

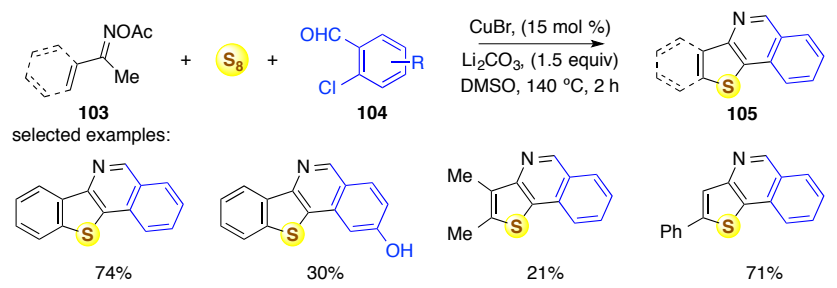

\section{Scheme 39.}

Acetylenes 106 bearing an aza anthraquinone moiety was found to react easily with elemental sulfur in a basic alcoholic solution (Scheme 40). ${ }^{[27]}$ The very short reaction time $(5 \mathrm{~min}$ ) could be explained by the presence of both ketone groups in the pyridine ring, which would facilitate the first step of aromatic sulfuration to fused thiophenes $\mathbf{1 0 7}$.

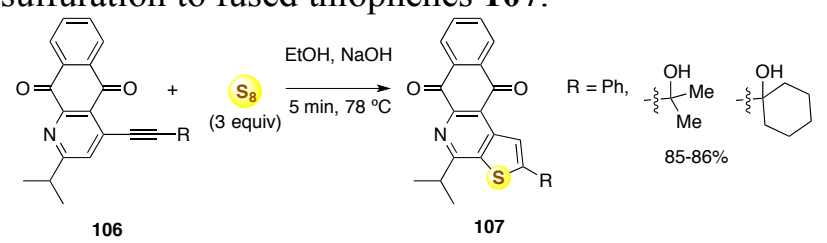

\section{Scheme 40.}

\subsubsection{Benzo[4',5'] thieno $\left[3^{\prime}, 2^{\prime}: 4,5\right]$ imidazo[1,2- a]pyridine}

Benzothieno-imidazo[1,2- $a$ ]pyridines 109 could be prepared in excellent yields (89-99\%) via sulfenylative cyclization of intramolecular sulfenocyclization of 2(2-halophenyl)imidazo[1,2-a]pyridine $\mathbf{1 0 8}$ using sulfur powder in the presence of copper catalyst (Scheme 41). ${ }^{[40]}$ Since $\mathrm{AcOH}$ was one of the reaction solvents and could react instantaneously with $t$-BuOK to 
provide $\mathrm{KOAc}$, the real base in this reaction should be KOAc.
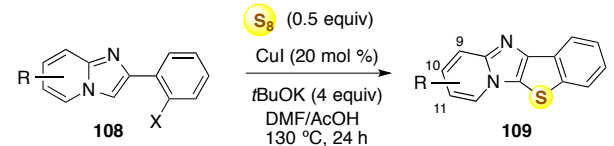

$\mathrm{R}=\mathrm{H}, \mathrm{X}=\mathrm{Br} 90 \%$

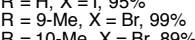
$\mathrm{R}=10-\mathrm{Me}, \mathrm{X}=\mathrm{Br}, 89 \%$ $\mathrm{R}=11-\mathrm{Me}, \mathrm{X}=\mathrm{Br}, 96 \%$

Scheme 41.

\subsubsection{Thieno[2,3-d]pyrimidine}

Thieno[2,3- $d$ ]pyrimidin-4-amines 111 could be conveniently synthesized via four-component reactions of ketones $\mathbf{1 1 0}$ and malononitrile with elemental sulfur in formamide (Scheme 42). ${ }^{[1]}$

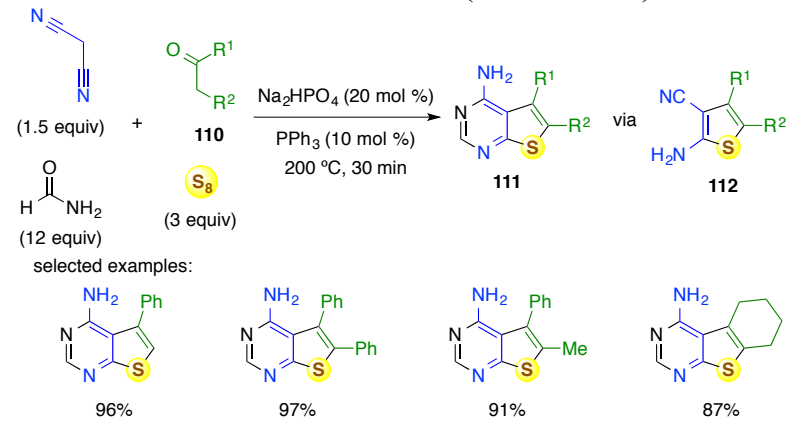

Scheme 42.

The reaction was based on a first step of threecomponent Gewald reaction, which occurred at lower temperature, followed by cyclocondensation of the Gewald adduct 112 with formamide. The second step required high temperature up to $200{ }^{\circ} \mathrm{C}$ and $\mathrm{Na}_{2} \mathrm{HPO}_{4}$ as a catalyst. The presence of a catalytic amount of triphenylphosphine was found to be beneficial to the reaction by preventing the dimerization of 112. A wide range of acetophenones as well as 2phenylacetophenone, propiophenone and cyclohexanone could be used as the ketone component in good to excellent yields.

\subsubsection{H-Thieno[3,2-b]chromen-9-one}

The skeleton of 114 could be formed by a cascade reaction of conjugated $o$-hydroxy dienone 113 with sulfur and chlorodifluoroacetate as difluorocarbene source (Scheme 43). ${ }^{[42]}$ The reaction was initiated by a base-induce cyclization into chromenone, followed by double sulfuration and carbene insertion.

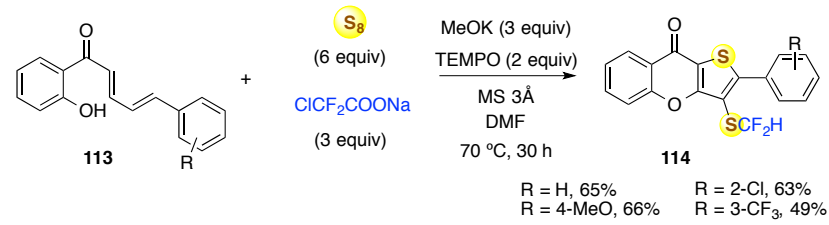

\section{Scheme 43.}

\subsubsection{Thiophene fused with thiazole}

In 2018, Deng et al reported a multicomponent access to thiophene-thiazole fused systems $116{ }^{[43]}$ On heating methyl ketone oxime acetates 115 with benzaldehydes and elemental sulfur in the presence of copper catalyst and $\mathrm{Li}_{2} \mathrm{CO}_{3}$ as a base in DMSO, a cascade of bis-heteroannulation was efficiently accomplished (Scheme 44). The method could also be applied to benzylideneacetone and $(E)$-3-methylpent- 3-en-2-one oxime acetates to yield 116d and 116e, respectively.

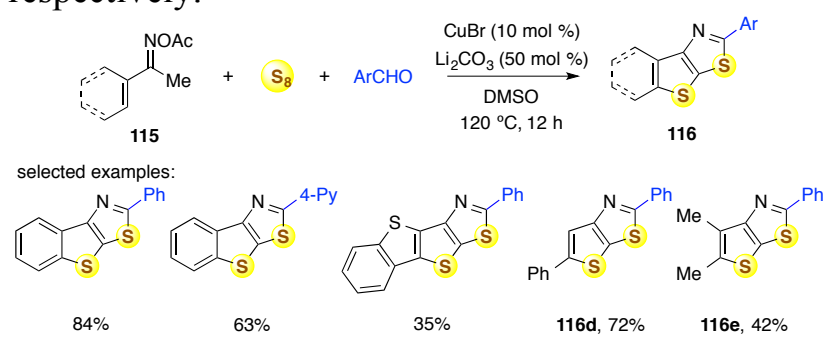

Scheme 44.

Inspired from this seminal finding, other extensions were developed by the same group and other (Scheme 45). All approaches were based on three-component reaction of sulfur with a $\mathrm{C}_{4} \mathrm{~N}_{1}$-synthon 117 and a $\mathrm{C}_{1}$ synthon 120, which provide $\mathrm{C}_{4} \mathrm{~N}_{1}$ and $\mathrm{C}_{1}$ fragments, respectively for the assembly of thieno[3,2-d] thiazole core 121. First, acetophenones oxime acetates could be replaced by $\alpha$-azidostyrene although much less efficiently with only one example in $33 \%$ yield (entry 1). ${ }^{[4]}$

Secondly, phenylacetylenes could be used as $\mathrm{C}_{1}$ synthon with loss of one carbon atom (entry 2). ${ }^{[4]}$ In both of these cases, the reactions required highly basic guanidine base triazabicyclodecene (TBD) in near stoichiometric amount.

Third, the presence of copper catalyst was found to be unessential as mentioned in the following cases (entries 3-10). Activated methyl groups could act as the $\mathrm{C}_{1}$-synthon as in the cases of methylhetarenes wherein the methyl group is in 2- or 4-position to the nitrogen atom of the azaheterocycles (entry 3), ${ }^{[4]}$ or acetophenones (entry 4), ${ }^{[4]}$ the reactions were accomplished with alkaline carbonates as the base catalyst.

Since acetophenone oxime acetates were prepared via two-step sequence from the parent acetophenones, an access involving directly acetophenones and a suitable nitrogen source would be highly desirable. Urea was suggested for this purpose (entries 5-6). ${ }^{[47]}$ By choosing appropriate additive, the reactions could proceed with loss (entry 5) or conservation (entry 6) of the methyl carbon of the acetophenone substrates. Moreover, it should be noted that acetophenone oximes themselves could be used directly as $\mathrm{C}_{4} \mathrm{~N}_{1}$ synthon with other acetophenones as $\mathrm{C}_{1}$-synthon (entry 7). ${ }^{[4]}$ Phenylacetic acids as well as their methyl esters could be employed as $\mathrm{C}_{1}$-synthon (entry 8). ${ }^{[49]} 2$ Acetonapthone as well as other acetylated poly(hetero)aromatic analogs could be used as $\mathrm{C}_{4-}$ synthon with benzylamines as $\mathrm{C}_{1} \mathrm{~N}_{1}$-synthon (entry 9). ${ }^{[50]}$ In this case the amino group of benzylamines acted as nitrogen building block for the construction thieno[3,2- $d$ ] thiazole core. It is evident that the polyaromatic system in 2-acetonapthone contributes to the success of the sulfuration of its $(\mathrm{C}-1)-\mathrm{H}$ bond, thus facilitate the formation of fused thieno[3,2- $d]$ thiazole. Indeed, similar reaction conditions applied to acetophenone resulted in 2,4-diphenylthiazole. Finally, Isothiocyanates could be used as $\mathrm{C}_{1}$-synthon, providing a convenient access to $N$-substituted 
thieno[3,2- $d$ ] thiazole derivatives. ${ }^{[51}$ In this case, reactions of alkyl isothiocyanates resulted in lower yields.

Concerning the reaction pathway, although the detailed mechanism was not fully elucidated, 3aminobenzothiophene was suggested to be the key intermediate, which is generated by successive sulfuration of the methyl group and the $o-\mathrm{C}-\mathrm{H}$ bond. Thanks to the presence of the sulfur atom of the benzothiophene ring, 3-aminobenzothiophene could be considered as an electron-enriched aniline, readily underwent an $o$-sulfuration upon heating as previously known. ${ }^{[85]-[90]}$ Subsequent oxidative condensation with $\mathrm{C}_{1}$-synthon promoted by elemental sulfur leading to benzothiophenes is a well-known process for the chemistry of this element.
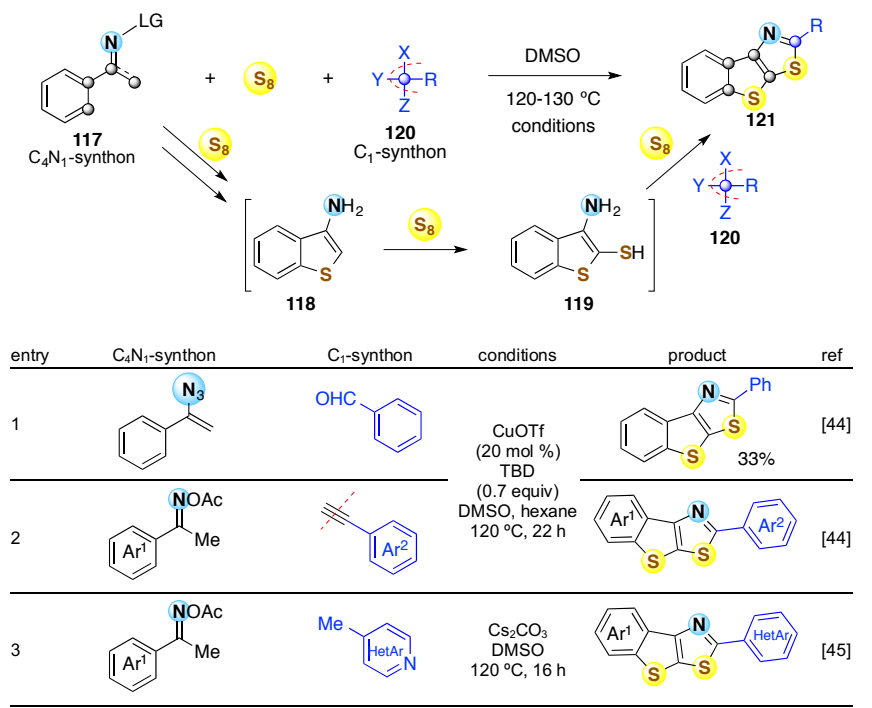

N

5 i

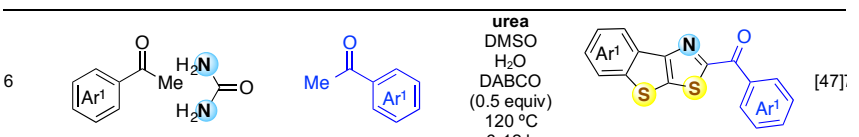

(12)

Scheme 45

According to the proposed reaction pathway, it is possible that 2-aminobenzothiophene 125 displays similar behavior (Scheme 46). ${ }^{[52]}$ Generated in situ from $o$-bromophenylacetonitriles $\mathbf{1 2 2}$ by copper- catalyzed sulfuration with elemental sulfur, this heteroaromatic amine could be further sulfuration and trapped with a benzadehyde to provide 2phenylbenzo[4,5] thieno[2,3- $d$ ] thiazole 124.

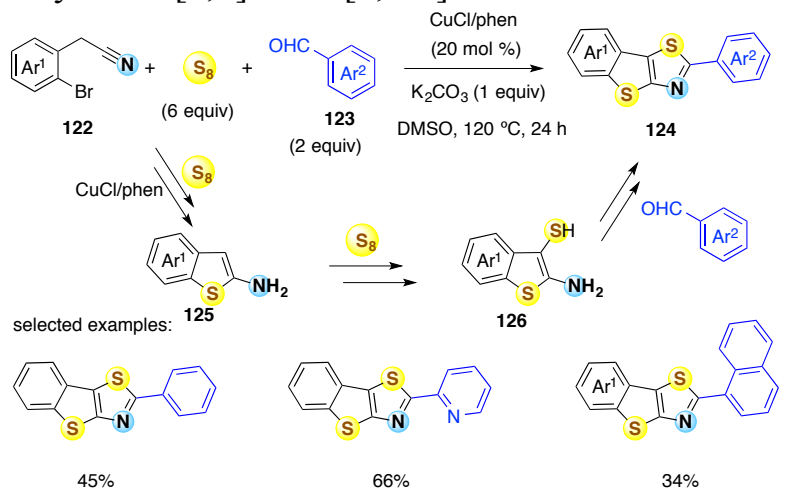

Scheme 46.

\subsection{1,2- and 1,3-Dithioles and other sulfa heterocycles with sulfur as the only heteroelement}

1,2-Dithiole-3-thione motif is found in numerous pharmaceuticals with interesting biological and medicinal utility. Reported recent syntheses were based on the use of elemental sulfur as both threesulfur atom donor and redox reagent on different derivatives of 1-arylpropynes $\mathbf{1 2 7}$ such as trifluoromethyl 127a $\mathbf{a}^{[53]}$ (Scheme 47, entry 1) or propargylamines 127b (Scheme 47, entry 2). ${ }^{[54]}$ In both cases, the reactions were performed in the presence of copper(I) salts as catalyst at $120{ }^{\circ} \mathrm{C}$. Sulfides issued from disproportionation reaction of elemental sulfur in the presence of inorganic bases such as $\mathrm{Cs}_{2} \mathrm{CO}_{3}$ and $\mathrm{K}_{3} \mathrm{PO}_{4}$, were suggested to initiate the reaction in these two cases. Alternatively, the reaction of arylpropenes 128a under thermal conditions required higher temperatures (Scheme 47, entry 3). ${ }^{[5]],[56]}$
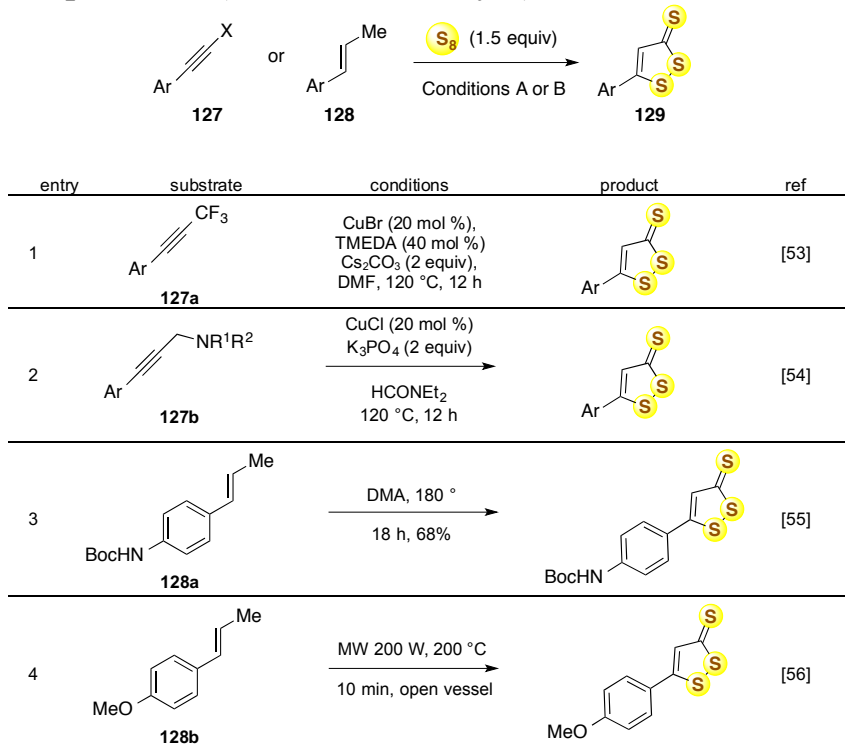

\section{Scheme 47.}

When a simple 1-arylpropene such as anethole $\mathbf{1 2 8 b}$ was used as a substrate (Scheme 47 , entry 4), ${ }^{[56]}$ 
various reaction conditions were applied to reduce the reaction time from several hours under conventional heating to $10 \mathrm{~min}$ under microwave irradiation, resulting in an improvement in yield and overcoming the undesired by-product formation associated with conventional methods. ${ }^{[57]}$

Curphey found that the combination of $\mathrm{P}_{4} \mathrm{~S}_{10}$, hexamethyldisiloxane (HMDO) and elemental sulfur was capable of converting 3-oxoesters 131 to dithiolethiones 132 with comparable or superior yields to those obtained with Lawesson's reagent. ${ }^{[58]}$ Interestingly, the byproducts of this method may be removed by a classical hydrolytic workup or by simple filtration through silica gel without chromatography, as required for Lawesson's reagent.

Recently, this method has been adapted to the synthesis of dithiolethiones presented in Scheme 48. ${ }^{[59]}$ Tetramethoxypropane $\mathbf{1 3 1}$ could be transformed into unsubstituted dithiolethiones with $\mathrm{P}_{4} \mathrm{~S}_{10} / \mathrm{S}_{8}$ without HMDO reducing agent since the two acetal group could play this role.

Open chain 3-oxoesters 131a as well as their cyclic 131b and benzo fused 131c analogues reacted smoothly to give substituted dithiolethiones 132a-c. Aldehyde derivative of malonate 131d under enol form reacted in the same manner, leading to ester 132d in moderate yield.

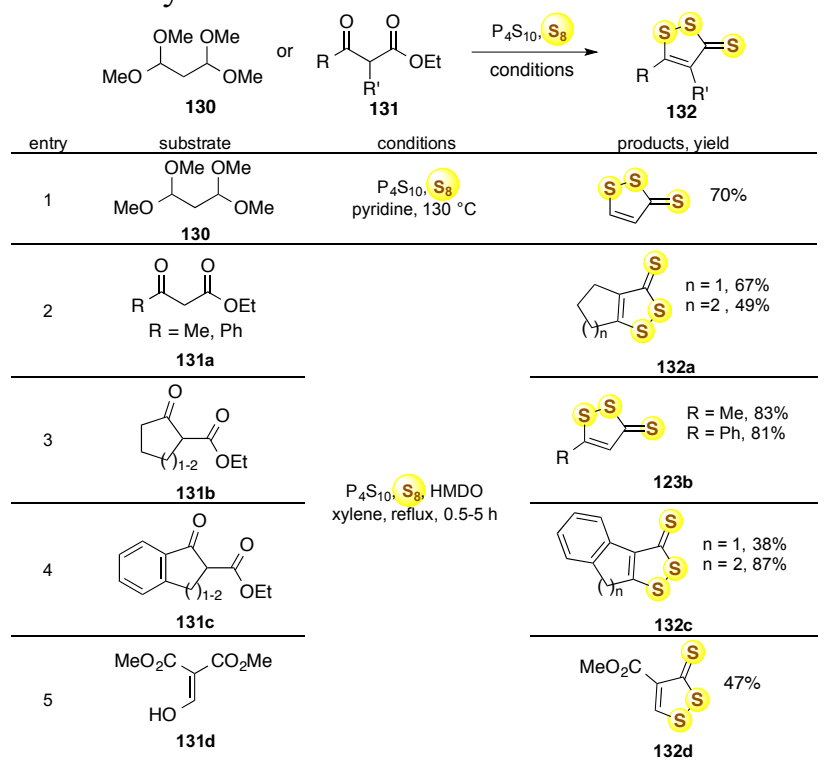

Scheme 48.

$o$-Bromothiobenzamides 133 were found to react with elemental sulfur to provide benzodithioles $\mathbf{1 3 4}$ under copper-catalyzed conditions (Scheme 49). ${ }^{[60]}$ Although the details on mechanism, especially the position of newly introduced sulfur atom, were not fully determined, it was proposed that the first step of the transformation is a migration of the sulfur atom of the thioamide function to the $o$-position via coppercatalyzed Ullmann coupling reaction and subsequent introduction of the sulfur from $\mathrm{S}_{8}$. When elemental selenium $\mathrm{Se}_{8}$ was used instead of $\mathrm{S}_{8}, o$-sulfur substituted products 135 were formed. In general, $\mathrm{N}$ aryl products 134a were obtained in higher yields than $\mathrm{N}$-alkyl 134b, which was tested for only one example.
Similar reactivity was previously observed with $o$ chlorobenzamidines ${ }^{[107]}$ and $o$-bromobenzamides ${ }^{[108]}$ (See section 2.8).

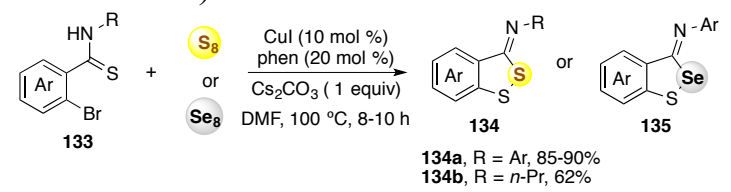

\section{Scheme 49.}

An unusual decarboxylative tetrasulfurative hexamerization of phenylacetic acid $\mathbf{1 3 6}$ was observed upon heating this acid with sulfur, $N$-methylpiperidine and DMSO (Scheme 50). ${ }^{[61]}$ Thiobenzaldehyde 138 generated in situ from decarboxylative sulfuration of phenylacetic acid with sulfur- $N$-methylpiperidine complex $\mathrm{S}_{\mathrm{n}}$-NMP was suggested to be the key intermediate involving in this oligomerization reaction. The next step was a dimerization of thiobenzaldehyde to dithiobenzoin 139 via a similar mechanism of benzoin condensation catalyzed by $\mathrm{S}_{\mathrm{n}}$-NMP complex. Further sequence of condensation of dithiobenzoin 139 as its ene-dithiol tautomer $\mathbf{1 4 0}$ with another molecule of thiobenzaldehyde 138 to trimer 141 and oxidative dimerization of trimer $\mathbf{1 4 1}$ resulted in hexamer 137.

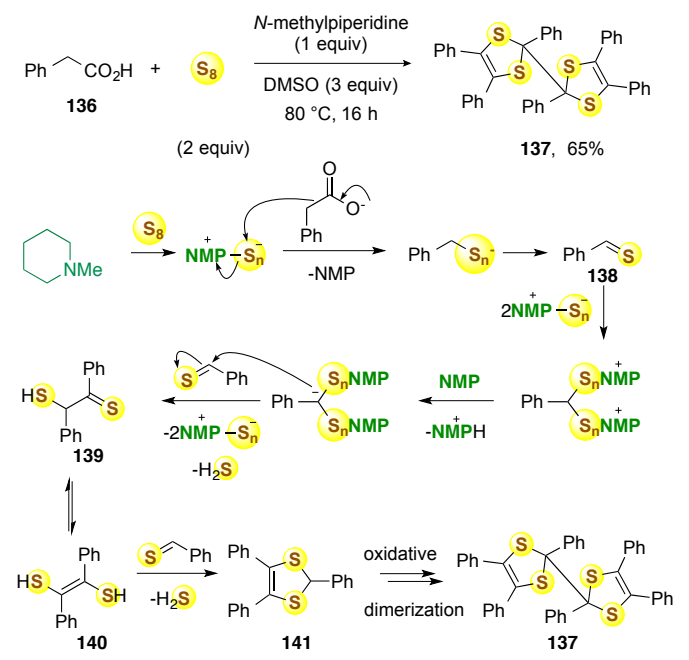

Scheme 50.

Perfluoroolefins 142 were known to react with sulfur in the presence of an alkaline fluoride as a catalyst (CsF or KF) the corresponding perfluorothioketones, which could involve in a wide range of cycloaddition reactions (Scheme 51). ${ }^{[62]}$

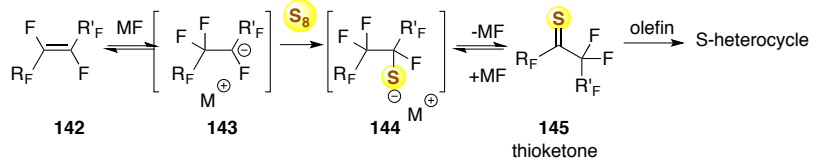

Scheme 51. Generation of thioketones for cycloadditions

According to the proposed mechanism of formation, the first step was a reversible addition of fluoride to the perfluoroolefin to form carbanion 143 stabilized by the presence of multiple fluorine atoms. Subsequent nucleophilic attack of 143 on sulfur resulted in thiolate 144, existing in equilibrium with thioketone 145 , which acted as dienophile in the next step of 
cycloaddition. In the case of nonsymmetrical olefins, it is clear that this process could lead to mixture of two isomeric carbanions $\mathbf{1 4 3}$.

It was found that the reaction of perfluoroolefin, sulfur and conjugated diene proceeded at $25-65^{\circ} \mathrm{C}$ in DMF solvent in the presence of $\mathrm{CsF}$ (or $\mathrm{KF}$ ) as a catalyst led to diverse adducts. ${ }^{[62],[63]}$

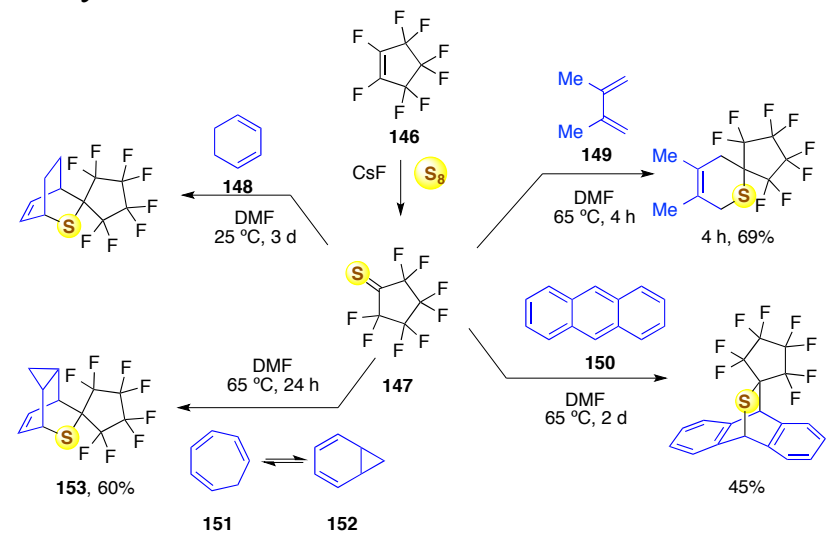

\section{Scheme 52.}

The reaction is general and can be applied to both linear and cyclic perfluorinated olefins. Some examples were given for thioketone 147 generated from perfluorocyclopentene 146 with cyclohexa-1,3diene 148, 2,3-dimethyl-1,3-butadiene 149, antharence 150 and cyclohepta-1,3,5-triene 151 (Scheme 52). It should be noted that the adduct with cyclohepta-1,3,5triene 153 is indeed the result of the reaction of the thioketone 147 and bicyclo[4.1.0]hepta-2,4-diene 152, existing in equilibrium with cycloheptatriene 151.

Similar reactions of perfluoropent-2-ene 153 were reported to be complex due to the generation of mixture of two regioisomeric thioketones, one of which is non-symmetrical (Scheme 53).

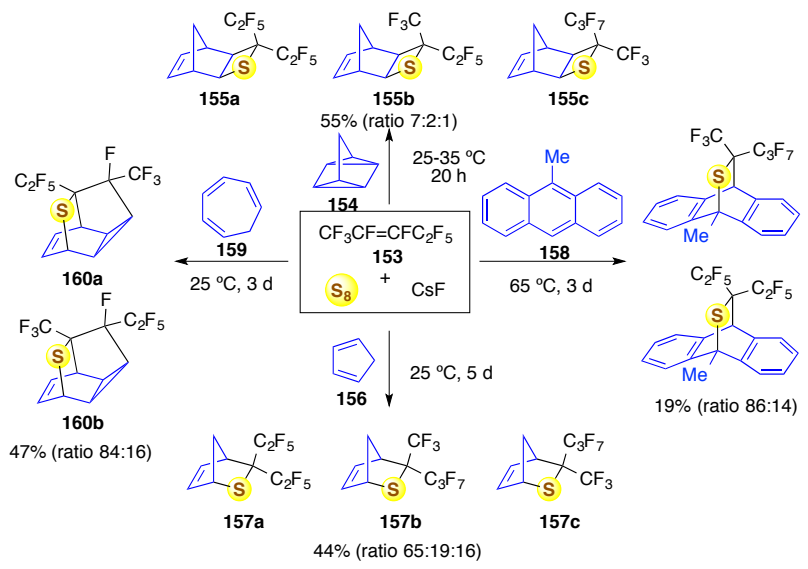

\section{Scheme 53.}

The reaction with quadricyclane was slightly exothermic, leading to the formation of three isomers 155a, 155b and 155c, with significant prevalence of symmetrical isomer 155a ${ }^{[62]}$ Cyclopentadiene $\mathbf{1 5 6}$ also was found to be active in this reaction, leading to the formation of three cycloadducts $157 \mathbf{a}-$ c. $^{[62]}$ The reaction with 9-methylanthracene $\mathbf{1 5 8}$ as diene was found to proceed at higher temperature due to the low solubility of this hydrocarbon at $\mathrm{rt}^{[62]}$ An unusual result was obtained in the reaction with cycloheptatriene 159, the reaction resulted in the formation of a mixture of two isomeric tetracyclic compounds 160a and $160 \mathrm{~b} .{ }^{[62]}$ The reaction required a stochiometric amount of $\mathrm{CsF}$ to increase the conversion.

It was demonstrated that the reaction of hexafluoropropene 161, sulfur and vinyl ether catalyzed by $\mathrm{CsF}$, proceeded under mild conditions, leading to the corresponding 2,2bis(trifluoromethyl)thietanes 163 (Scheme 54). ${ }^{[64]}$

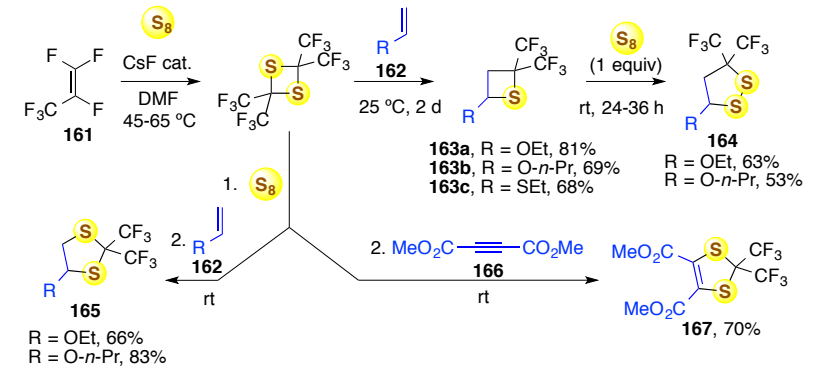

\section{Scheme 54.}

The addition of second mole of sulfur to the solution of 2,2-bis(trifluoromethyl)-4-alkoxy-thietanes 163a,b inserted another sulfur atom into thietane ring with the formation of the corresponding cyclic disulfides 3,3bis(trifluoromethyl)-alkoxy-1,2-dithietanes 164. On the other hand, if the addition of second equivalent of sulfur preceded that of vinyl ether 162, 2,2bis(trifluoromethyl)-4-alkoxy-1,3-dithiolanes 165 was formed exothermically. This procedure failed to produce the corresponding 1,3-dithiolanes from electron deficient olefins, such as dimethyl maleate or 1,1-bis(trifluoromethyl)ethylene but rapidly yield 1,3dithiolene 167 with dimethyl acetylenedicarboxylate 166. $^{[64]}$

A mixture of two adducts 169a,b of similar structure was obtained in $44 \%$ combined yield when perfluoropent-2-ene $\mathbf{1 6 8}$ was allowed to react with sulfur under similar conditions (Scheme 55). ${ }^{[62]}$

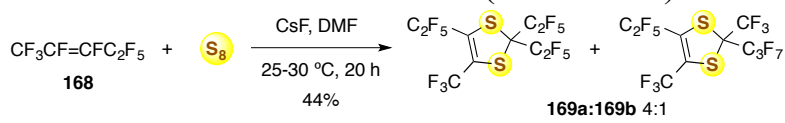

\section{Scheme 55.}

Some unusual but interesting results were observed when propargylamines $\mathbf{1 7 0}$ or $\mathbf{1 7 1}$ were heated with sulfur in the presence of $\mathrm{Co}(\mathrm{acac})_{2}-\mathrm{PPh}_{3}-\mathrm{AlEt}_{3}(1: 2: 4)$ catalyst (Scheme 56) with dithiolactone $\mathbf{1 7 2}$ or 173 was formed, respectively. ${ }^{[13]}$

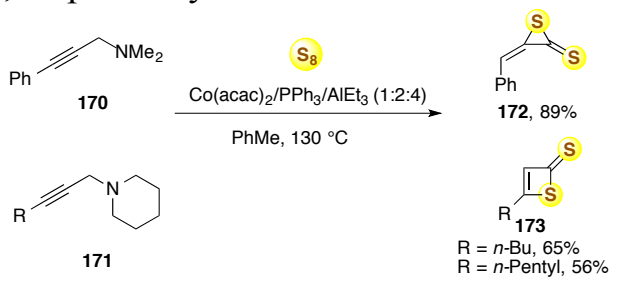

Scheme 56. 
4-Arylbutyrolactones 174 were found to react with sulfur to provide thiolactones 175 with $\mathrm{InCl}_{3}$ catalyst and phenylsilane as a deoxygenating agent in moderate yields (Scheme 57). ${ }^{[65]}$ The reaction was found to depend strongly on the structure of the lactone skeleton.

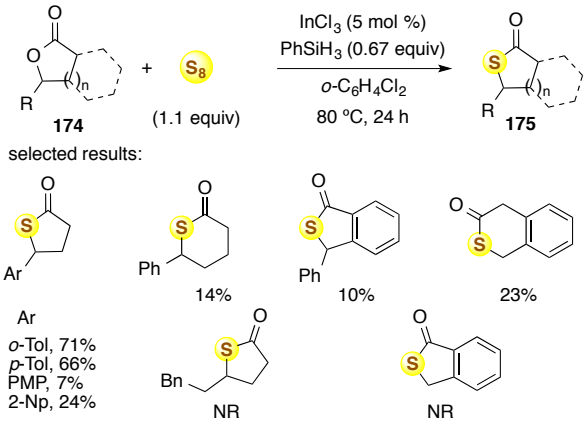

\section{Scheme 57.}

Copper was known to promote (i) $[3+2]$ cycloaddition reactions of alkynes with azides to 1,2,3triazoles, and (ii) $\mathrm{C}-\mathrm{H}$ alkylsulfuration of monosubstituted 1,2,3-triazoles with alkyl sulfonate and elemental sulfur. Consequently, a combination of these two reactions in one pot involving bearing two reactive functions would be an excellent strategy for synthesis of triazoles fused with a sulfa heterocycle 180-181 (Scheme 58). ${ }^{[66]}$ For this purpose, two types of reactions were proposed: (i) alkyne 176 with tosylate-azide 178 and (i) alkyne-tosylate 177 with azide 179. In both cases, the whole sequence was found to be initiated by an azide-alkyne [3+2] cycloaddition.

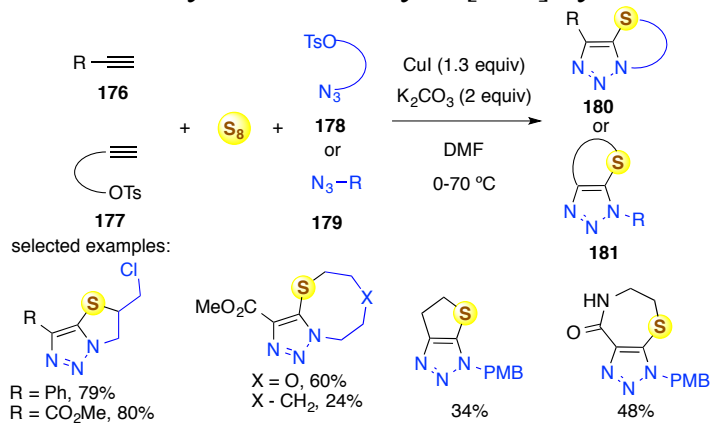

Scheme 58.

ortho-Nitrophenylethylnyl thiother $\mathbf{1 8 4}$ generated in situ from trimethylsilyl alkyne $\mathbf{1 8 2}$ was found to undergo a cascade of reactions to tetracycle $\mathbf{1 8 5}$ at $\mathrm{rt}$ (Scheme 59). ${ }^{[67]}$ Since the isolation proved to be complex, this reaction was not further developed.

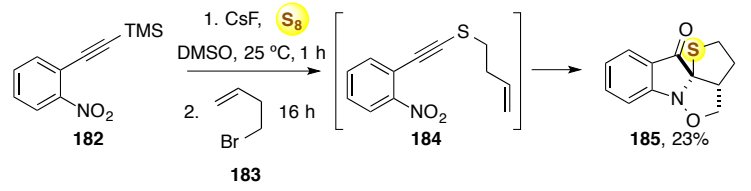

Scheme 59.

\subsection{Thiazole}

Trisubstituted thiazoles 187 bearing an electron withdrawing group in the position 5 such as benzoyl or ester could be synthesized via sulfuration of the corresponding enamine $\mathbf{1 8 6}$ with elemental sulfur in the presence of $\mathrm{FeCl}_{3}$ as a catalyst under aerobic conditions (Scheme 60). ${ }^{[68]}$

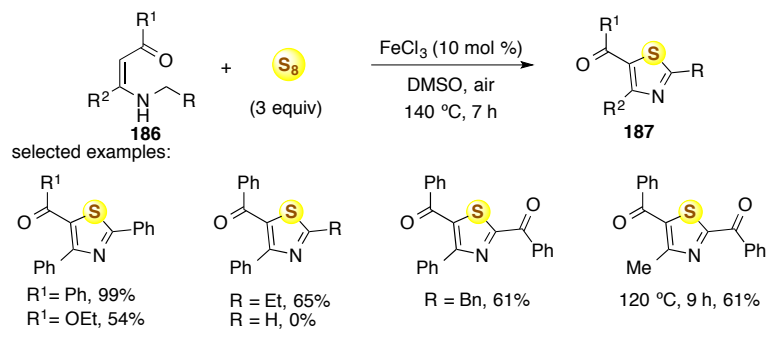

\section{Scheme 60.}

In order to construct thiazole $\mathbf{1 8 9}$ with a free 2amino group, $\mathrm{Fu}$ et al employed unsubstituted cyanamide with enaminone $\mathbf{1 8 8}$ and sulfur (Scheme 61). ${ }^{[69]}$ In this case, a cascade of 2-sulfuration of enaminone, nucleophilic addition of cyanamide and cyclization was proposed as the reaction pathway leading to the product with a wide range of aromatic, heteroaromatic and unsaturated substituents $\mathrm{R}$.

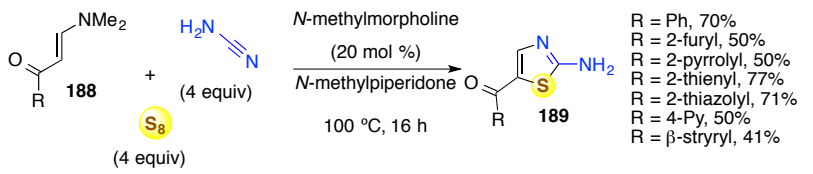

\section{Scheme 61.}

Wu et al found that thiazol-2(3H)-one heterocycles 192 could be obtained via reaction of adducts of $\mathrm{A}^{3}$ coupling reaction 190 with thiocarbonyl generated in situ from sulfur and carbon monoxide (Scheme 62). ${ }^{[70]}$ Phloroglucinol triformate $\mathbf{1 9 1}$ could be used as a solid source of carbon monoxide. The reaction proceeded with gentle heating with a strong base such as $t$-BuOK in DMSO.

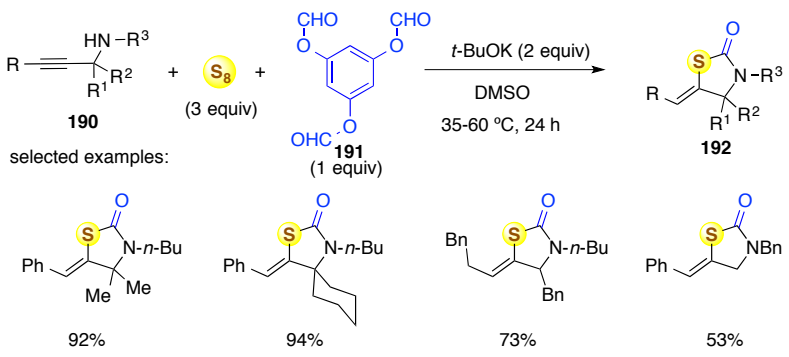

\section{Scheme 62}

A major inherent drawback of these approaches to thiazoles 187, 189 and 192 is the diversity of the products depends only in the only one organic starting material, which is not readily available and should be synthesized. To overcome this constraint, several multicomponent strategies starting from simple and readily available substrates have been investigated.

Jiao et al focused on the combination of phenylacetaldehydes 193 with primary amines 194 and sulfur, including benzylamines and long chain aliphatic amines under $\mathrm{Cu}$-catalyzed aerobic oxidative conditions (Scheme 63). ${ }^{[71]}$ According to the proposed mechanism, enamine 197 generated from phenylacetaldehyde and primary amine was sulfurated by $\mathrm{S}_{8}$ in the $\alpha$ position to the phenyl ring to generate polysulfurated amine 198. After aerobic oxidation took 
place on the alkyl group of amine 198 to imine 199, cyclization and aromatization would lead to thiazole product 195. In general yields obtained with benzylamines were better than with aliphatic amines.

$$
\text { selected examples: }
$$

Scheme 63.

Similarly, when phenylacetaldehyde was replace by acetophenone, regioisomers 2,5-diarylthiazoles $\mathbf{2 0 0}$ were obtained upon heating the reaction mixture in DMSO with isonicotinic acid additive (Scheme 64). ${ }^{[50]}$ The reaction required a higher temperature but copper catalyst was not necessary. The reaction scope is however limited to benzylamines.

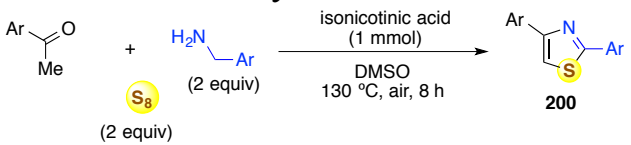

\section{Scheme 64.}

Terminal alkynes $\mathbf{2 0 1}$ and isothiocyanates 202 were found to combine with sulfur in the presence of copper catalyst to provide 3,4-disubstituted 1thiazol-2(3H)ones 203 (Scheme 65). ${ }^{[72]}$ Copper was hypothesized to catalyze the first step of sulfuration of alkyne, followed by a nucleophilic addition to isothiocyanate and cyclization to the product. The reaction conditions were applicable to both substrates bearing either aryl or alkyl group.

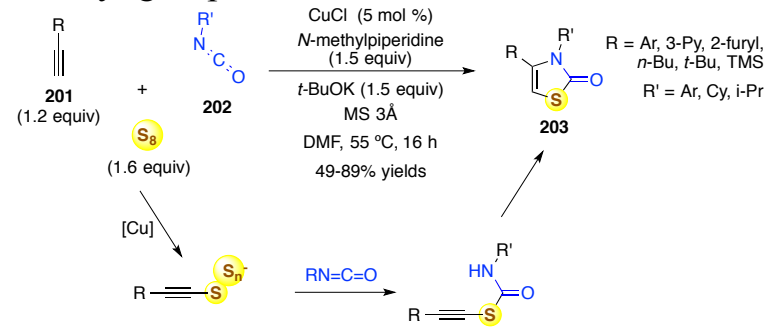

\section{Scheme 65.}

Deng and Huang focused on the assembly of acetophenone, benzaldehyde, ammonia and sulfur to thiazole (Scheme 66). This five-component provided a wide range of trisubstituted thiazoles 204 from in expensive starting materials although the reaction conditions were harsh. ${ }^{[73]}$

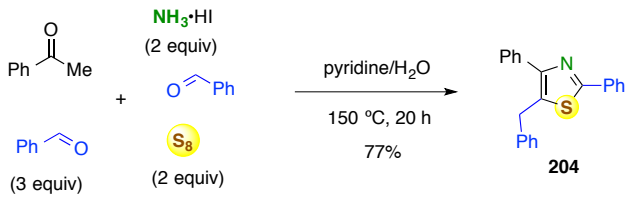

Scheme 66.
When ketones 205 bear an alkyl chain longer than methyl were used, the construction of thiazole products 206 required only one equiv of benzaldehyde (Scheme $67)$.

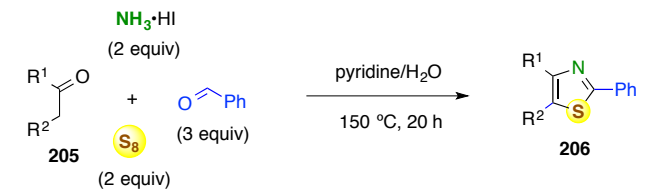

selected examples:
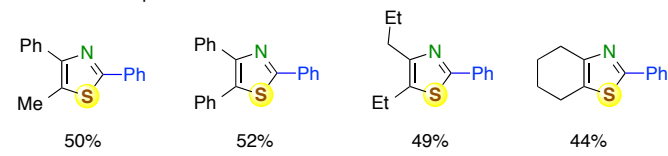

Scheme 67.

With methyl alkyl ketones 207, the reaction was demonstrated to follow the same sequence to provide 4-methyl thiazoles as a reactive intermediate, which underwent benzylidenation with another equiv of benzaldehyde to give $\mathbf{2 0 8}$ (Scheme 68). In this case, using of benzoic acid additive helped lower reaction temperature.

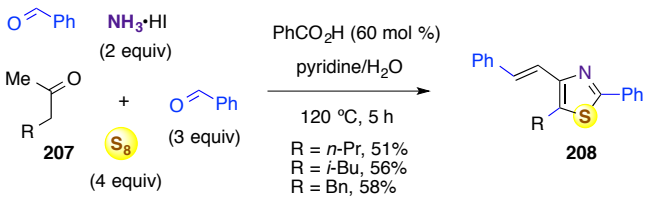

\section{Scheme 68.}

\subsection{Isothiazoles}

Isothiazoles 211 could be formed easily via threecomponent reaction of isocyanides $\mathbf{2 0 9}$ with acetylenes 210 bearing two electron withdrawing group and elemental sulfur in $\mathrm{CS}_{2}$ and $\mathrm{CH}_{2} \mathrm{Cl}_{2}$ without any added catalyst. High yields were obtained even at rt. The first step of the reaction was hypothesized as an addition of isocyanide to the triple bond, followed by a cyclizing sulfuration via different pathways. ${ }^{[74]}$

$$
\text { selected examples: }
$$

Scheme 69.

\subsection{Benzothiazoles}

\subsubsection{From o-haloanilines}

Sulfur could be used as a sulfide source in the reaction with an $o$-iodoaniline 212 to provide the coresponding 2-aminothiophenol, which could further involve in an oxidative condensation reaction with a suitable C-2 precursor $\mathbf{2 1 3}$ and result in 2-substituted benzothiazoles 214 (Scheme 70). ${ }^{[75]-[82]}$ 


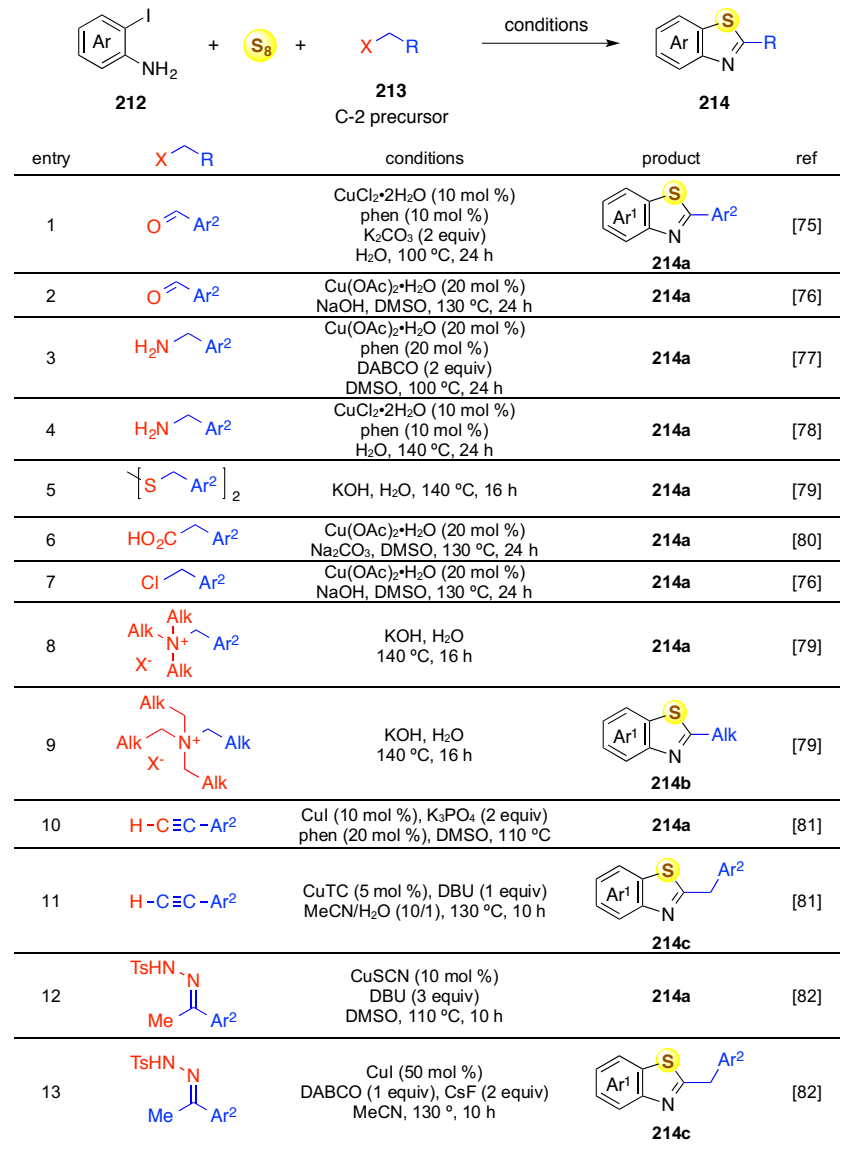

\section{Scheme 70.}

Benzaldehydes (entries 1-2), benzylamines (entries 3-4), dibenzyl disulfides (entry 5), phenylacetic acids (entry 6), benzyl chlorides (entry 7) could be used as $\mathrm{C}-2$ precursor. Phase transfer agents such as tetrasubstituted ammonium salts could also be used for this purpose. In this case, both benzyl and long chain alkyl could act as $\mathrm{C}-2$ precursors with higher reactivity for the benzyl group (entry $8 v s$ entry 8 ). Notably, these phase transfer agents should be used in equimolar amounts, i.e. only one substituent involved in the reaction. When phenylacetylenes (entries 10-11) or acetophenone tosyl hydrazines (entries 12-13) were used as C-2 precursors, the benzothiazole products were formed with loss or conservation of the carbon skeleton according to the reaction conditions. In most cases, the reactions required a copper catalyst, except for tetrasubstituted ammonium salts (entries 8-9).

\subsubsection{From o-hydroanilines}

The thermal reaction of anilines with sulfur has been known for over one century to give rise to 2aminothiophenols and the corresponding polysulfides. ${ }^{[83]}$ In the presence of a wide range of substrates that provide the $\mathrm{C}-2$ building block for benzothiazole core, the formation of this heterocycle upon heating of simple anilines or naphthylamines was observed. ${ }^{[84]}$ Some selected significant examples were presented in Scheme 71. Heating primary aromatic amines with elemental sulfur and 2- or 4-picoline (entries 1-4, 9-10), benzylic ester (entry 5), thioacetanilide (entry 6), benzyl alcohol (entry 7), acetophenone (entry 8), 2-methylquinoline (entry 11-
12), 2-methylbenzothiazole (entry 13), 4methylpyrimidine (entry 14), benzaldehyde (entry $15) \ldots$ produced 2 -substituted benzothiazoles. ${ }^{[85]-[90]}$

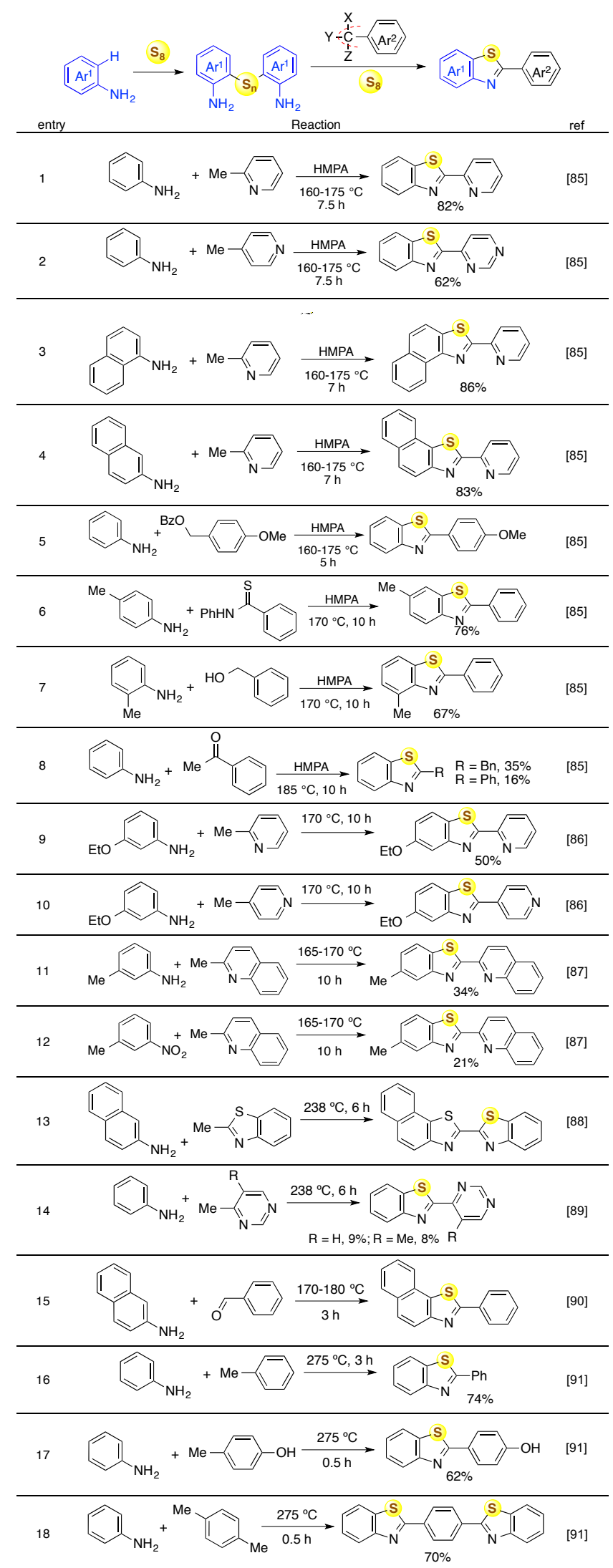

Scheme 71. 
Interestingly, since $\mathrm{H}_{2} \mathrm{~S}$ generated during the course of the reaction could reduce a nitro group, the starting aniline could be replace by the corresponding nitrobenzene as described in entry 12 .

Under these classical conditions, refluxing the reaction mixtures was very common, possibly as a mean to control the temperature. The reactions with substrates bearing non activated methyl groups such as toluene, $p$-cresol or $p$-xylene (entries 16-18) required higher temperature and were performed under high pressure. ${ }^{[91]}$

Based on these observations, some modifications have been developed recently. In 2017, a synthesis of 2-substituted naphtho[2,1- $d]$ thiazoles 217 via heating of the corresponding $N$-substituted 2-naphthylamines 215 with elemental sulfur at $140{ }^{\circ} \mathrm{C}$ was reported (Scheme 72). ${ }^{[92]}$ The reaction could proceed via the oxidation of the $N$-methylene group into the corresponding imine 216. Substrates bearing a substituent $\mathrm{R}$ that is aromatic, heteroaromatic, styryl, ester or benzoyl are competent substrates. When $\mathrm{R}$ is an aliphatic group such as $t$ - $\mathrm{Bu}$, the expected product was obtained in moderate yield.

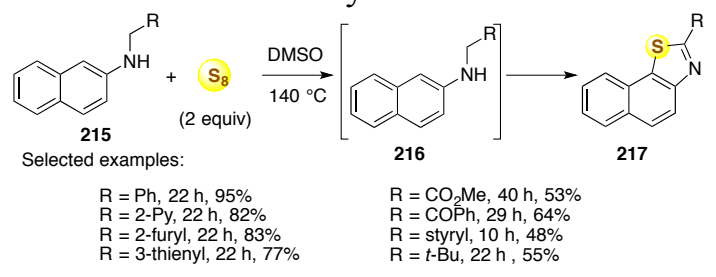

\section{Scheme 72.}

In the aniline series 218, four examples were reported in which the aniline ring was substituted by electron donating groups, possibly for facilitating the key step of sulfuration (Scheme 73).

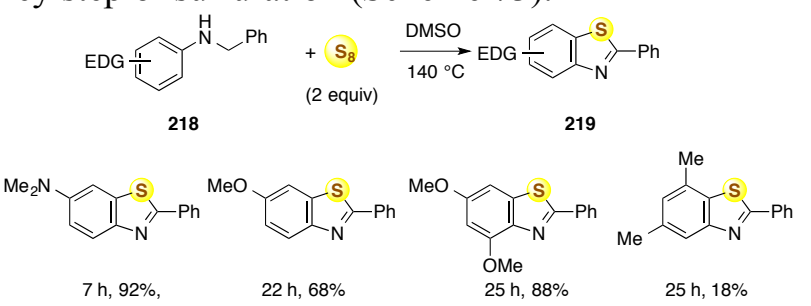

\section{Scheme 73.}

The main drawback of the method is the starting substrates $N$-substituted anilines were not readily available and should be prepared from $\mathrm{NH}_{2}$ anilines via reduction of their imines with aldehydes. To avoid this unnecessary operation, Deng et al. suggested a direct access to benzothiazoles $\mathbf{2 2 3}$ from anilines and benzaldehydes. ${ }^{[93]}$ The reaction was found to be improved by adding iodide salts such as $\mathrm{KI}, \mathrm{NH}_{4} \mathrm{I}$ and molecular sieves. While the reactivity was found to be only slight influenced by the nature of the substituents on aromatic aldehydes, the success of the reaction depended strongly on the nature of aromatic amine substrates 220 and 221. As in the previous case,${ }^{[92]} 2$ naphthylamine 220 was proven to be more reactive than anilines 221 and its reactions could proceed at 140 ${ }^{\circ} \mathrm{C}$. In cases of anilines 221, despite the presence of multiple electron donating groups such as alkyl, alkoxy, their reactivity remained lower than that of 2napthylamine 220. The role of oxygen is not essential in this reaction since both sulfur and DMSO could act as oxidants for this transformation.

Similar conditions were also applied to the couple aniline 221/2-methylquinoline 222 (Scheme 74). ${ }^{[94]}$

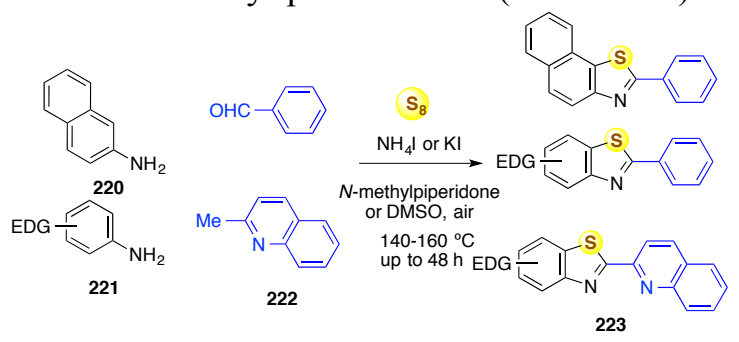

\section{Scheme 74.}

When styrenes or phenylacetylenes 22 were used as C-2 precursors for the formation of benzothiazoles, the reaction was found to proceed via Willgerodt mechanism with the oxidation of the terminal carbon atom along with reduction of the internal carbon (Scheme 75). ${ }^{[95]}$

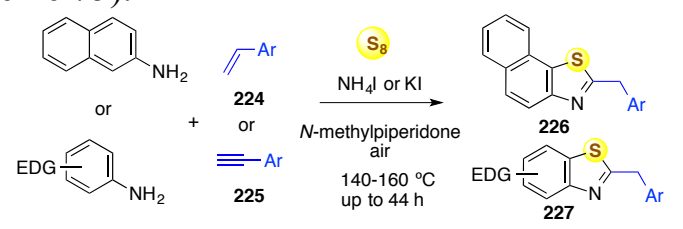

Scheme 75.

The reaction with acetophenones as $\mathrm{C}-2$ building block in the presence of $\mathrm{I}_{2} / \mathrm{TBAI} / \mathrm{DMSO}$ occurred with loss of one carbon, benzothiazoles products were obtained with an aromatic 2-substituent (Scheme 76). ${ }^{[96]}$

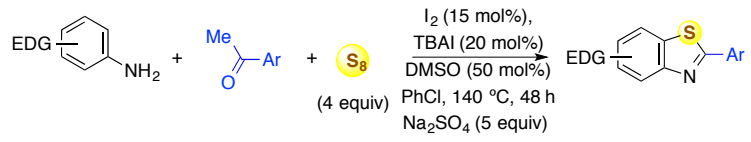

\section{Scheme 76.}

When tert-butyl hydroperoxide/KI was added to the reaction mixtures as oxidant, the method could be extended to ether substrates $\mathbf{2 2 8}$ as C-2 precursors (Scheme 77). ${ }^{[97]}$

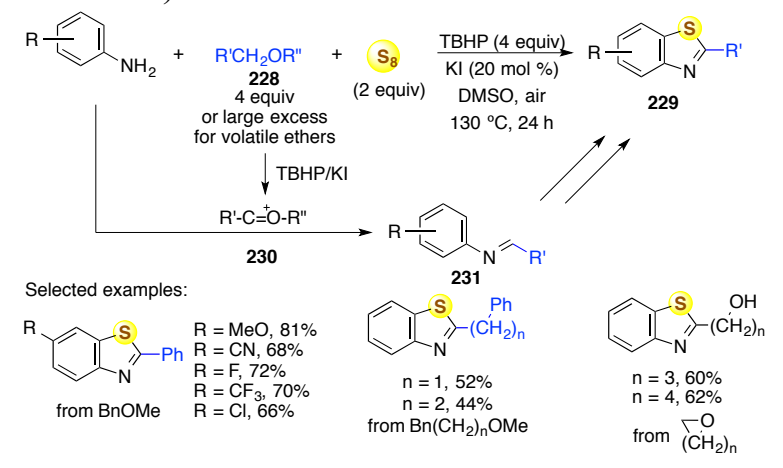

\section{Scheme 77.}

This system of oxidant was known to oxidize ether into oxonium 230, which was next attack by amino species to provide the corresponding imines 231 . Thanks to stronger oxidizing potential of TBHP, 
further reactions on $\mathbf{2 3 0}$ provided $\mathbf{2 2 9}$ benzothiazoles with wider scope for both C-2 substituents and anilines bearing an electron withdrawing group. The main drawback of this method is however the use of ether substrates in large excess (4 equiv), especially for volatile ones (as solvent).Recently, the reaction with aromatic aldehydes was applied to the synthesis of $\beta$ carboline tethered thiazolo[4,5-c]carbazole 234 with luminescent properties from 1-formyl- $9 H$ - $\beta$-carbolines 233, arylamines (including 3-aminocarbazoles 232) and elemental sulfur with molecular iodine as a catalyst (Scheme 78). ${ }^{[98]}$ Alternatively, the corresponding acetal of aldehydes 233 could be used instead of aldehyde with KI was employed in place of $\mathrm{I}_{2}$, opening up avenues for the synthesis of benzothiazoles from acetals when aldehydes are unstable.

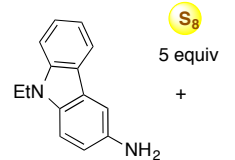

$$
\begin{aligned}
& \stackrel{232}{\mathrm{R}}=\stackrel{\mathrm{H}, \mathrm{Me}, \mathrm{Et}, \mathrm{Pr}, \mathrm{Bu}, \mathrm{Bn} \text {, propargyl }}{233} \\
& \mathrm{R}^{1}=\mathrm{H}, \mathrm{COOMe}
\end{aligned}
$$
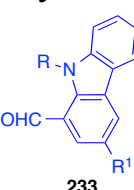

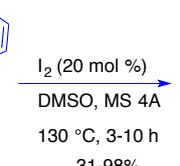

31-98\%

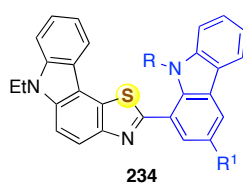

234

\section{Scheme 78.}

When iron salt in catalytic amount was added to the reaction medium, the by-product $\mathrm{H}_{2} \mathrm{~S}$ generated during the oxidative sulfuration process could be trapped and used to reduce in situ nitrobenzenes to anilines.

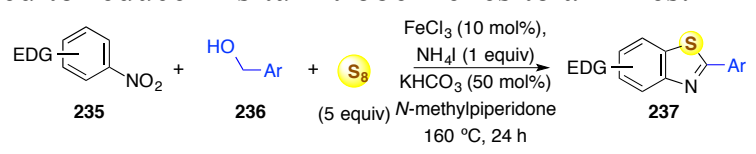

\section{Scheme 79.}

Consequently, the formation of benzothiazoles from benzyl alcohols followed a similar pathway (Scheme 79). The reaction temperature for this cascade transformation remained high $\left(160^{\circ} \mathrm{C}\right)$.

\subsubsection{From o-aminothiophenols}

When 2-aminothiophenols are readily available, the corresponding benzothiazoles could be synthesized by the reaction with styrenes or phenylacetylenes and sulfur as report by Deng et al (Scheme 80 ) ${ }^{[99]}$ Since the aromatic sulfuration step, which is most energetically demanding, is not required, the reaction temperature is significantly lower than similar reactions of the corresponding $o$-unsubstituted anilines. ${ }^{[95]}$

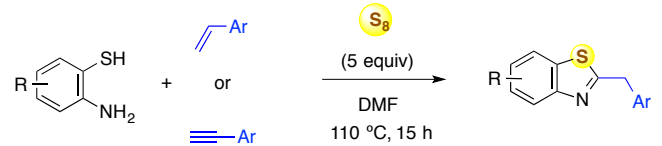

\section{Scheme 80.}

\subsubsection{From o-halonitrobenzene}

All the above-mentioned methods suffer from at least one of the following drawbacks: high reaction temperatures, availability of the starting material, regioselectivity, requirement of copper catalyst, ligand, strong base, limited scope of substrates. In this context, we suggested a new strategy to broaden the scope of benzothiazole synthesis while using inexpensive and readily available starting materials even in a wide range of structures. In 2013, we disclosed a threecomponent reaction involving $o$-halonitrobenzenes, elemental sulfur and 4-picoline bearing an activated methyl group to produce 2-pyridylbenzothiazole under solvent-free conditions (Scheme 81 ) ${ }^{[100]}$ The products were formed as a result of a cascade of metal-free nitro group displacement by sulfur, reduction of the nitro group, oxidation of the methyl group, and condensation to form benzothiazoles core. Interestingly, the reaction conditions could be applied to all four halogens in $o$-halonitrobenzenes substrates. Later, it was found that the method could be extended to benzylamines, ${ }^{[101]}$ phenylacetic acids, ${ }^{[102]}$ acetophenones ${ }^{[103]}$ as reducing partners. In all cases, sulfur was found to be an external complementary reducing agent.

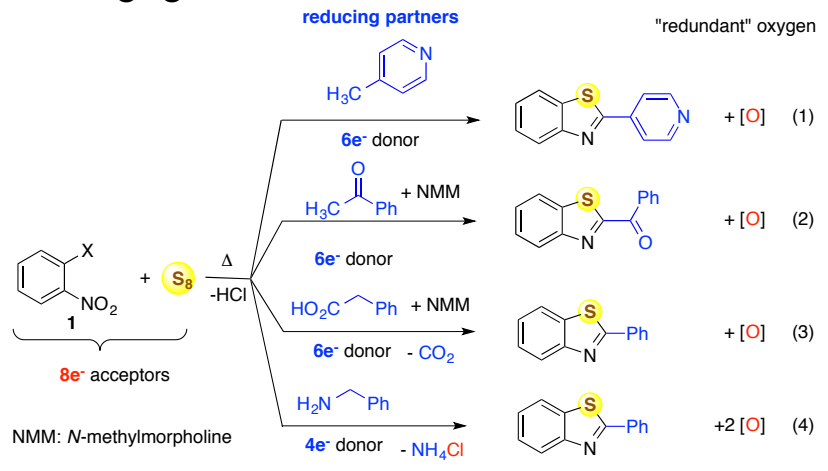

\section{Scheme 81.}

The generality of this transformation was recently demonstrated with benzaldehydes, benzyl alcohols, dibenzyl disulfide, phenylglycine, mandelic acid, phenylglyoxalic acid ${ }^{[04]}$ as well as benzyl chlorides (Scheme 82). ${ }^{[105]}$ In the last case with benzyl chlorides, $\mathrm{N}$-methylpiperidine was used as solvent, in which one equivalent was involved in the generation quaternary $\mathrm{N}$-benzylated piperidinium, which underwent next the redox condensation with $o$-chloronitrobenzene substrates.

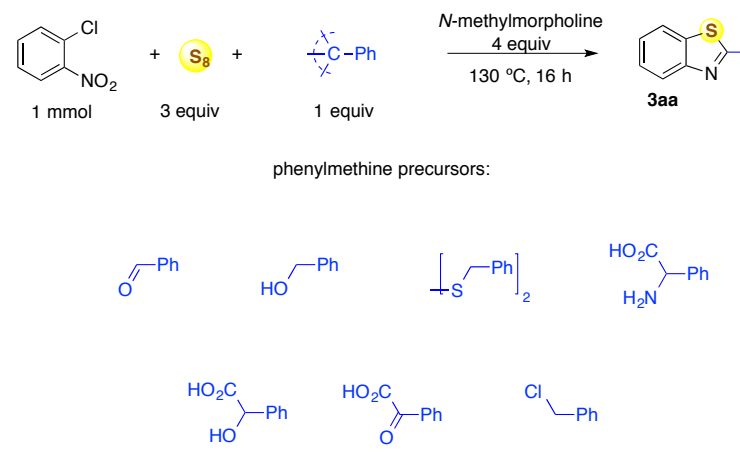

\section{Scheme 82.}

Although the reaction mechanism is not fully determined, we have suggested the following mechanism adapted for benzaldehyde substrate (Scheme 83). The reaction started with the formation of polysulfide chain $\mathbf{2 3 8}$ by the attack of the base to $S_{8}$ molecule. This polysulfide could act as both oxidant for oxidation of aldehyde and sulfur nucleophile for displacement of the halogen atom of $O$ halonitrobenzene. At this moment, an intramolecular 
redox process on 241 occurs likely via stepwise transfer of oxygen atoms from the nitro group to an internal sulfur atom of the polysulfur chain of 241. Formation of nitrososulfoxide 141 with subsequent cascade of redox reactions involving an of $\mathrm{SO}_{3}-\mathrm{N}$ methylmorpholine adduct led to 2phenylbenzothiazole.

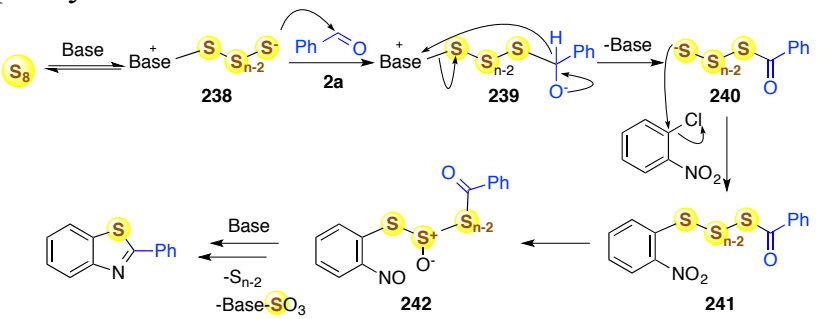

Scheme 83.

\subsubsection{From cyclohex-2-enone O-acetyl oximes}

An original way to construct napthothiazoles and benzothiazoles 244 was developed by Deng et al via three-component reaction of $\alpha$-tetralone/conjugated cyclohexenone oxime acetates 243 , with aldehydes and elemental sulfur (Scheme 84). Different aldehydes could be used with $\alpha$-tetralone oxime acetates $\mathbf{2 4 3}$ although lower yields were observed with some aliphatic aldehydes. ${ }^{[106]}$ While examples of conjugated cyclohexenone oxime acetates substituted in 2- or 3position or fused with furan/thiophene were given with reasonable yields, the reaction of the simplest cyclohexenone oxime acetate was not reported. While all the used aldehydes are commercially available, the method required oxime acetates in excess (1.5 equiv). Mechanistically, a key step of this transformation consists in a thiolation with elemental sulfur of the neighboring methylene to the oxime acetate moiety, followed by condensation with aldehyde and subsequent aromatization.

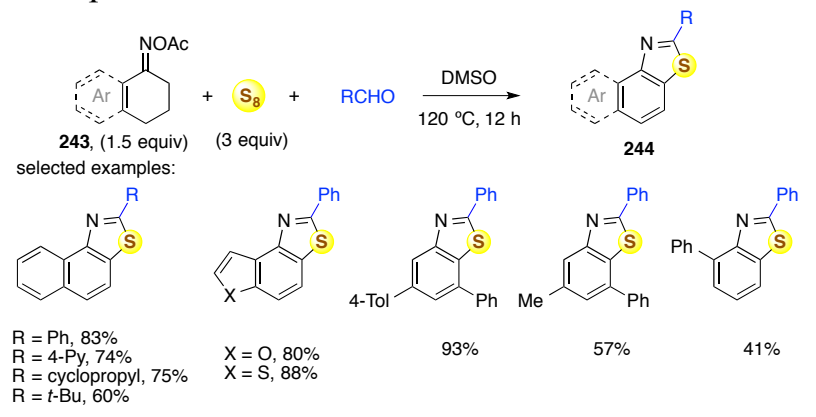

Scheme 84.

\subsection{Benzoisothiazole}

Upon prolonged heating of $o$-chlorobenzamidines 245 with sulfur and $\mathrm{K}_{3} \mathrm{PO}_{4}$, benzoisothiazoles 246 were produced (Scheme 85 ). ${ }^{[107]}$ The key step of this transformation was suggested to be an attack of the amidine moiety of $\mathbf{2 4 5}$ to elemental sulfur to form the $\mathrm{N}-\mathrm{S}$ bond, and subsequent cyclization via intramolecular aromatic nucleophilic substitution of the chlorine by the newly introduced sulfur. Consequently, high reactivity was noticed with substrates bearing electron withdrawing groups. Although the method could be applied to $N$-alkyl or
$\mathrm{NH}_{2}$ amidines, the substrate scope is limited to substituents which are not sensitive to strong base $\mathrm{K}_{3} \mathrm{PO}_{4}$ such as alkyl, alkoxy, halo and $\mathrm{CF}_{3}$.

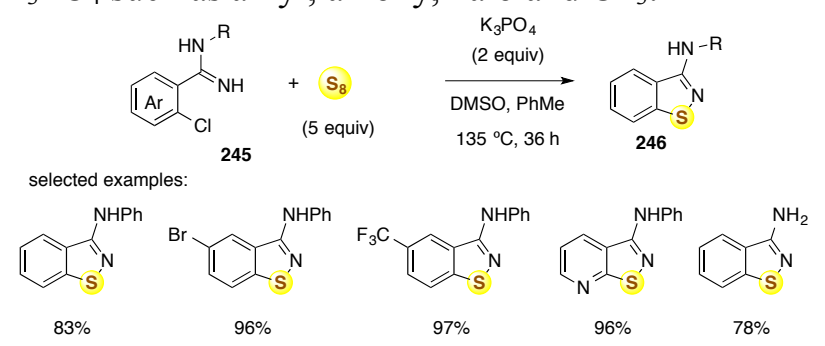

\section{Scheme 85.}

When benzamides ${ }^{[108]}$ were used in place of benzamidines, Liu et al found that $o$-iodo derivatives 247 were particularly reactive for a similar transformation, especially in the presence of $\mathrm{CuBr}_{2}$ as a catalyst (Scheme 86). The expected benzoisothiazole products 248 could be formed for less than $10 \mathrm{~min}$ upon microwave irradiation with sulfur and triethylamine.

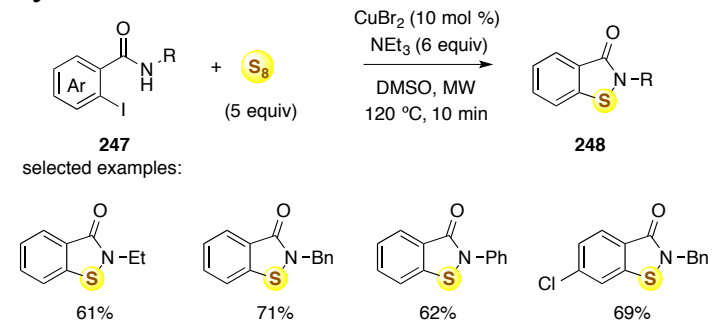

\section{Scheme 86.}

Previously, a similar reaction with bromo derivative 249 was studied in the presence of up to $50 \mathrm{~mol} \%$ of copper catalyst and ligand 1,10-phenanthroline (Scheme 87). ${ }^{109]}$ It should be noted that the ester function could favor sulfur incorporation.

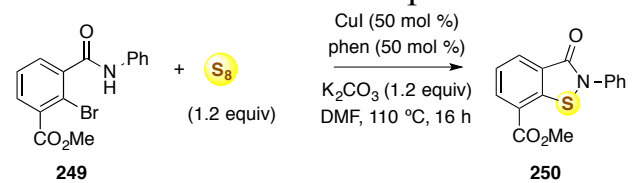

\section{Scheme 87.}

Another strategy for the synthesis of benzoisothiazolone $\mathbf{2 5 2}$ based on $o-\mathrm{C}-\mathrm{H}$ functionalization was studied (Scheme 88)..$^{[10]}$ Although benzamides with unsubstitued o-positions could be used, the method requires 2-(Nmethylbenzimidazolyl)isopropyl as an $N, N$-bidentate directing group. Furthermore, the use expensive nickel triflate catalyst, strong oxidant $\mathrm{KMnO}_{4}$ and high molecular weight additive TBAI as well as high temperature under high pressure conditions makes the reactions less attractive as a synthetic method. Previously, (2-pyridyl)isopropyl directing group was developed for similar transformations. ${ }^{[111]}$
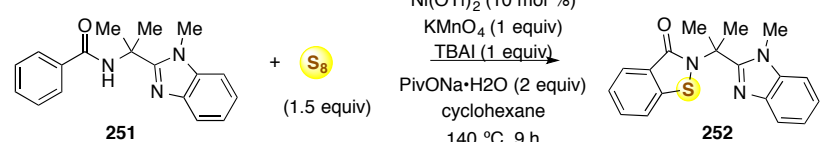

Scheme 88. 


\subsection{Thiadiazole}

\subsubsection{1,2,3-Thiadiazole}

4-Aryl-1,2,3-thiadiazoles 254 could be synthesized from the corresponding acetophenone tosylhydrazones 253 and sulfur under different oxidant conditions (Scheme 89).

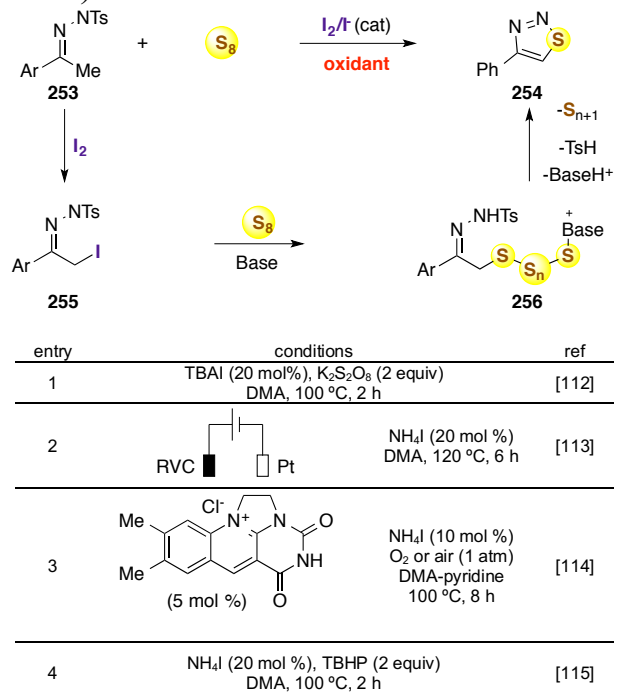

Scheme 89.

All four reported methods were based on redox catalysis of $\mathrm{I}_{2} / \mathrm{I}^{-}$couple. Suitable oxidant or oxidation conditions could be applied for recycling of $\mathrm{I}_{2}$ from I $\mathrm{I}^{-}$, including $\mathrm{K}_{2} \mathrm{~S}_{2} \mathrm{O}_{8},{ }^{[112]} \mathrm{TBHP}^{[115]}$ as well as more sophisticated electrolytic ${ }^{[113]}$ or flavin-catalyzed aerobic $^{[114]}$ conditions. Mechanistically, the first step was an iodination of the methyl group of $\mathbf{2 5 3}$ into $\mathbf{2 5 5}$ to facilitate the introduction of sulfur chain to the carbon skeleton. Subsequent shortening of sulfur chain and elimination of tolylsulfinic acid of $\mathbf{2 5 6}$ produced the expected heterocycle.

Hydrazone substrates under enamine form $\mathbf{2 5 8}$ could be generated in situ directly from conjugated enaminones and tosyl hydrazine as illustrated by the example given in Scheme 90. Subsequent steps followed the same pathway as described in Scheme 89. While aromatic and heteroaromatic as well as cinnamyl ketone were competent substrates, reaction of alkyl ketones did not result in the expected heterocycles, probably due undesirable reactions on these side chains.
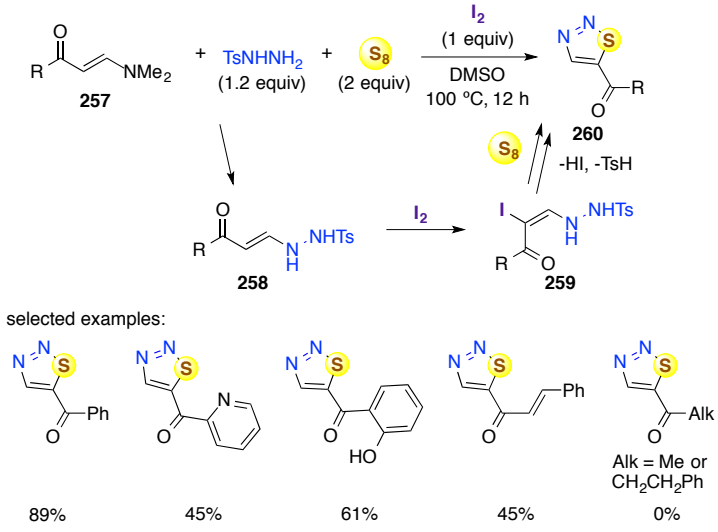

Scheme 90.

\subsubsection{1,2,4-Thiadiazole}

This kind of heterocycles 263 could be prepared via oxidative coupling of benzamidines $\mathbf{2 6 1}$ and sulfur with a C-5 precursor $\mathbf{2 6 2}$ of various natures, ranging from $\mathrm{CS}_{2}$, 2-methylquinolines, benzaldehydes to benzyl halides and acetophenones (Scheme 91). In all cases, the reaction required a base to activate sulfur.

Table 1

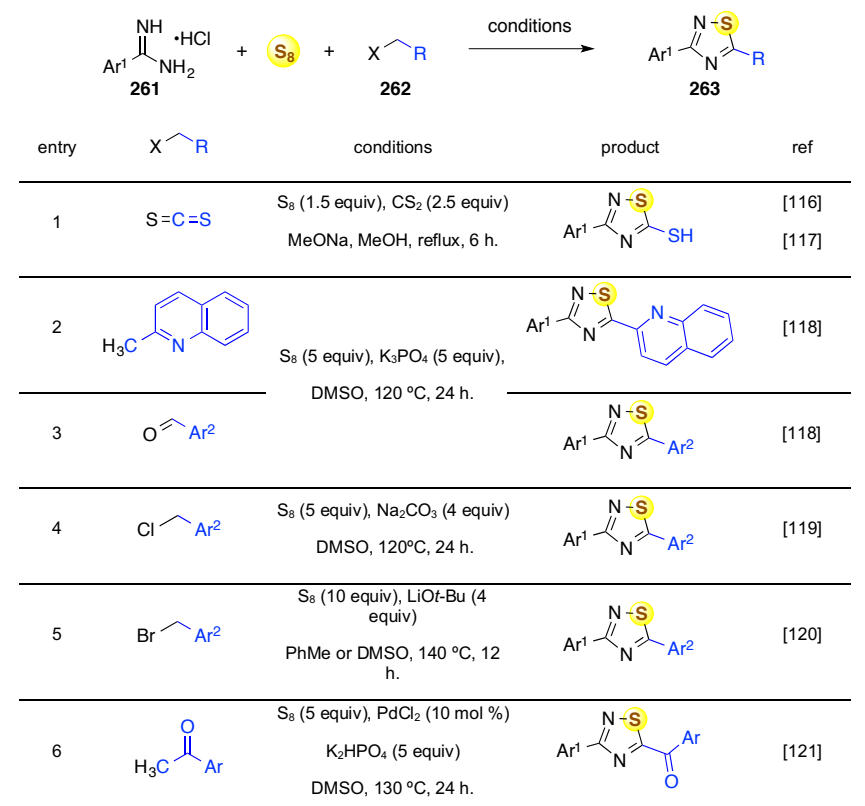

Scheme 91.

\subsection{1,2,3,4-Thiatriazole}

A one-pot two-step synthesis of 5-aryl-1,2,3,4thiatriazoles 266 was developed (Scheme 92). ${ }^{[122]}$ Starting from aromatic nitriles 264, the first step consists in a formation of the corresponding thiohydrazides 265 from hydrazine hydrate and elemental sulfur. DMSO was found to be a particularly useful solvent in accelerating this first step. Subsequent diazotization of thiohydrazides with nitrous acid induced the cyclization into 1,2,3,4thiatriazoles 266. While excellent yields were observed with aromatic cyanides, benzyl cyanide or tert-butyl cyanide was not successful substrates, probably due to low stability of the corresponding thiohydrazides.

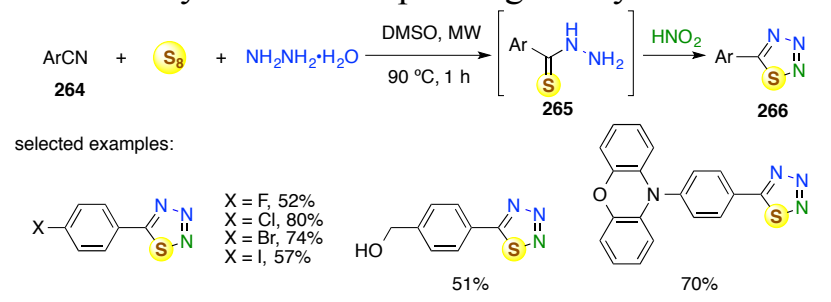

\section{Scheme 92.}

\subsection{Benzothiazines}

In 2017, we disclosed a synthesis of sultams $\mathbf{2 6 8}$ by heating $o$-nitrochalcones 267 with elemental sulfur (Scheme 93). ${ }^{[123]}$ Two set of conditions have been developed based on the use of a weak base such as 3picoline or $\mathrm{N}$-methylmorpholine to promote the 
incorporation of elemental sulfur into the $O$ nitrostyrenes without loss of any atom. Mechanistically, the reaction was thought to be initiated by an addition of the nitrogen base to the double bond of $o$-nitrochalcone substrate $\mathbf{2 6 7}$ followed by a sulfuration of the resulting zwitterion 269 . Subsequent migration of two oxygen atoms of the nitro group to newly installed sulfur atom occurred with cyclization to the sultam product $\mathbf{2 6 8}$.
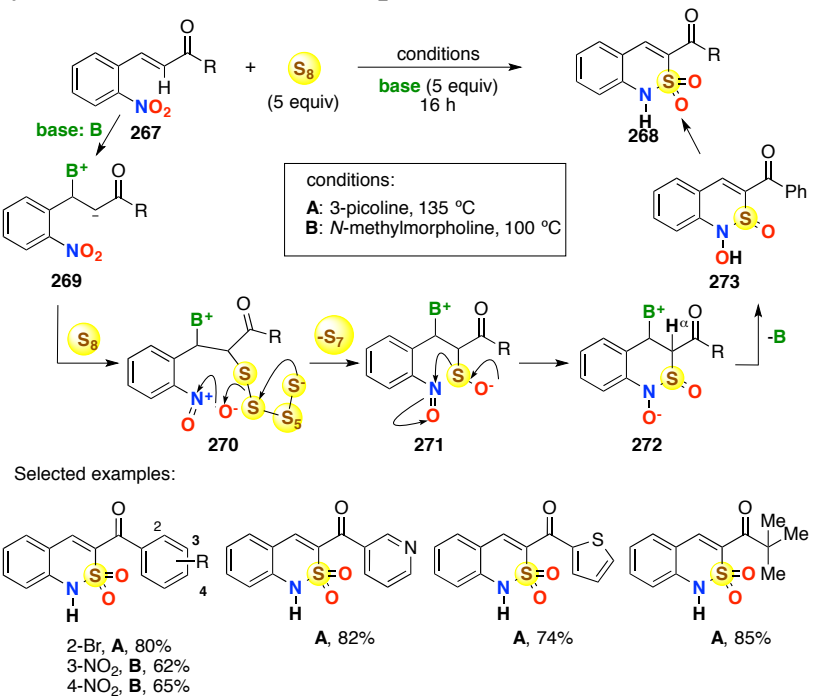

\section{Scheme 93.}

The strategy was subsequently applied to $o$ nitrostilbazole substrates $\mathbf{2 7 4}$ to provide a wide range of sultams 275 bearing different heterocyclic substituents (Scheme 94). ${ }^{[124]}$

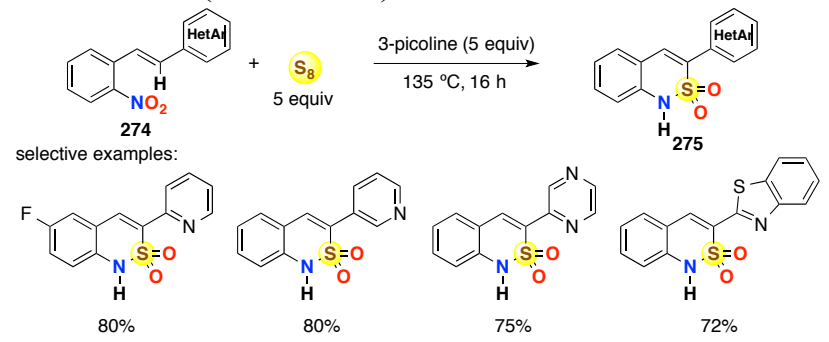

Scheme 94.

Benzothiazine derivative $\mathbf{2 7 8}$ could be synthesized in $52 \%$ yield via a one one-pot synthetic strategy from the reaction of $o$-alkynylaniline 276 (Scheme 95). ${ }^{[75]}$ The first step was a formation of isothiocyanate $\mathbf{2 7 7}$ with difluorocarbene generated from sodium bromodifluoroacetate in the presence of a copper salt catalyst and a base. Addition of dibutylamine to isothiocyanate 277 will induce cyclization to 278 . It should be emphasized that the introduction of only one carbon of the isothiourea function into $\mathbf{2 7 8}$ required high molecular weight sodium bromodifluoroacetate as well as 3 equiv of base to trap hydrogen halides (1 $\mathrm{HBr}$ and $2 \mathrm{HF}$ ).

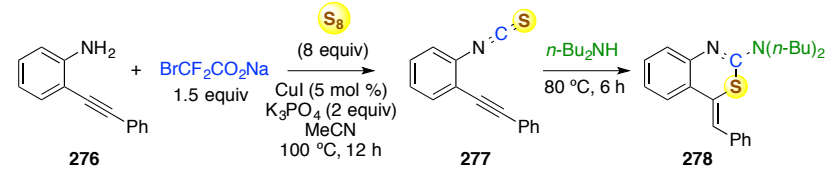

A three-component reaction of $o$-iodobenzamides 279, elemental sulfur and dichloromethane providing 2,3-dihydrobenzothiazinones $\mathbf{2 8 0}$ was described (Scheme 96). Using copper/1,10-phenanthroline catalyst, the reaction consisted in a first step of thiolation of aromatic C-I bond and subsequent reaction with $\mathrm{CH}_{2} \mathrm{Cl}_{2} \cdot{ }^{[108]}$

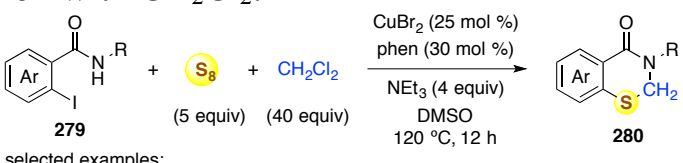

$$
\begin{aligned}
& \text { selected examples: }
\end{aligned}
$$

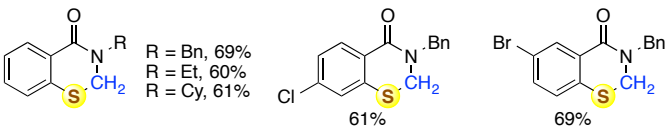

\section{Scheme 96 .}

A four-component reaction of acetophenone with two molecules of anilines and sulfur leading to $2 \mathrm{H}$ benzo $[b][1,4]$ thiazin-2-imine $\mathbf{2 8 1}$ was reported (Scheme 97). ${ }^{[126]}$ This transformation was based on the $o$-sulfuration of anilines at high temperature with elemental sulfur to provide $o, o^{\prime}$-diamino diphenyl oligo sulfides, which was previously described. ${ }^{[83],[84]}$ While the scope of acetophenones is relatively large, competent anilines should not bear electron withdrawing group.

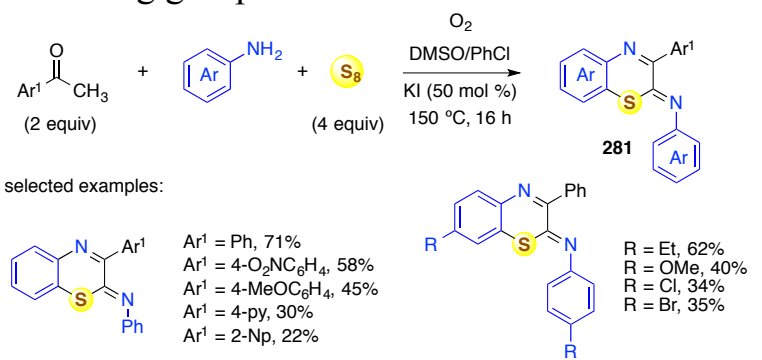

\section{Scheme 97.}

Although sulfur could interfere any step of this cascade transformation, its role was shown to be essential only in the sulfuration step. Indeed, compound $\mathbf{2 8 1}$ could be obtained via three component reaction of $o$-aminothiophenol, aniline and acetophenone under similar conditions at lower temperature without sulfur (Scheme 98). ${ }^{[127]}$

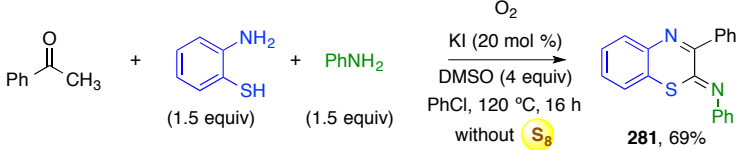

\section{Scheme 98.}

1,2,3,4-Tetrahydroquinolines and $N$-substituted anilines $\mathbf{2 8 2}$ were found to react with cyclohexanones 283 and sulfur under similar aerobic conditions (KI or $\mathrm{I}_{2}$ catalyst, DMSO additive, $\mathrm{PhCl}$ solvent) to provide phenothiazines 284 (Scheme 99). ${ }^{[128]}$

Scheme 95. 


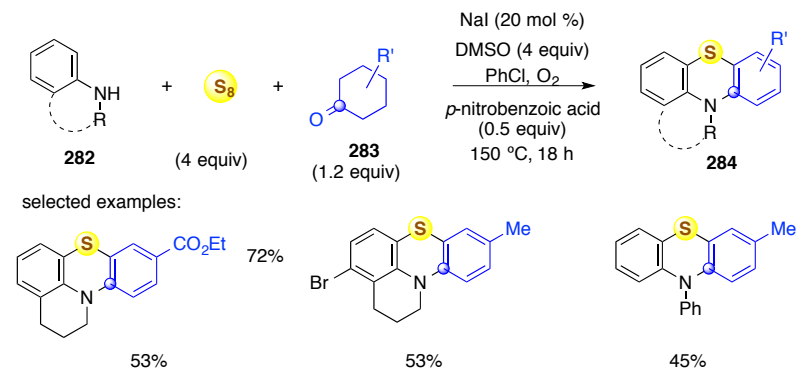

Scheme 99.

While the $\mathrm{I}_{2}$-catalyzed reaction of $N, N$ diarylanilines with sulfur leading to phenothiazines was known for more than one century, ${ }^{129]}$ there is an obvious possibility for the involvement of phenothiazines in the transformation, which could be generated from oxidative condensation of 1,2,3,4tetrahydroquinolines or $N$-substituted anilines $\mathbf{2 8 2}$ with cyclohexanones.

\subsection{Fused 1,3,6-thiadiazepine}

A three-component reaction of 1-(2aminoaryl)pyrroles 285, simple ethers, and elemental sulfur for constructing aza-heterocycle-fused 1,3,6benzothiadiazepines $\mathbf{2 8 6}$ under iodine-catalyzed conditions has been developed (Scheme 100). ${ }^{[130]}$ Simple ethers such as THF, MeTHF, tetrahydropyran, diethyl ether... act as reactive solvent in this reaction.

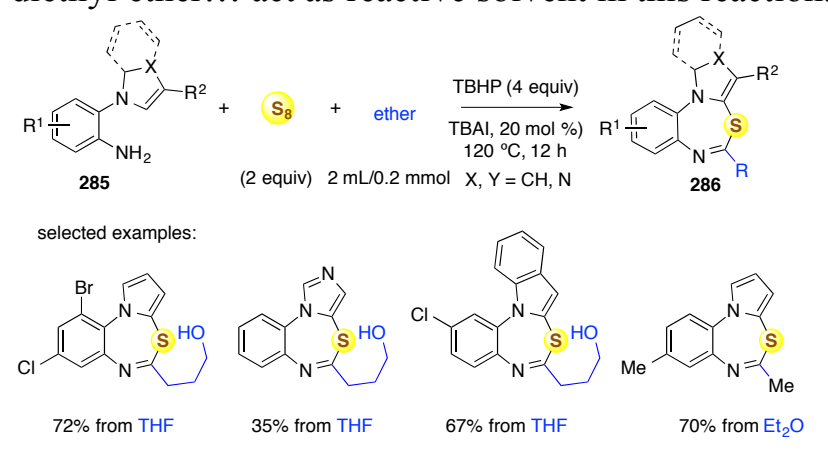

Scheme 100.

\subsection{1,3-Oxathiolan-2-one}

$\mathrm{Wu}$ et al developed a carbonylation procedure involving the cyclization of propargylic alcohols $\mathbf{2 8 7}$ with elemental sulfur and gaseous carbon monoxide. With DBU (10 mol \%) as the catalyst, elemental sulfur and carbon monoxide can form carbonyl sulfide $\mathrm{O}=\mathrm{C}=\mathrm{S}$ and react with propargylic alcohols (Scheme $101){ }^{[131]}$ Good to excellent yields of the desired 1,3oxathiolan-2-ones $\mathbf{2 8 8}$ are obtained even at room temperature for secondary and tertiary alcohol substrates. However, primary propargylic alcohols failed to give the product, probably due to instability under the present conditions.

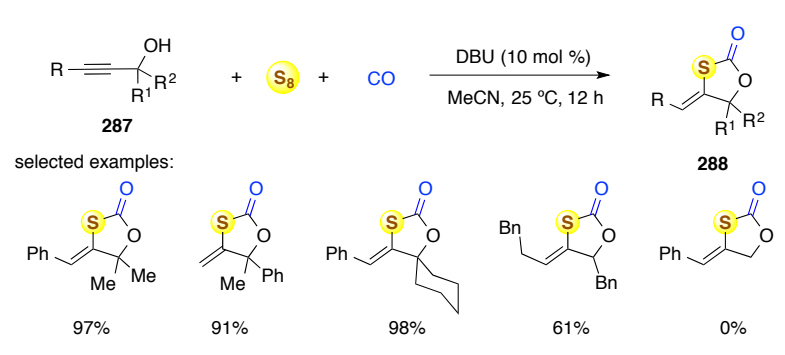

Scheme 101.

When phloroglucinol triformate was used as a solid $\mathrm{CO}$ surrogate, the same reactions requires higher temperature $\left(60^{\circ} \mathrm{C}\right)$ and longer reaction time $(48 \mathrm{~h}) .{ }^{[132]}$

A three-component reaction of nitromethane and elemental sulfur with a wide range of oxiranes $\mathbf{2 8 9}$ was developed with silver salt catalyst (Scheme 102). ${ }^{[133]}$ This reaction procedure provides a practical strategy to construct 1,3-oxathiolane heterocycles 290 with high functional group tolerance and good to excellent yields. Although the stereochemistry aspect of this work was not well documented for both starting oxiranes and 1,3-oxathiolane, only one product was described for each reaction.

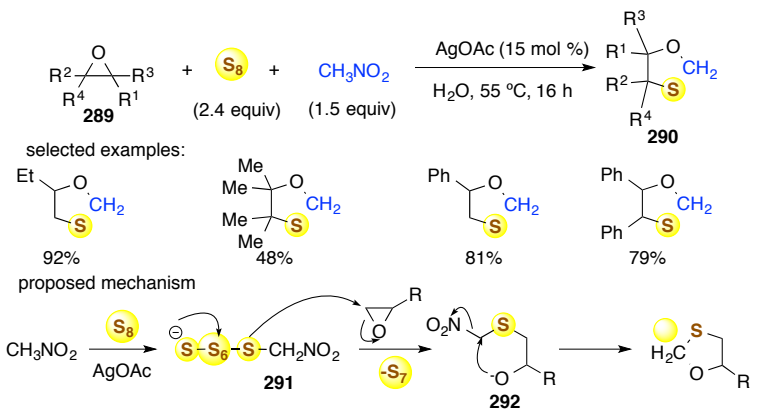

\section{Scheme 102.}

According to the proposed mechanism, the ring opening of oxiranes $\mathbf{2 8 9}$ was effected with sulfurnitromethane adduct $\mathbf{2 9 1}$ generated from two starting components by a silver-catalyzed process (Scheme 103). Subsequent cyclization of the resulfying nitrosulfide 292 to 1,3-oxathiolane product with nitrite ion as a leaving group proceeded via an $\mathrm{S}_{\mathrm{N}} 2$ pathway, which explained low yields (nitroethane, nitropropane) or even absence of reactivity (nitroisopropane) with higher homologs of nitromethane (Scheme 103).

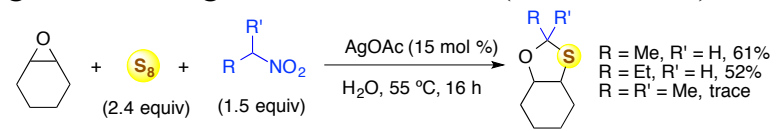

Scheme 103.

\subsection{2,3-Dihydrobenzo[b][1,4]oxathiine}

This heterocycle scaffold 294 could be synthesized by copper-catalyzed sulfuration with elemental sulfur of $o$-iodophenyl propargyl ether 293 (Scheme 104). ${ }^{[134]}$ 


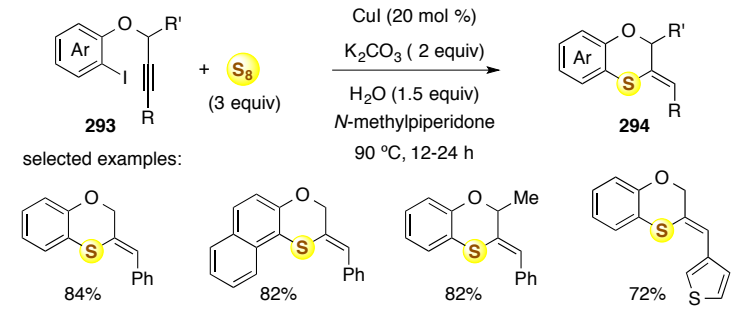

Scheme 104.

\subsection{Sulfur-free heterocycles}

Reaction of $o$-hydroxylphenyl-functionalized enaminones 295 with sulfur and molecular iodine resulted in the formation of chromone sulfides $\mathbf{2 9 6}$ (Scheme 105). ${ }^{[135]}$ Substrates bearing electronwithdrawing group such as chloro atom in the phenyl ring of $\mathbf{2 9 5}$ were not able to yield the corresponding chromone sulfide products.

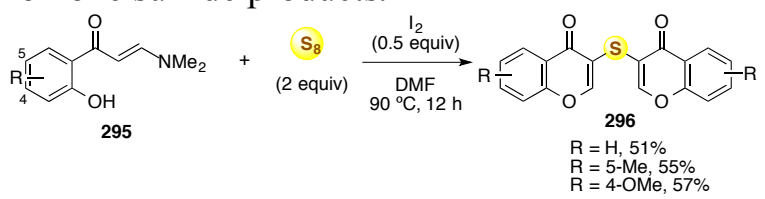

\section{Scheme 105.}

In a similar manner, $o$ '-hydroxychalcones 297 reacted with sulfur in the presence of sodium chlorodifluoroacetate to yield 3(difluoromethylthio)chromen-4-ones Mechanstically, the reaction was started by a baseinduce cyclization of $o^{\prime}$-hydroxychalcones 297 to chroman-4-ones 299, which were next sulfurated by $\mathrm{S}_{8}$ to $\mathbf{3 0 0}$ and next oxidized by TEMPO to chroman-4-one sulfides 301 (Scheme 106). The final products 298 were obtained by a combination of sulfides $\mathbf{3 0 1}$ with difluorocarbene generated from chlorodifluoroacetate followed by a protonation. Better results were obtained with chalcones unsubstituted on the phenol ring. However, the reaction failed $o$-substituted chalcones ( $\mathrm{R}=1$-naphthyl, 2-methoxyphenyl) as well as when $\mathrm{R}$ $=2-\mathrm{Py}, \mathrm{NMe}_{2}$ or alkyl.

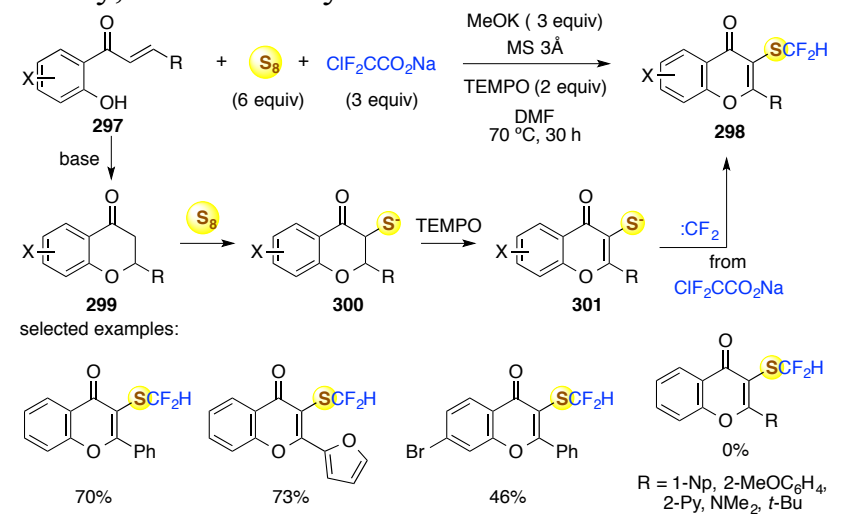

Scheme 106.

A synthesis of indolizine thioketones 304 was developed from 2-picolines $\alpha$-substituted by an EWG 302, aryl propynals $\mathbf{3 0 3}$ and elemental sulfur (Scheme 107). ${ }^{[136]}$ While 2-picoline substrates bearing an oxygenated EWG (ester, acetyl) reacted rapidly (within $1 \mathrm{~h}$ ), those having nitrogenated EWG $(\mathrm{CN}$, amides) required molecular iodine $(10 \mathrm{~mol} \%)$ as a catalyst with longer reaction time $(4 \mathrm{~h})$. The transformation is initiated by a condensation between the methylene moiety of picolines $\mathbf{3 0 2}$ and the aldehyde function of $\mathbf{3 0 3}$, followed by a cyclization and sulfuration.

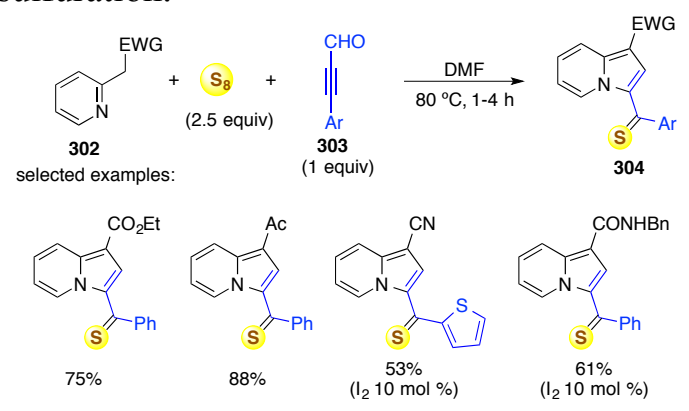

Scheme 107.

\section{Elemental sulfur not acting as a sulfur source}

\subsection{Elemental sulfur acting as oxidizing agent}

One of the most interesting aspects of elemental sulfur is it can act as an oxidant to oxidize selectively a nucleophilic compound $\mathbf{N u}^{1}$ into an electrophilic intermediate $\mathbf{E l}^{1}$. This highly reactive species could be attacked by excess starting nucleophilic compound $\mathbf{N u}{ }^{1}$ or by another nucleophilic component $\mathbf{N u}^{2}$ that is stable to the oxidation sulfur, leading to final adduct $\mathbf{N u}^{1}-\mathbf{E l}^{1}$ or $\mathbf{N u}^{2}-\mathbf{E l}^{1}$ (Scheme 108). Although the basic idea is simple, the scope of this strategy is extremely large with appropriate choice of substrates as well as reaction conditions.

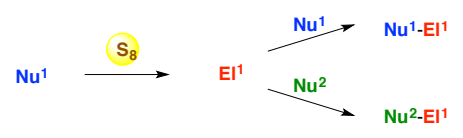

\section{Scheme 108.}

We found that all the reactions reviewed in this section could be conveniently classified as formal cycloadditions promoted by sulfur. Accordingly, this will be applied throughout this section.

\subsubsection{Five-membered ring syntheses}

3.1.1.1 [4+1]

Sulfur-promoted Willgerodt-Kindler type reactions were developed as an innovative strategy to achieve oxidative cyclocondensation. The main different with the original Willgerodt-Kindler reaction is a bisnucleophile is used in place of amine. Such a modification would result in cyclized product with hydrogen sulfide as a by-product. Consequently, even though sulfur is not present in the final heterocyclic products, the reaction follows a similar Willgerodt rearrangement mechanism.

In 2017, we developed this strategy for the synthesis of 2-substituted benzoxazoles 307 starting from $o$ aminophenols 306 and ketones 305 (Scheme 109). ${ }^{[137]}$ The reactions required both sulfur and $N$ methylpiperidine in stoichiometric amounts and could be applied to a wide range of methyl ketones, including 
acetophenones, acetylhetarenes and methyl alkyl ketones with satisfactory yields.

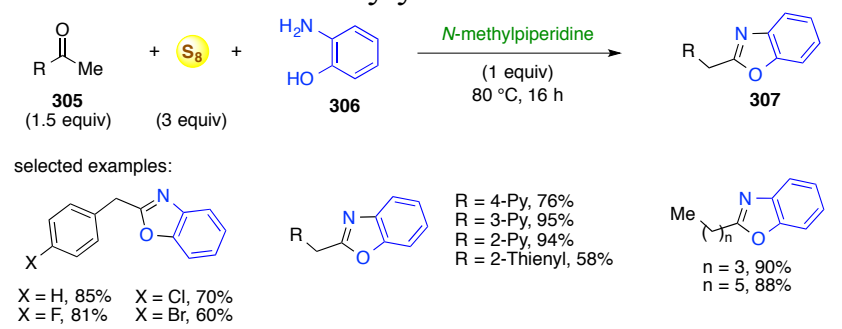

\section{Scheme 109.}

One of the most striking experimental proofs of a Willgerodt-type pathway is the migration of the benzoxazolyl moiety to the end of the chain when ethyl ketone and higher analogues $\mathbf{3 0 8}$ were used (Scheme 110). It should be noted that the yields of $\mathbf{3 1 0}$ dropped with the distance of migration, which is in full agreement with Willgerodt reaction mechanism.

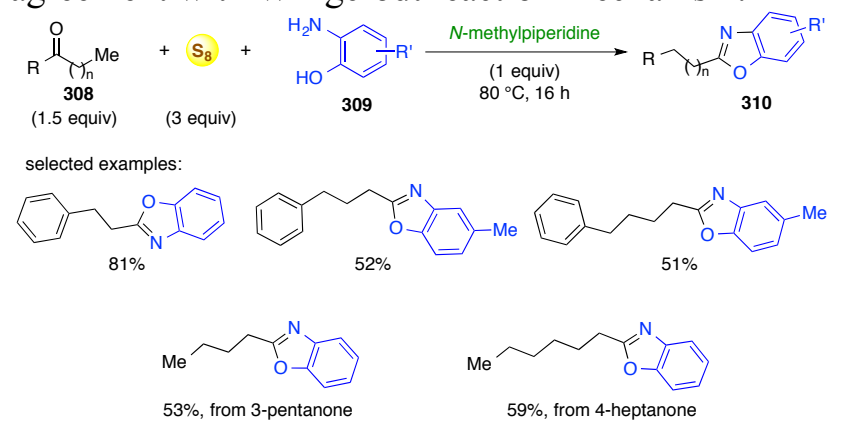

Scheme 110.

This strategy was next adapted to the synthesis of benzoxazoles or benzimidazoles from 2-aminophenols or $o$-phenylenediamines with phenylacetylenes as a more expensive synthetic equivalent of acetophenones. ${ }^{[138]}$

Very recently, we could apply this method to the synthesis of 2-substituted benzoxazoles 312 via oxidative coupling of benzaldehydes or cyclohexane carboxaldehyde 311 with $o$-aminophenols 309 by sulfur in DMSO (Scheme 111). ${ }^{[139]}$ The reaction was found to be efficiently catalyzed by sodium sulfide. Although similar approaches were previously known with other oxidants, including molecular oxygen, the reaction based on elemental sulfur was particularly attractive in term of low reaction volume as solid sulfur was used stoichiometric amount.

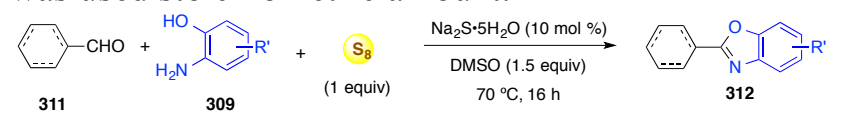

\section{Scheme 111.}

Monoamide of maleic acids $\mathbf{3 1 4}$ could involve in a decarboxylative coupling reaction with bisnucleophiles $\mathbf{3 1 5}$ such as 2-aminophenol, $o$ phenylenediamine or 1,3-propanediamine promoted by sulfur/ $N$-methylpiperidine/DMSO to provide $\alpha$ hetarylacetamides 316 (Scheme 112). ${ }^{[140]}$ Such a decarboxylation was found to occur under mild condition of heating, which could be explained by the presence of the amide function of electron attracting nature. Interestingly, the starting substrates monoamide of maleic acids could be easily prepared in the same pot by spontaneous equimolar combination of amines 313 with cheap maleic anhydride.

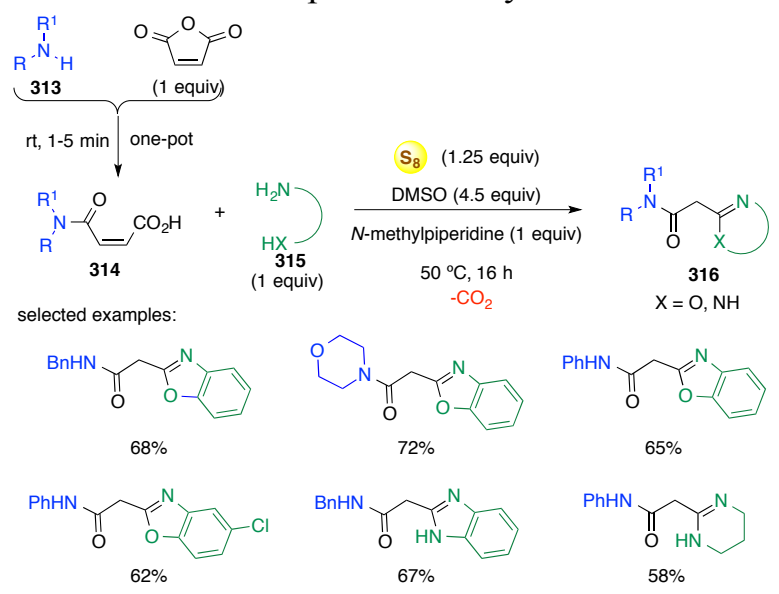

Scheme 112.

In a similar manner, fumaric acid monoester displayed the same reactivity, leading to $\alpha$ hetarylacetates (Scheme 113).

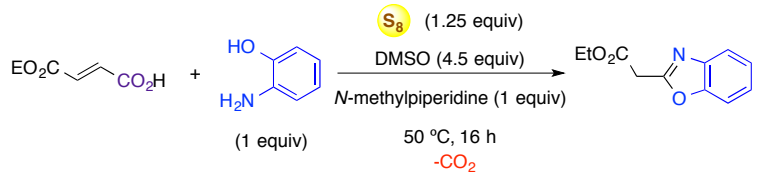

\section{Scheme 113.}

A synthesis of 2-(trifluoromethylmethyl)benzazoles 319 involving sulfur was described from the parents $O$ substituted anilines $\mathbf{3 1 7}$ and 2-bromo-3,3,3trifluoropropene 318 (Scheme 114). ${ }^{[141]}$

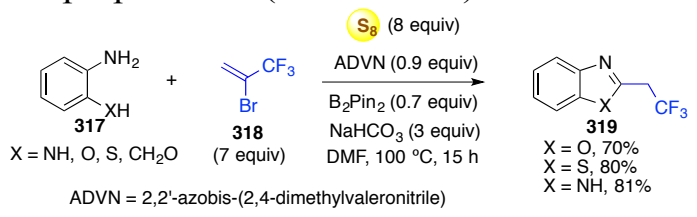

\section{Scheme 114.}

The obvious drawback of this method the use of radical initiators $\mathrm{ADVN}$ and $\mathrm{B}_{2} \mathrm{Pin}_{2}$ in near stoichiometric amounts as well as sulfur and expensive 2-bromo-3,3,3-trifluoropropene in large excess (7 equiv).

Sulfur was found to promote oxidative cyclocondensation of acylhydrazides $\mathbf{3 2 0}$ and isonitriles $\mathbf{3 2 1}$ to produce 2-amino-1,3,4-oxadiazoles 322 upon heating in DMSO (Scheme 115). ${ }^{[142]}$

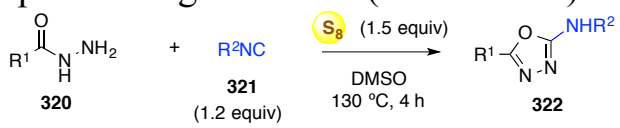

$$
\text { selected examples: }
$$


The method was compatible with aliphatic, aromatic and heteroaromatic substrates. In situ formation of isothiocyanates by thermal reaction of isonitriles $\mathbf{3 2 1}$ and sulfur was hypothesized as the key step.

\subsubsection{2 [3+2]}

One of the strategies for the formation of heterocycles based on formal cycloaddition was previously relied on non-redox condensation (substitution and addition/elimination) between a bisnucleophile with a bis-electrophile. The latter precursor is in general highly reactive, not readily available in a wide range of structure, and therefore should be prepared prior to the reaction. On the other hand, in the oxidative condensation approach, by using an oxidant compatible with the bis-nucleophile, the bis-electrophile could be generated in situ from monoelectrophile, which is more stable and more readily available. Accordingly, the expected heterocycles could be obtained in a more direct manner with cheaper precursor. Sulfur was suggested to be the oxidant of choice in our reaction between 2-aminopyridines $\mathbf{3 2 3}$ with cyclohexanones as well as higher homologs 324 (Scheme 116). ${ }^{[143]}$

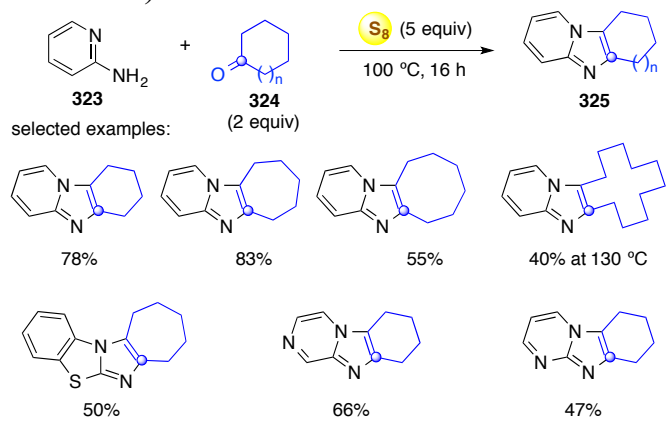

Scheme 116.

The reactions were performed under solvent-free conditions, using 5 equiv of sulfur and at a temperature near the melting point of pure sulfur to keep the reaction mixture liquid. The reaction could be extended to 2-aminobenzothiazole, aminopyrazine and 2 -aminopyrimidine. Highly oxidizable under aerobic conditions bis-nucleophiles such as $O$ phenylenediamines could be used in the same manner for synthesis of fused quinoxalines (See section 3.1.2).

Several versions of this strategy have been developed. First, Deng et al disclosed in the same time their study focused on the use of 2aminobenzothiazoles $\mathbf{3 2 6}$ as 1,3-bis-nucleophile in place of 2-aminopyridines under aerobic conditions in DMSO at temperature up to $130{ }^{\circ} \mathrm{C}$ (Scheme 117). ${ }^{[144]}$ The reaction involved in only one equivalent of sulfur, suggesting that bot oxygen and DMSO could act as complementary oxidants. The reaction was found to be less efficient when performed under argon. It should be noted that, this set of aerobic oxidative coupling conditions was not compatible with 2-aminopyridine.

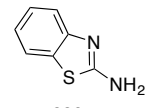

326

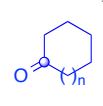

(1.5 equiv)

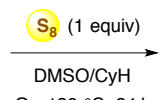

$\mathrm{O}_{2}, 130^{\circ} \mathrm{C}, 24 \mathrm{~h}$

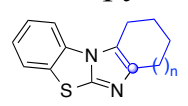

327
Scheme 117.
Second, cycloalkanone components could be replaced by phenylacetaldehydes and other aliphatic aldehydes 328 (Scheme 118). ${ }^{[145]}$ The reactions performed in mixture of DMSO/cyclohexane required a higher temperature $\left(120{ }^{\circ} \mathrm{C}\right)$ but with a shorter reaction time $(1 \mathrm{~h})$.

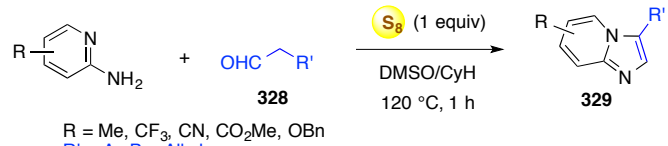

$$
\begin{aligned}
& \begin{array}{l}
\mathrm{R}=\mathrm{Me}, \mathrm{CF}_{3}, \mathrm{CN}, \mathrm{CO}_{2} \mathrm{Me}, \mathrm{OB} \\
\mathrm{R}^{\prime}=\mathrm{Ar}, \mathrm{Bn}, \text { Alkyl }
\end{array}
\end{aligned}
$$

\section{Scheme 118.}

Mechanistically, it was suggested that the reaction was initiated by a condensation of the two substrates to imine 330 in an equilibrium with enamine 331 (Scheme 119). ${ }^{[143]}$ Subsequent sulfuration of $\mathbf{3 3 1}$ by elemental sulfur would lead to polysulfide imine 332, existing in an equilibrium with enamine $\mathbf{3 3 3}$. Cyclization of $\mathbf{3 3 3}$ to $\mathbf{3 3 4}$ followed by elimination of hydropolysulfide chain from $\mathbf{3 3 4}$ resulted in tricyclic 325.

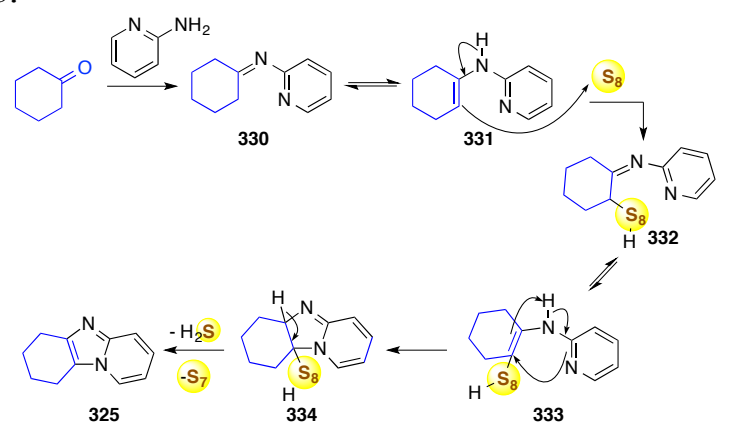

Scheme 119.

2-Picolines $\alpha$-substituted $\mathbf{3 3 5}$ by an electron withdrawing group could react with a primary amine to yield imidazo[1,5- $a$ ]pyridine $\mathbf{3 3 6}$ under oxidative conditions promoted by elemental sulfur in DMSO (Scheme 120). ${ }^{[146]}$ While both benzylamines and aliphatic amines could be used as the primary component, only 2-picolines with an $\alpha$-ester or $\alpha$ carboxamide were found to be reactive. Reactions failed with $\mathrm{EWG}=\mathrm{CN}$ or $\mathrm{Bz}$, presumably due to their incompatibility with amine at high temperature. The proposed mechanism was depicted with the oxidation of the methylene moiety of picolines and subsequent condensation with amine as the first step.

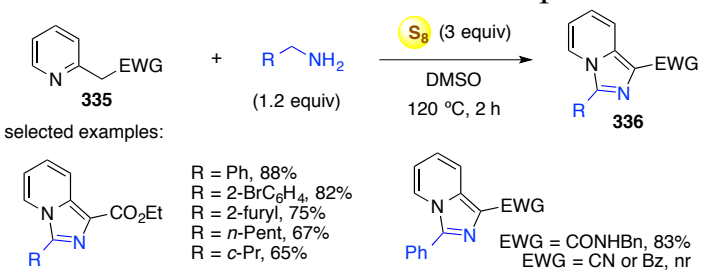

\section{Scheme 120.}

By simply heating phenylacetonitrile with elemental sulfur and DMSO in the presence of a catalytic amount of DABCO, we accomplished an unusual oxidative trimerization leading to polysubstituted pyrrole heterocycle $\mathbf{3 3 7}$ in excellent yields with $E$ configuration (Scheme 121). ${ }^{[147]}$ The reaction 
conditions in general were not applicable to $o$ substituted phenylacetonitrile substrates. Mechanistically, the reaction was initiated by an oxidation of phenylacetonitrile with sulfur to thiobenzoyl cyanide 338. As a bis-electrophile, this thioketone could condense with two other phenylacetonitrile molecules to provide trimer 339340, which would undergo isomerization and cyclization to the trimer product.

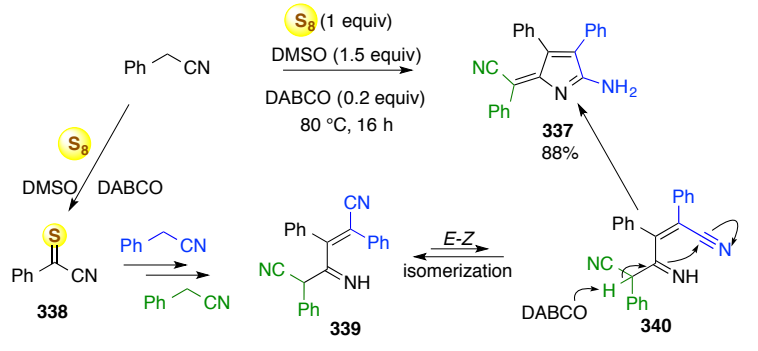

Scheme 121.

\subsubsection{3 [2+2+1]}

In 2018, Huang and Deng et al reported a convenient multicomponent access to tetrasubstituted imidazoles 342 from oxidative condensation of enolizable ketones 341 with two molecules of aliphatic amines (Scheme 122). ${ }^{[148]}$

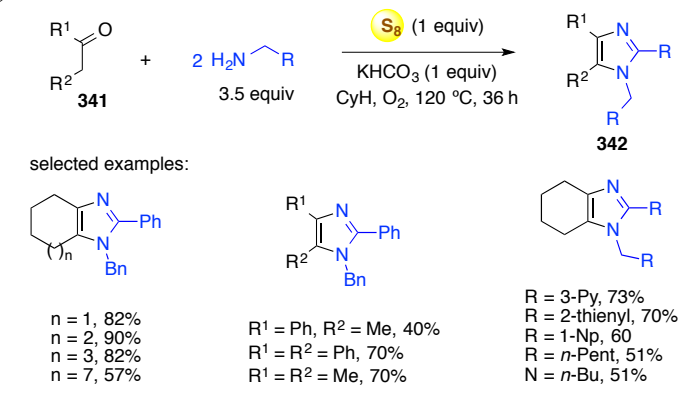

\section{Scheme 122.}

This reaction involved both sulfur (1 equiv) and oxygen (1 atm) as oxidants. Cyclohexanones and higher homologs as well as acyclic ketones were competent carbonyl substrates. With regard to amines, benzylic type ones shown better reactivity although $n$ pentylamine and $n$-hexylamine could also be used with moderate yields ( $51 \%$ for both cases).

In order to introduce two different amines (a benzyl amine and an aliphatic amine), a one-pot two-step protocol was suggested: (1) non oxidative condensation of benzylamine with ketone 341 to $N$ benzylimine; (2) reaction of the resulting imine $N$ benzylimine with the aliphatic amine under oxidative conditions of $\mathrm{S}_{8}$ and $\mathrm{O}_{2}$ (Scheme 123).

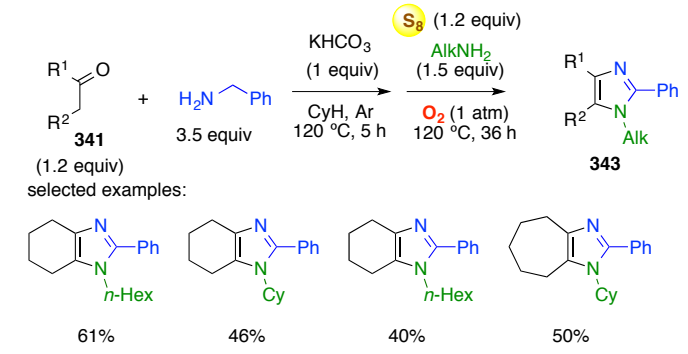

Scheme 123.

\subsubsection{Six-membered ring syntheses}

\subsubsection{1 [4+2]}

Although $o$-phenylenediamine 344 is well known for its rapid oxidation under ambient conditions, easily darkening in air, this bis-nucleophile is relatively stable with sulfur even at high temperature (Scheme 124). Based on this compatibility, we studied the oxidative coupling between $o$-phenylenediamine 344 and cycloalkanones 324. ${ }^{[143]}$ The corresponding quinoxalines 345 could be easily obtained when heated with sulfur at near melting point of this elemental.
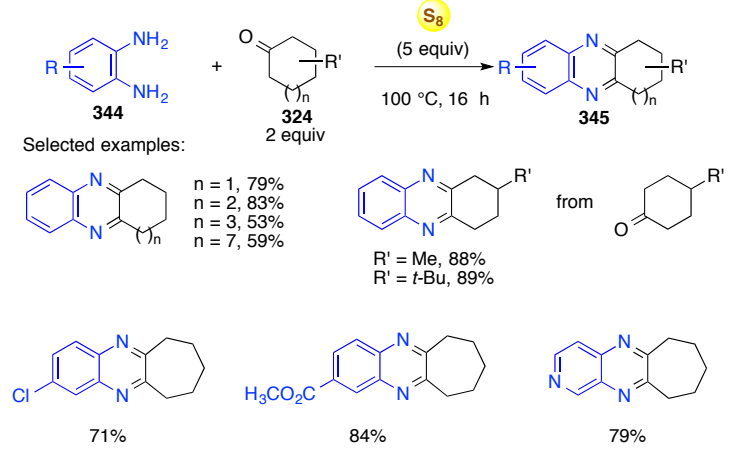

\section{Scheme 124.}

In case of quinoxaline $\mathbf{3 4 6}$ derived from cyclohexanones, a further direct introduction of a substituted amino group to the $\alpha$-methylene group with simultaneous aromatization leading to 1aminophenazines 347 could be achieved when heating with elemental sulfur and DMSO (Scheme 125). ${ }^{[149]}$

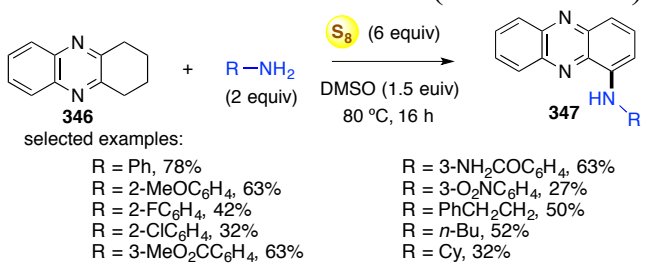

\section{Scheme 125.}

We noticed also that when a monosubstituted cyclohexanone 324 was heated with two equivalent of $o$-phenylenediamine, fused pentacycle 348 was formed in DMSO (Scheme 126). Reasonable yields could be achieved when a strong acid such as TFA, $\mathrm{HCl}$, PTSA... was used as a catalyst. ${ }^{[150]}$
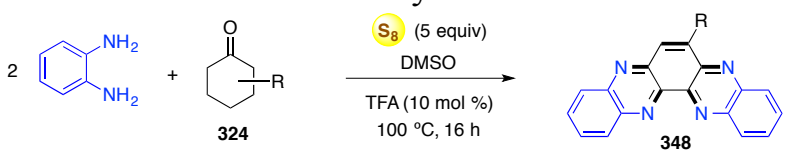

\section{Scheme 126.}

According to the proposed mechanism, the reaction introduction of a second $o$-phenylenediamine to 2,3(tetramethylene)quinoxaline occurred via a sequence of imine-enamine tautomerization/Michael addition/aromatization/Michael cyclizing addition /aromatization (Scheme 127). The global process consists in removal of seven hydrogen molecules. 


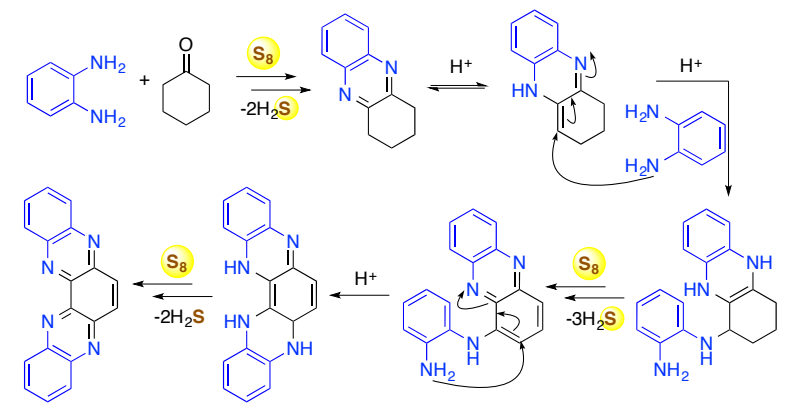

Scheme 127.

With cycloheptanone, introduction of two molecules $o$-phenylenediamine took place under the same conditions with lower yields (Scheme 128). Notably, in this case, the aromatization of the cycloheptane core is not possible, suggesting that the aromatization in the previous case with monosubstituted cyclohexanone is not a driving force for this kind of reaction.

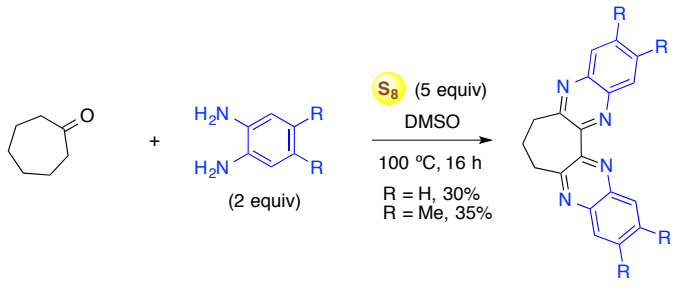

Scheme 128.

When 1,4-cyclohexadione monoprotected as dioxolane derivative $\mathbf{3 4 9}$ was submitted to the same reaction with $o$-phenylenediamine, phenazine $\mathbf{3 5 0}$ was formed as a result of an introduction of only one molecule $o$-phenylenediamine with ring opening of dioxolane and aromatization of the cyclohexanone ring (Scheme 129). The ring opening step was shown be independent of the presence of the acid catalyst.

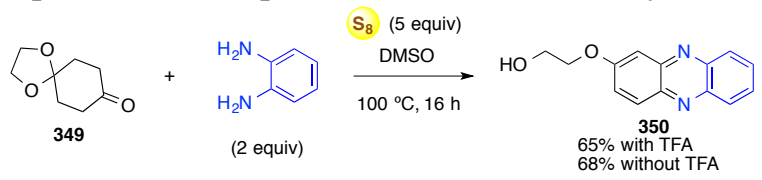

\section{Scheme 129.}

In the presence of $\mathrm{K}_{2} \mathrm{CO}_{3}$ as a basic activator, sulfur was found to promote an oxidative condensation of indole 351 with $o$-salicylaldehydes $\mathbf{3 5 2}$ to yield chromeno[2,3-b] indole 353 (Scheme 130). ${ }^{[151]}$
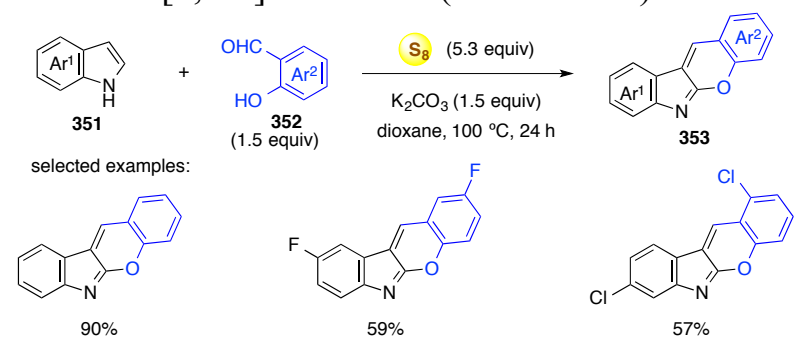

Scheme 130.

\subsubsection{2 [5+1]}

The methyl group of an acetophenone or pinacolone 354 could be oxidized with elemental sulfur in DMSO (Scheme 131). ${ }^{[152]}$ In the presence of an anthranilamide
355 as s bis-nucleophile, the corresponding product could be formed. The reaction required $N$ methylpiperidine in stoichiometric amount as a sulfur activator. Notably, a wide range of secondary anthranilamides $\mathbf{3 5 5}$ could be easily obtained in onepot via catalyst-free and solvent-free decarboxylative condensation reaction of a primary amine with isatoic anhydride.

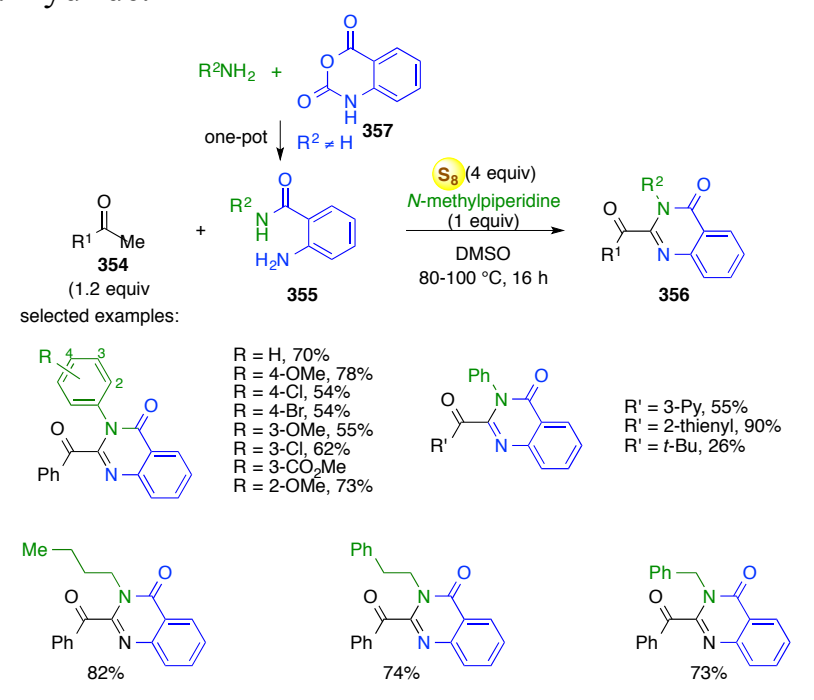

\section{Scheme 131.}

The method could be applied to the synthesis of natural product tryptanthrin 359 starting from $o$ aminoacetophenone $\mathbf{3 5 7}$ and isatoic anhydride (Scheme 132).

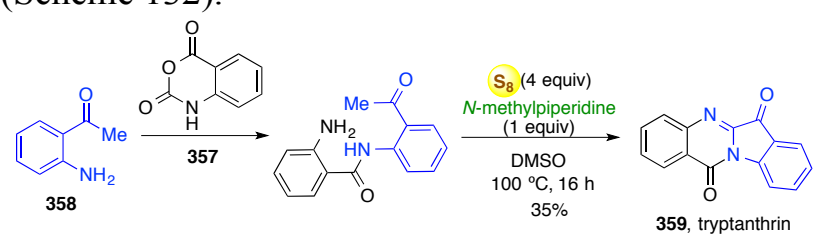

\section{Scheme 132.}

\subsubsection{3 [1+2+3]}

1,3,5-Triaryltriazines $\mathbf{3 6 2}$ could be synthesized by sulfur-promoted oxidative condensation of one molecule of benzyl chloride $\mathbf{3 6 1}$ with two molecules of benzamidine 360 under basic conditions (Scheme 134). ${ }^{[119]}$

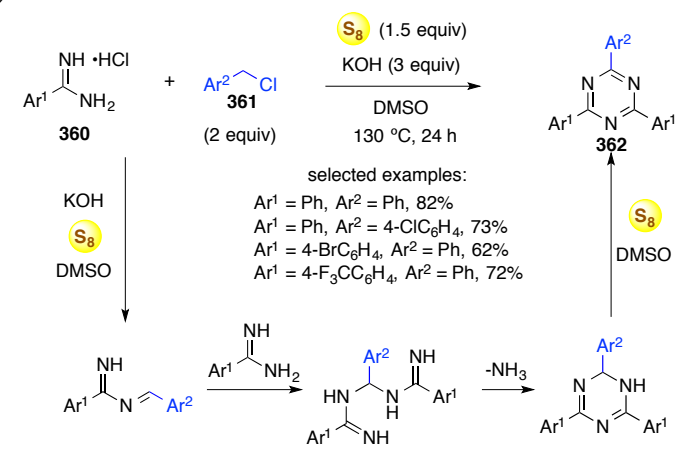

\section{Scheme 133.}

The first step of this transformation is an oxidation of the methyl moiety of benzyl chloride $\mathbf{3 6 1}$ as well as its derivatives issued from nucleophilic displacement of chloro group by other nucleophiles present in the 
reaction medium. Subsequent condensation with two benzamidines $\mathbf{3 6 0}$ followed by cyclization and aromatization would result in the expected product $\mathbf{3 6 2}$. The reaction failed however with 4-methoxybenzyl chloride. When both benzamidines and sulfur were used in excess ( 2 and 5 equiv based on benzyl chlorides, respectively), the reaction led to 1,2,4-thiadiazoles (See section 2.9.2).

\subsubsection{4 $[2+1+2+1]$}

A metal-free synthetic approach to monosubstituted 1,2,4,5-tetrazines $\mathbf{3 6 4}$ was developed based on multicomponent reaction between dichloromethane, hydrazine hydrate and nitriles 363 in two step (Scheme 134). ${ }^{[153]}$ Sulfur was used as oxidative promoter in the first step followed by a second step of aromatization under diazotization conditions.

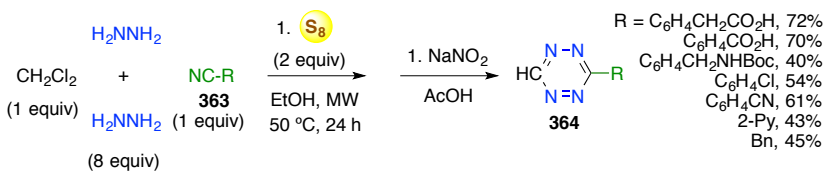

\section{Scheme 134.}

According to the proposed mechanism, the first steps were a reaction of the sulfur-hydrazine adduct and hydrazine itself with DCM, followed by an addition step of nitrile to provide mixture of two adducts, which undergo a cyclization to hexahydrotetrazine (Scheme 135). Finally, a double elimination followed by an oxidative aromatization step would lead to monosubstituted tetrazine.

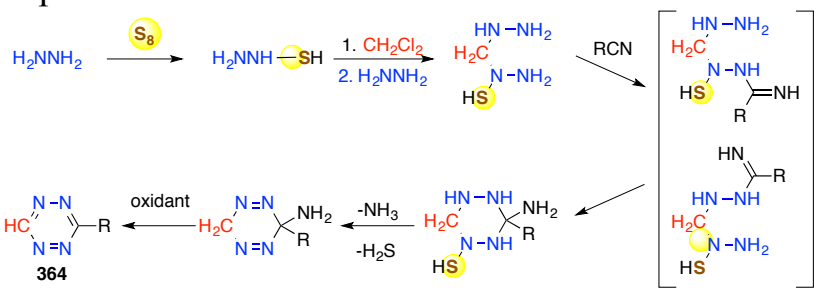

Scheme 135.

\subsubsection{Seven-membered ring syntheses}

$\alpha$-Chloroacetamides 366 could be conveniently used as one-carbon building-block in the synthesis of dibenzo[1,3]diazepines $\mathbf{3 6 7}$ starting from 2,2'biphenyldiamines 365 in the presence of sulfur activated by triethylamine (Scheme 136). ${ }^{[154]}$ The reaction was suggested to proceed via a Willgerodt type reaction to form 2-thioxoacetamide, which was trapped by the two amino group of 2,2'biphenyldiamines 365 . While the scope of $\alpha$ chloroacetamides 366 is large, with $\mathrm{N}$-aromatic, $\mathrm{N}$ aliphatic and $\mathrm{NH}_{2}$ amides are all competent substrates, the reaction is strongly affected by substituent pattern on the 2,2'-biphenyldiamines $\mathbf{3 6 5}$ of both steric (omethyl or $o, o$ '-dimethyl substrate) and electronic (electron withdrawing group such as nitro in the para position to the amino group) reasons. $\alpha$-Fluoro, bromo or iodo acetamide reacted in the same manner as $\alpha$ chloroacetamide with the lowest efficiency with $\alpha$ bromoacetamide.
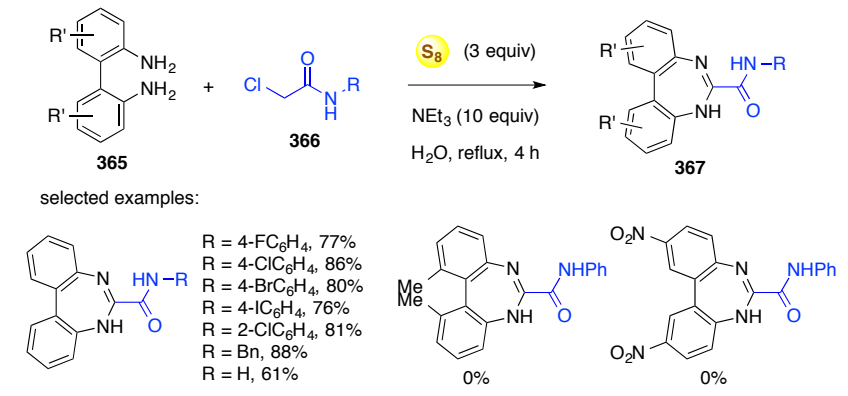

\section{Scheme 136.}

When $\alpha$-chloroacetic acid 368a was used in place of $\alpha$-chloroacetamide, thiourea product was yielded as a result of a further decarboxylation (Scheme 137). Ethyl $\alpha$-chloroacetate $\mathbf{3 6 8 b}$ reacted in the same manner with a slightly lower yield.

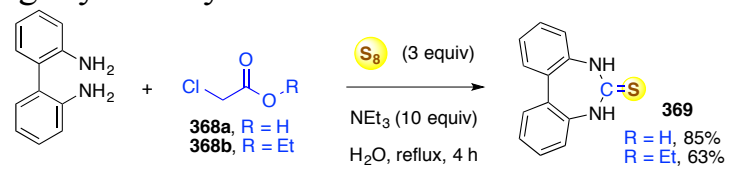

Scheme 137.

\subsection{Elemental sulfur acting as catalyst for redox condensations}

\subsubsection{Iron-sulfur catalyst}

The nitro group is well known as one of the most versatile and readily available nitrogen containing functional groups. The nitro group has been widely used as a precursor of nitrogen compounds including azaheterocycles but traditionally with prior reduction in a separate step. In 2013, we have reported iron/sulfur catalyst generated from the elemental forms of both components to promote the redox condensation between $o$-nitroanilines and $o$-nitrophenols 370 with a wide range of 2- or 4-methyl hetarenes 371 such as 2and 4-picolines, quinadine, lepidine and 2methylbenzimidazole (Scheme 138). ${ }^{155]}$

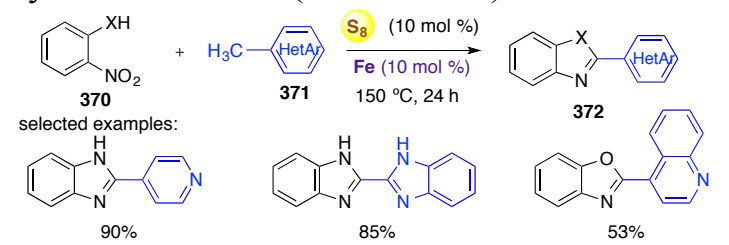

\section{Scheme 138.}

As mentioned above, the reaction is limited to hetarenes bearing a 2- or 4-methyl. To expand the scope of the reaction, others reducing partners could be considered. When aliphatic alkylamine $\mathbf{3 7 5}$ and $\mathbf{3 7 6}$ were used as reducing partners or when $o$ nitrobenzamides 374 were used as oxidizing partners with primary benzylamines $377, \mathrm{FeCl}_{3} \cdot 6 \mathrm{H}_{2} \mathrm{O}$ and $\mathrm{S}_{8}$ catalyst showed its superior catalytic activity, leading to benzimidazoles $\mathbf{3 7 8}$ and quinazolinones $\mathbf{3 7 9}$ (Scheme 139). ${ }^{[156]}$ 


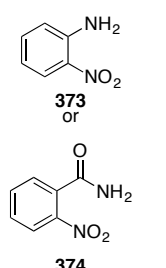

374
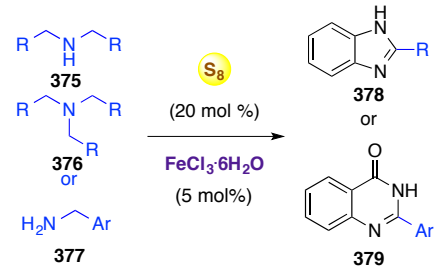

379

\section{Scheme 139.}

When the 2-phenethylamine $\mathbf{3 8 0}$ was use instead of benzylamine, another mode of redox condensation occurs with an initial oxidation of the $\alpha$-methylene to imine (Scheme 140). Subsequently, the $\beta$-methylene group became more reactive and underwent a further oxidation. ${ }^{[157]}$ Consequently, quinoxalines $\mathbf{3 8 1}$ were formed as a result of the oxidation of two carbon atoms. Longer aliphatic amines such as octylamine were shown to be less reactive with competitive formation of the 6-heptylbenzimidazole.

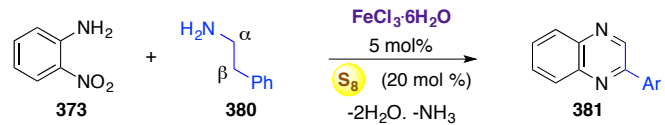

\section{Scheme 140.}

Some limitations of the reaction became obvious. First, the methyl group of methylhetarene should locate in the 2 or 4 position of the heterocycle for an efficient stabilization of the corresponding reactive intermediate. Second, using four-electron donor benzylamines with six-electron acceptor nitro group required additional benzylamine to act as reducing agent with the formation of by-products. We proposed phenylacetic acids $\mathbf{3 8 0}$ as an alternative reducing partners, which underwent decarboxylation and 6-electron oxidation (Scheme 141). ${ }^{[158]}$

$$
\text { traceless activating group } \begin{gathered}
\mathrm{N} \text {-methylpiperidine } \\
(40 \mathrm{~mol} \%) \\
130^{\circ} \mathrm{C}, 20 \mathrm{~h}
\end{gathered}
$$

\section{Scheme 141.}

This catalyst system could also be applied to 2,2'dinitrodiphenyldisulfide (Scheme 142).

$$
\underbrace{\mathrm{NO}_{2}}_{382}
$$

\section{Scheme 142.}

Interestingly, sodium sulfide was also found to be a suitable for acting as both sulfur source for $\mathrm{Fe} / \mathrm{S}$ catalyst and external complementary reducing agent when benzyl alcohols or glycols were used as reducing agent. ${ }^{[159]}$

Recently, we found that benzyl cyanides 384 could act efficiently as benzylidyne source (Scheme 143). ${ }^{[160]}$ In this case, the cyano group acts as a leaving group and can be trapped as non-toxic thiocyanide ion when sulfur was used in excess amounts.

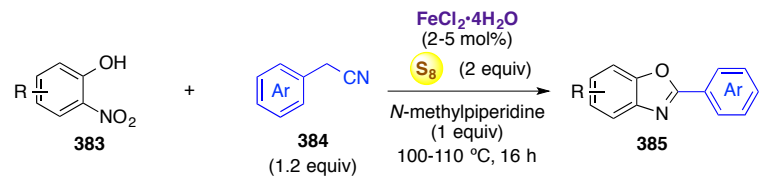

Scheme 143.

Recent applications include synthesis of 2arylbenzazoles via redox coupling of $o$ nitrophenols/thiophenols/anilines with dibenzyl disulfide. ${ }^{[161]}$

\subsubsection{Sulfur catalyst}

Recently, we reported a benzazolation reaction of anilines $O$-substituted by a cyclizable group such as $\mathrm{OH}$ or $\mathrm{NH}_{2} \mathbf{3 8 7}$ by dibenzyl disulfide $\mathbf{3 8 6}$ using DMSO as an oxidant in near stoichiometric amount in the presence of sulfur as a catalyst and $N$-methylpiperidine as a sulfur activator. ${ }^{[162]}$ Since the expected benzazole products 388 did not contain sulfur issued from the starting dibenzyl disulfide 386, these sulfur atoms were extruded to the reaction medium and could in turn act as a catalyst (Scheme 144). Consequently, the catalyst loading of sulfur could be lower significant. Indeed, excellent yields could be obtained even with 1 and 5 mol $\%$ of sulfur catalyst (based on atomic sulfur) for benzoxazole and benzimidazole, respectively.

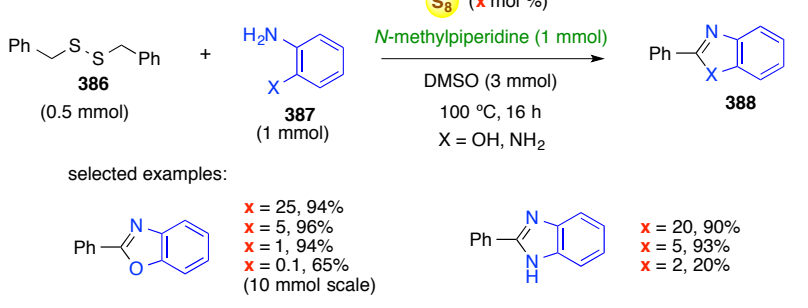

\section{Scheme 144.}

A plausible mechanism was proposed for aliphatic amine (Scheme 145). Adduct of this amine with sulfur could induce a fragmentation of dibenzyl disulfide to generate in situ thiobenzaldehyde, which is a key intermediate of this reaction. Highly electrophilic, the thioaldehyde function could react easily with $o$ aminophenol with elimination of $\mathrm{H}_{2} \mathrm{~S}$ and the corresponding adduct could be oxidized by either sulfur or DMSO to provide thioamide.

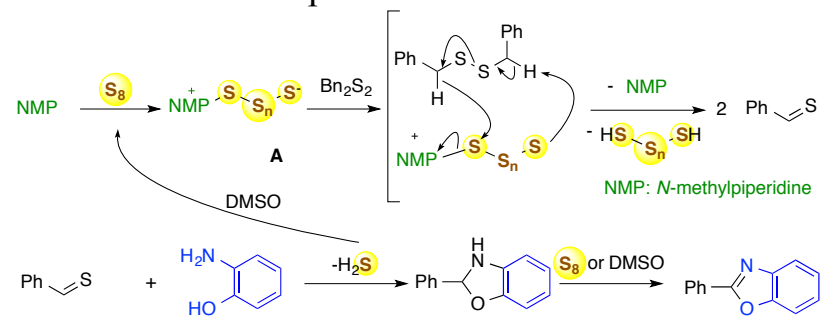

\section{Scheme 145.}

The methylene moieties of 5,6,7,8-tetrahydroquinoline 390 and isoquinoline 391 could be oxidized and coupled with an $o$-phenylenediamine in the presence of sulfur and TFA in catalytic amounts and DMSO as an oxidant (Scheme 146). This strategy offered an inexpensive and rapid way to construct fused phenazine-pyridine heterocycles 391-392. ${ }^{[150]}$ 


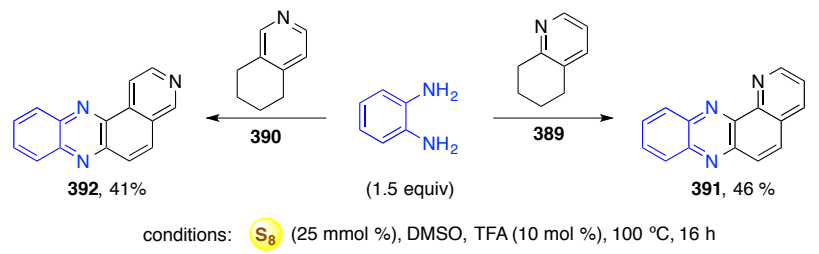

Scheme 146.

Sulfur was found to be an efficient catalyst for oxidative coupling of two molecules $o$-aminophenols with a cyclohexanone with DMSO as an oxidant. The heteropropellane products 393 could be formed in excellent yields and good functional group tolerance (Scheme 147). It should be noted that the reaction proceeded with complete regio- and stereo- selectivity. In all cases, the coupled products were the most thermodynamically stable stereoisomers of all possibility with two axial $\mathrm{C}-\mathrm{N}$ bonds and two equatorial $\mathrm{C}-\mathrm{O}$ bonds.

Starting monosubstituted substrate, while 3- and 4substituted cyclohexanones led convergently to the same results in term of regio- and stereo- chemistry, 2substituted cyclohexanones had only the position 6 as reactive site, resulting in only one possible regioisomer. We emphasized that only one stereoisomer was observed in all these cases with the substituent $\mathrm{R}$ in equatorial position.

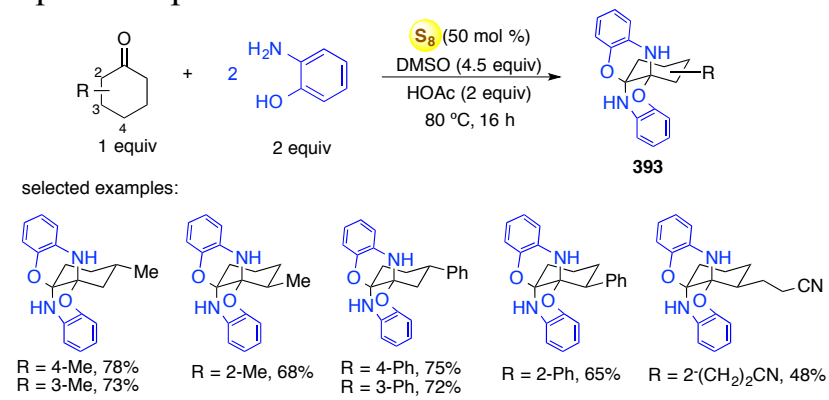

\section{Scheme 147.}

$o$-Nitrophenols were found to condense with phenylacetic acids, benzyl chlorides and benzaldehydes to provide 2-phenylbenzoxazoles (Scheme 148).

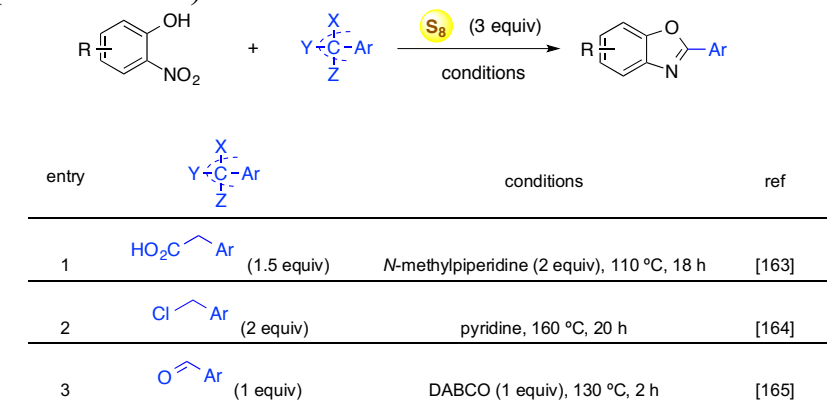

\section{Scheme 148.}

In all the cases, although sulfur was used up to 3 equiv, the reaction should proceed via $6 \mathrm{e}^{-}$reduction of the nitro group of $o$-nitrophenols and concomitant oxidation of phenylacetic acids $\left(6 \mathrm{e}^{-}\right)$, benzyl chlorides $\left(4 \mathrm{e}^{-}\right)$and benzaldehydes $\left(2 \mathrm{e}^{-}\right)$. While the oxidation step could be achieved with elemental sulfur with hydrogen sulfide as the byproduct, the reduction of nitro could be done by either hydrogen sulfide to regenerate sulfur or by sulfur itself to yield sulfur compounds with sulfur in its positive oxidation states.

\subsection{Elemental sulfur acting as catalyst for non- redox condensations}

Elemental sulfur (in $20 \mathrm{~mol} \%$ as $\mathrm{S}_{8}$ or $160 \mathrm{~mol} \%$ as atomic sulfur) was found to promote the condensation of anilines $o$-substituted by a cyclizable group (such as $\left.\mathrm{NH}_{2}, \mathrm{OH}, \mathrm{SH}\right) 394$ with $\alpha$-bromo- $\alpha, \alpha-$ difluoro acetamides/acetates $\mathbf{3 9 5}$ to provide the corresponding benzazole-2-yl carboxamides or carboxylates 396 (Scheme 149). ${ }^{[166]}$ The reactions proceeded at high temperature for $o$ phenylenediamines $\left(130{ }^{\circ} \mathrm{C}\right.$ for $\left.16 \mathrm{~h}\right)$, whereas $o$ aminothiophenols reacted under milder conditions $\left(90{ }^{\circ} \mathrm{C}, 12 \mathrm{~h}\right)$. High nucleophilicity of polysulfide, generated in situ from the reaction of sulfur with $\mathrm{Na}_{2} \mathrm{CO}_{3}$ at elevated temperature, was inarguably responsible for this condensation with triple dehydrohalogenation via cascade of nucleophilic substitution and addition/elimination steps.

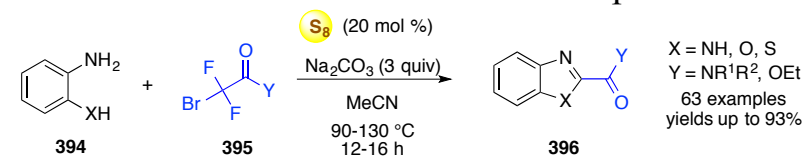

Scheme 149.

Sulfur was found to catalyze efficiently the condensation of 2-aminopyridines 397 as bis-1,3nucleophiles and $\beta$-ketoester $\mathbf{3 9 8}$ as bis-1,3electrophiles, leading to $2 H$-pyrido[1,2-a]pyrimidin-2ones 399 under solvent-free conditions (Scheme 150). ${ }^{[167]}$ The reactions conditions tolerate a wide range of functional groups and can be extended to 2-aminothiazole. In term of redox balance, the global transformation is only a simple condensation with removal of a water and an ethanol molecules without change in oxidation states of any atom. It could be possible that, as in the previous case ${ }^{[166]}$ highly nucleophilic polysulfide generated in situ from the reaction of sulfur with 2-aminopyridine, acted as nucleophilic catalyst.

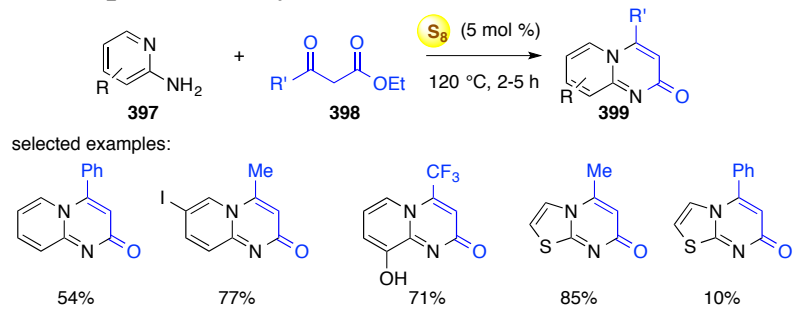

Scheme 150.

\section{Conclusion}

In this update review, the recent advances in organic synthesis of heterocycles involving elemental sulfur from 2017 are discussed. When sulfur is employed as a sulfur precursor, the strategy opens new avenues to sulfa heterocycles with a broad range of applications while avoiding many inconveniences related to the 
handle of other sulfur precursors, especially disagreeable odor of volatile thiols and sulfides compounds. On the other hand, sulfur was found to be a versatile reagent for oxidation reactions and oxidative coupling, not only as an excellent alternative oxidant to its smaller congener oxygen as well as other commonly used oxidizing agents but also as an oxidant with unique, rich and tunable chemistry. In this field, the study for catalytic reactions involving this element as the sole catalyst or in combination with iron was recently initiated and explored. As mentioned above, these approaches are particularly attractive and promising, since both sulfur and iron are abundant, easily available, nontoxic with a wide range of reactivities known in biological world. Diverse heterocyclic compounds including sulfur containing and sulfur-free heterocycles can be synthesized easily and conveniently. In most cases, the transformations proceed via cascade and/or multicomponent processes with the formation of many new bonds and allow access to original heterocyclic structures that are much more complex or "impossible" to obtain otherwise.

However, some challenges are still to be explored. In some cases, the reported reaction conditions remained harsh with prolonged heating at high temperature under pressure with large excess solvents and additives. We are focusing our effort on development of milder reaction conditions.

Consequently, more efficient methods using this element in heterocyclic chemistry are continuously disclosed, and their application for the synthesis of drugs and materials, especially in large scale and low cost, is anticipated.

\section{References}

[1] For some reviews on sulfuration reactions, see: a) J. Liu, L. Zheng, Adv. Synth. Catal. 2019, 361, 1710; b) H, Liu, X. Jiang, Chem. Asian J. 2013, 8, 2546.

[2] a) T. B. Nguyen, Adv. Synth. Catal. 2017, 359, 1106; b) T. B. Nguyen, Asian J. Org. Chem. 2017, 6, 477.

[3] T. B. Nguyen, P. Retailleau, Green Chem. 2018, 20, 387.

[4] Z. Wang, Z. Qu, F. Xiao, H. Huang, G. Deng, Adv. Synth. Catal. 2018, 360, 796.

[5] M Adib, S. Rajai-Daryasarei, R. Pashazadeh, M. Jahani, R. Yazzaf, M. Amanlou, Eur. J. Org. Chem. 2018, 3001 .

[6] M. Adib, S. Rajai-Daryasarei, R. Pashazadeh, M. Jahani, M. Amanlou, Synlett 2018, 29, 1583.

[7] S. Jin, Z. Kuang, Q. Song, Org. Lett. 2020, 22, 615.

[8] For some reviews on Gewald reactions, see: a) K. Bozorov, F. Nie, J. Zhao, H. A. Aisa, Eur. J. Med. Chem. 2017, 140, 465; b) K. Gewald, Chem. Heterocycl. Compd. 1976, 12, 1077; b) Z. Puterova, A. Krutosikova, D. Veghc, Arkivoc 2010, 1, 209; c) Y. Huang, A. Domling, Molec. Divers. 2011, 15, 3; d) A. El-Mekabaty, Synth. Commun. 2014, 44, 1; e) R. W.
Sabnis, Color. Technol. 2016, 132, 49; f) R. Shah, P. K. Verma, Chem. Central J. 2018, 12, 137.

[9] W. Shao, S. J. Kaldas, A. K. Yudin, Chem. Sci. 2017, 8,4431 .

[10] J. Thomas, S. Jana, M. Sonawane, B. Fiey, J. Balzarini, S. Liekens, W. Dehaen, Org. Biomol. Chem. 2017, 15, 3892.

[11] K. Kavitha, D. Srikrishna, P. K. Dubey, P. Aparna, J. Sulfur Chem. 2019, 40, 195.

[12] T. T. T. Nguyen, V. A. Le, P. Retailleau, T. B. Nguyen, Adv. Synth. Catal. 2020, 362, 160.

[13] A. G. Ibragimov, G. A. Makhmudiyarov, M. G. Shaibakova, L. M. Khalilov, U. M. Dzhemilev, Russian J. Org. Chem. 2019, 55, 1890.

[14] a) L. Feng, T. Hu, S. Zhang, H. Xiong, G. Zhang, Org. Lett. 2019, 21, 9487; for a previous work, see: G. Zhang, H. Yi, H. Chen, C. Bian, C. Liu, A. Lei, Org. Lett. 2014, 16, 6156.

[15] N. Nagahora, I. Takemoto, M. Fujii, K. Shioji, K. Okuma, Org. Lett. 2017, 19, 2110.

[16] Nguyen, T. B.; Retailleau, P. Org. Lett. 2017, 19, 4858.

[17] Nguyen, T. B.; Retailleau, P. Org. Lett. 2018, 20, 186.

[18] S. Moon, M. Kato, Y. Nishii, M. Miura, Adv. Synth. Catal. 2020, 362, 10.1002/adsc.202000112.

[19] S. Sakai, K. Sato, K. Yoshida, Tetrahedron Lett. 2020, $61,151476$.

[20] T. Higashino, A. Ueda, J. Yoshida, H. Mori, Chem. Commun. 2017, 53, 3426.

[21] J. A. Elix, G. C. Morris, Tetrahedron Lett. 1969, 8, 671.

[22] a) W. Fan, N. Liang, D. Meng, J. Feng, Y. Li, J. Houa, Z. Wang, Chem. Commun. 2016, 52, 11500; b) Y. Ma, Z. Shi, A. Zhang, J. Li, X. Wei, T. Jiang, Y. Li, X. Wang, Dyes Pigments 2016, 135, 41; c) R. K. Gupta, D. S. S. Rao, S. K. Prasad, A. S. Achalkumar, Chem. Eur. J. 2018, 24, 3566; d) G. Li, S. Wang, T. Liu, P. Hao, Z. Liu, F. Li, L. Yang, Y. Zhang, D. Li, S. Yang, J. Zhao, J. Li, H. Yan, B. Tang, J. Mater. Chem. C 2018, 6, 12601; e) F. Zhang, X. Huang, X. Wei, H. Ren, T. Jiang, X. Li, J. Wu, Y. Ma, J. Chem. Res. 2020, 44, 60.

[23] a) S. M. Chintala, J. T. Petroff II, A. Barnes, Andrew; R. D. McCulla, J. Sulfur Chem. 2019, 40, 503; b) W. Jiang, H. Qian, Y. Li, Z. Wang, J. Org. Chem. 2008, 73,7369 .

[24] H. Langhals, S. Kirner, Eur J. Org. Chem. 2000, 365.

[25] C. Chen, P. Xia, T. Du, Y. Deng, Y. Xiao, Yi, Org. Lett. 2019, 21, 5529.

[26] T. I. Solomentseva, V. I. Rogovik, T. A. Chibisova, V. F. Traven', B. I. Stepanov, J. Org. Chem. USSR 1986, 943; Zhur. Org. Khim. 1986, 22, 1050.

[27] L. G. Fedenok, K. Y. Fedotov, E. A. Pritchina, N. E. Polyakov, Tetrahedron Lett. 2016, 57, 1273. 
[28] F. Su, S. Chen, X. Mo, K. Wu, J. Wu, W. Lin, Z. Lin, J. Lin, H. Zhang, T. Wen, Chem. Sci. 2020, 11, 1503.

[29] J. Wu, D. He, Y. Wang, F. Su, Z. Guo, J. Lin, H. Zhang, Org. Lett. 2018, 20, 6117.

[30] T. Shoji, K. Miura, A. Ohta, R. Sekiguchi, S. Ito, Y. Endo, T. Nagahata, S. Mori, T. Okujima, Org. Chem. Front. 2019, 6, 2801.

[31] T. Prochnow, A. Maroneze, D. F. Back, G. Zeni, J. Org. Chem. 2019, 84, 2891.

[32] J. Liu, Y. Zhang, Y. Yue, Z. Wang, H. Shao, K. Zhuo, Q. Lv, Z. Zhang, J. Org. Chem. 2019, 84, 12946.

[33] P. Ni, B. Li, H. Huang, F. Xiao, G. Deng, Green Chem. 2017, 19, 5553 .

[34] T. T. Nguyen, P. H. Tran, RSC Adv. 2020, 10, 9663.

[35] H. Zhang, F. Wen, W. Sheng, P. Yin, C. Zhang, C. Peng, D. Peng, D. Liao, R. Fu, Tetrahedron Lett. 2019, 60,80 .

[36] C. Lu, H. Huang, X. Tuo, P. Jiang, F. Zhang, G. Deng, Org. Chem. Front. 2019, 6, 2738.

[37] Z. Liu, R. Gao, J. Lou, Y. He, Z. Yu, Adv. Synth. Catal. 2018, 360, 3097.

[38] C. Teja, F. R. N. Khan, Org. Lett. 2020, 22, 1726.

[39] Z. Xu, G. Deng, F. Zhang, H. Chen, H. Huang, Org. Lett. 2019, 21, 8630.

[40] R. Semwal, C. Ravi, S. Saxena, S. Adimurthy, J. Org. Chem. 2019, 84, 14151.

[41] T. Shi, C. J. Zerio, J. Sivinski, A. J. Ambrose, K. T. Moore, T. Buckley, L. Kaneko, M. Zhang, D. D. Zhang, E. Chapman, Eur. J. Org. Chem. 2019, 3269.

[42] P. Zhang, W. Chem, M. Liu, H. Wu, Org. Lett. 2019, 21,9326

[43] H. Huang, Z. Xu, X. Ji, B. Li, G. Deng, Org. Lett. 2018, $20,4917$.

[44] P. Zhou, Y. Huang, W. Wu, W. Yu, J. Li, Z. Zhu, H. Jiang, Org. Biomol. Chem. 2019, 17, 3424.

[45] H. Huang, Q. Wang, Z. Xu, G. Deng, Adv. Synth. Catal. 2019, 361, 591

[46] P. H. Pham, K. X. Nguyen, N. P. Nguyen, H. T. B. Pham, T. T. Nguyen, N. T. S. Phan, Asian J. Org. Chem. 2020, 9, 622.

[47] P. H. Pham, K. X. Nguyen, H. T. B. Pham, T. T. Nguyen, N. T. S. Phan, Org. Lett. 2019, 21, 8795.

[48] P. Zhou, Y. Huang, W. Wu, J. Zhou, W. Yu, H. Jiang, Org. Lett. 2019, 21, 24, 9976.

[49] P. H. Pham, K. X. Nguyen, H. T. B. Pham, T. T. Tran, T. T. Nguyen, N. T. S. Phan, RSC $A d v$., 2020, 10, 11024 .

[50] P. Ni, J. Tan, R. Li, H. Huang, F. Zhang, G. Deng, RSC $A d v .2020,10,3931$.
[51] H. Huang, Z. Qu, X. Ji, G. Deng, Org. Chem. Front. 2019, $6,1146$.

[52] W. Zhang, S.Tao, H. Ge, Q. Li, Z. Ai, X. Li, B. Zhang, F. Sun, X. Xu, Y. Du, Org. Lett. 2020, 22, 448.

[53] F. Wei, X. Shen, X. Zhang, Adv. Synth. Catal. 2018, $360,3911$.

[54] H. Xu, X. Zhang, X. Zhang, J. Org. Chem. 2019, 84, 7894.

[55] M. D. Hammers, L. Singh, L. A. Montoya, A. D. Moghaddam, M. D. Pluth, Synlett 2016, 27, 1349.

[56] D. Pournama, G. A. Heropoulos, M. Koufaki, Tetrahedron Lett. 2017, 58, 2378.

[57] B. Böttcher, A. Lüttringhaus, Justus Liebigs Ann. Chem. 1948, 560, 201.

[58] T. J. Curphey, J. Org. Chem. 2002, 67, 6461.

[59] Z. Song, F. Bai, B. Zhang, J. Fang, J. Agric. Food Chem. 2020, 68, 2214.

[60] M. Huang, T. Li, J. Liu, A.Shatskiy, M. D. Kärkäs, X. Wang, Org. Lett. 2020, 22, 3454.

[61] T. B. Nguyen, P. Retailleau, Org. Lett. 2019, 21, 279.

[62] V. Petrov, R. J. Dooley, A. A. Marchione, E. L. Diaz, B. S. Clem, J. Fluorine Chem. 2019, 225, 1.

[63] V. Petrov, A. A. Marchione, R. Dooley, Chem. Commun. 2018, 54, 9298.

[64] V. A. Petrova, W. Marshall J. Fluorine Chem. 2010, $131,1144$.

[65] N. Sakai, S. Horikawa, Y. Ogiwara, Synthesis 2018, 50, 565.

[66] L. Zhang, Y. Li, T. Gao, S. Guo, B. Yang, Z. Meng, Q. Dai, Z. Xu, Q. Wu, Synthesis 2019, 51, 4170.

[67] N. Marien, B. N. Reddy, F. De Vleeschouwer, S. Goderis, K. Van Hecke, G. Verniest, Angew. Chem. Int. Ed. 2018, 57, 5660; Angew. Chem. 2018, 130, 5762.

[68] M Wu, Y. Jiang, Z. An, Z. Qi, R. Yan, Adv. Synth. Catal. 2018, 360, 4236.

[69] R. Fu, Y. Wang, F. Xia, H. Zhang, Y. Sun, D. Yang, Y. Wang, P. Yin, J. Org. Chem. 2019, 84, 12237.

[70] J. Ying, H. Wang, X. Qi, J. Peng, X. Wu, Eur. J. Org. Chem. 2018, 688.

[71] X. Wang, X. Qiu, J. Wei, J. Liu, S. Song, W. Wang, N. Jiao, Org. Lett. 2018, 20, 2632.

[72] F. Heydari-Mokarrar, R. Heydari, M. Maghsoodlou, A. Samzadeh-Kermani, J. Sulfur Chem. 2020, 41, 258.

[73] J. Jiang, H. Huang, G. Deng, Green Chem. 2019, 21, 986.

[74] K. Banert, N. Singh, M. Korb, H. Lang, Synthesis 2015 , 47, 533.

[75] H. Deng, Z. Li, F. Ke, X. Zhou, Chem. Eur. J. 2012, 18,4840 . 
[76] Z. Yang, R. Hu, X. Li, X. Wang, R. Gu, S. Han, Tetrahedron Lett. 2017, 58, 2366.

[77] R. Wang, Y. Ding, H. Liu, S. Peng, J. Ren, L. Li, Tetrahedron Lett. 2014, 55, 945,

[78] H. Xu, C. Luo, Z. Li, H. Xiang, X. Zhou, J. Heterocycl. Chem. 2016, 53, 1207.

[79] L. Pan, L. Yu, Z. Wu, Z. Li, H. Xiang, X. Zhou, RSC Adv. 2014, 4, 27775.

[80] X. Wang, X. Li, R. Hu, Z. Yang, R. Gu, S. Ding, P. Li, S. Han, Synlett 2018, 29, 219.

[81] Y. Huang, D. Yan, X. Wang, P. Zhou, W. Wu, H Jiang, Chem. Commun. 2018, 54, 1742.

[82] Y. Huang, P. Zhou, W. Wu, H. Jiang, J. Org. Chem. 2018, 83, 2460.

[83] a) H. H. Hodgson, J. Chem. Soc. Trans. 1912, 101, 1693; b) H. H. Hodgson, A. G. Dix, J. Chem. Soc., Trans. 1914, 105, 952; c) H. H. Hodgson, J. Chem. Soc., Trans., 1924, 125, 1855; d) M. T. Bogert, L. Smidth, J. Am. Chem. Soc. 1928, 50, 428; e) H. H. Hodgson and H. V. France, J. Chem. Soc. 1933, 296; f) H. H. Hodgson, H. V. France, J. Chem. Soc. 1934, 1140; g) A. P. Bindra, J. A. Elix, G. C. Morris, Aust. J. Chem. 1969, 22, 2483; h) W. A. Pryor, In Mechanisms of Sulfur Reactions, McGraw-Hill, New York 1962; c) Schmidt, Inorg. Macromol. Rev. 1970, 1, 101.

[84] a) L. Bukowski, M. Janowiec, Pharmazie, 1996, 51, 27; b) H. Saikachi, Hisano, T. Chem. Pharm. Bull. 1959, 7, 349; c) H. Saikachi, T. Hisano, Chem. Pharm. Bull. 1960, 8, 51; d) 2-methylbenzothiazole: H. Saikachi, T. Hisano, J. Pharm. Soc. Jpn 1959, 79, 1305; e) H. Saikachi, T. Hisano, Chem. Pharm. Bull. 1959, 7, 716; f) T. Hisano, Y. Yabuta, Chem. Pharm. Bull. 1973, 21, 511; g) K. V. Martin, J. Am. Chem. Soc. 1958, 80, 233; h) H. D. Porter, J. Am. Chem. Soc. 1954, 76, 127; i) E. Miller, G. L. Oliver, J. R. Dann, J. W. Gates Jr. J. Org. Chem. 1957, 22, 664.

[85] J. Perregaard, S. O. Lawesson, Acta Chem. Scand. B 1977, 31, 203.

[86] T. Hisano; M. Ichikawa; K. Tsumoto; M. Tasaki Chem. Pharm. Bull. 1982, 30, 2996.

[87] 2-Methylquinoline, 2- and 4-picolines with anilines or nitrobenzenes: T. Hisano; M. Ichikawa, Chem. Pharm. Bull. 1974, 22, 2051.

[88] B. Emmert; A. Holz, Chem. Ber. 1954, 87, 676.

[89] H. Bredereck, W. Jentzsch, Chem. Ber. 1960, 93, 2410.

[90] J. Van Alphen, G. Drost, Recl. Trav. Chim. Pays-Bas 1949, 68, 301.

[91] L. F. Zhang, Z. H. Ni, D. Y. Li, Z. H. Qin, X. Y. Wei, Chinese Chem. Lett. 2012, 23, 281.

[92] X. Zhu, Y. Yang, G. Xiao, J. Song, Y. Liang, G. Deng, Chem. Commun. 2017, 53, 11917.

[93] X. Che, J. Jiang, F. Xiao, H. Huang, G. Deng, Org. Lett. 2017, 19, 4576 .
[94] G. Li, H. Xie, J. Chen, Y. Guo, D. Deng, Green Chem. 2017, 19, 4043.

[95] J. Jiang, G. Li, F. Zhang, H. Xie, G. Deng, Adv. Synth. Catal. 2018, 360, 1622.

[96] Y. Liu, X. Yuan, X. Guo, X, Zhang, B. Chen, Tetrahedron 2018, 74, 6057.

[97] J. Zhang, X. Zhao, P. Liu, P. Sun, J. Org. Chem. 2019, $84,12596$.

[98] M. Singh, P. Awasthi, V. Singh, Eur. J. Org. Chem. $2020,1023$.

[99] G. Li, J. Jiang, F. Zhang, F. Xiao, G. Deng, Org. Biomol. Chem. 2017, 15, 10024.

[100] T. B. Nguyen, L. Ermolenko, A. Almourabit, Org. Lett. 2013, 15, 4218.

[101] T. B. Nguyen, P. Retailleau, L. Ermolenko, A. Almourabit, Angew. Chem. Int. Ed. 2014, 53, 13808.

[102] T. Guntreddi, R. Vanjari, K. N. Singh, Org. Lett. 2015, 17, 976 .

[103] T. B. Nguyen, K. Pasturaud, L. Ermolenko, A. Almourabit Org. Lett. 2015, 17, 2562.

[104] Nguyen, L. A.; Ngo, Q. A.; Retailleau, P.; Nguyen, T. B. Green Chem. 2017, 19, 4289.

[105] X. Wang, D. Miao, X. Li, R. Hu, Z. Yang, R. Gu, S. Han, Tetrahedron 2017, 73, 5194.

[106] Z. Xu, H. Huang, H. Chen, G. Deng, Org. Chem. Front. 2019, 6, 3060

[107] H. Xie, G. Li, F. Zhang, F. Xiao, G. Deng, Green Chem. 2018, 20, 827.

[108] J. Xiong, G. Zhong, Y. Liu, Adv. Synth. Catal. 2019, 361,550 .

[109] H. M. Gordhan, S. L. Patrick; M I. Swasy, A. L. Hackler, M. Anayee, J. E. Golden, J. C. Morris, D. C. Whitehead, Bioorg. Med. Chem. Lett. 2017, 27, 537.

[110] J. Guo, J. Gong, M. Song, Org. Biomol. Chem. 2019, 17,5029 .

[111] F.-J. Chen, G. Liao, X. Li, J. Wu, B.-F. Shi, Org. Lett. 2014, 16, 5644.

[112] J. Chen, Y. Jiang, J. T. Yu, J. Cheng, J. Org. Chem. 2015, 81, 271.

[113] S. K. Mo, Q. H. Teng, Y. M. Pan, H. T. Tang, $A d v$. Synth. Catal. 2019, 361, 1756.

[114] T. Ishikawa, M. Kimura, T. Kumoi, H. Iida, ACS Catal. 2017, 7, 4986.

[115] W. Li, J. He, P. Liu, J. Zhang, B. Dai, Chem. Select 2019, 4, 10587.

[116] T. Ishikawa, N. Matsunaga, H. Tawada, N. Kuroda, Y. Nakayama, Y. Ishibashi, M. Tomimoto, Y. Ikeda, Y. Tagawa, Y. Iizawa, K. Okonogi, S. Hashiguchi, A. Miyake, Bioorg. Med. Chem. 2003, 11, 2427. 
[117] R. S. Harris, D. A. Harki, A. L. Perkins-Harki, M. A. Carpenter, M. Li Ming, WO2013074059 (A2), 2013.

[118] H. Xie, J. Cai, Z. Wang, H. Huang, G. Deng, Org. Lett. 2016, 18, 2196.

[119] Y. Zhang, Y. Liu, J. Zhang, R. Gu, S. Han, Tetrahedron Lett. 2019, 60, 151289.

[120] Z. Zhou, M. Liu, S. Sun, E. Yao, S. Liu, Z. Wu, J. Yu, Y. Jiang, J. Cheng, Tetrahedron Lett. 2017, 58, 2571.

[121] Z. Wang, H. Xie, F. Xiao, Y. Guo, H. Huang, G. Deng, Eur. J. Org. Chem. 2017, 1604.

[122] Y. Qu, P. Pander, A. Bucinskas, M. Vasylieva, Y. Tian, F. Miomandre, F. B. Dias, G. Clavier, P. Data, P. Audebert, Chem. Eur. J. 2019, 25, 2457.

[123] T. B. Nguyen, P. Retailleau, Org. Lett. 2017, 19, 3879.

[124] T. M. Nguyen, H. A. Cao, T. T. T. Cao, S. Koyama, D. H. Mac, T. B. Nguyen, unpublished result.

[125] W. Feng, X. Zhang, Chem. Commun. 2019, 55, 1144.

[126] J. Jiang, X. Tuo, Z. Fu, H. Huang, G. Deng, Org. Biomol. Chem. 2020, 18, 3234.

[127] J. Zhao, Z. Luo, J. Xu, Adv. Synth. Catal. 2020, 362, 1988.

[128] Q. Chen, R. Xie, H. Jia, J. Sun, G. Lu, H. Jiang, M. Zhang, J. Org. Chem. 2020, 85, 5629.

[129] a) E. Knoevenagel, J. Prak. Chem. 1914, 89, 23; for further examples, see: b) N. P. Buu-Hoi, J. Chem. Soc. 1950, 1146; c) Chatel, S. Morel, G. Boyer, J. P. Galy, Heterocycles 2000, 53, 2535; d) P. Lopez-Alvarado, C. Avendano, J. C. Menendez, Heterocycles 1991, 32, 1003.

[130] J. Zhang, C. Song, L. Sheng, P. Liu, P. Sun, J. Org. Chem. 2019, 84, 2191.

[131] Y. Hu, Z. Yin, T. Werner, A. Spannenberg, X. Wu, Eur. J. Org. Chem. 2018, 1274.

[132] J. Ying, C. Zhou, X. Wu, Org. Biomol. Chem. 2018, $16,1065$.

[133] Mehdi Khalaj, M. Taherkhani, F. Naderi, S. M. Mousavi-Safavi, Monat. Chem. 2018, 149, 63.

[134] D. Gattaiah, A. S. Reddy, S. A. Khan, K. C. K. Swamy, J. Organomet. Chem. 2019, 889, 33.

[135] Y. Gao, L. Wei, Y. Liu, J. Wan, Org. Biomol. Chem. 2017, 15, 4631.

[136] Z. Chen, P. Liang, F. Xu, Z. Deng, L. Long, G. Luo, M. Ye, J. Org. Chem. 2019, 84, 12639.

[137] T. B. Nguyen, P. Retailleau, Org. Lett. 2017, 19, 3887.

[138] H. Gan, Chem. Select 2019, 4, 8598.

[139] L. A. Nguyen, T. D. Dang, Q. A. Ngo, T. B. Nguyen, Eur. J. Org. Chem. 2020, DOI: 10.1002/ejoc. 202000523 .
[140] L. A. Nguyen, P. Retailleau, T. B. Nguyen, Adv. Synth. Catal. 2019, 361, 2864.

[141] Z. Li, J. Dong, J. Wang, D. Yang, Z. Weng, Chem. Commun. 2019, 55, 13132.

[142] W. Bao, C. Chen, N. Yi, J. Jiang, Z. Zeng, W. Deng, Z. Peng, J. Xiang, Chin. J. Chem. 2017, 35, 1611.

[143] Nguyen, T. B.; Retailleau, P. Adv. Synth. Catal. 2017, $359,3843$.

[144] Y. Xie, X. Chen, Z. Wang, H. Huang, B. Yi, G. Deng, Green Chem. 2017, 19, 4294.

[145] J. Tan, P. Ni, H. Huang, G. Deng, Org. Biomol. Chem. 2018, 16, 4227.

[146] J. Sheng, J. Liu, H. Zhao, L. Zheng, X. Wei, Org. Biomol. Chem. 2018, 16, 5570.

[147] Nguyen, T. B.; Retailleau, P. J. Org. Chem, 2019, 84, 5907.

[148] X, Chen, Z. Wang, H.Huang, G. Deng, Adv. Synth. Catal. 2018, 360, 4017.

[149] Nguyen, T. B.; Retailleau, P. Adv. Synth. Catal. 2018, $360,2389$.

[150] T. B. Nguyen, L. A. Nguyen, P. Retailleau, Org. Lett. 2019, 21, 6570 .

[151] J. Liu, X. Yan, N. Liu, Y. Zhang, S. Zhao, X. Wang, K. Zhuo, Y. Yue, Org. Chem. Front. 2018, 5, 1034.

[152] T. B. Nguyen, J. Hu, Retailleau, P. Adv. Synth. Catal. 2019, 361, 3337.

[153] Y. Qu, F-X. Sauvage, G. Clavier, F. Miomandre, P. Audebert, Angew. Chem. Int. Ed. 2018, 57, 12057.

[154] T. A. Tikhonova, K. A. Lyssenko, I. V. Zavarzin, Y. A. Volkova, J. Org. Chem. 2019, 84, 15817.

[155] T. B. Nguyen, L. Ermolenko, A. Almourabit, J. Am. Chem. Soc. 2013, 135, 118.

[156] T. B. Nguyen, J. Le Bescont, L. Ermolenko, A. Almourabit, Org. Lett. 2013, 15, 6218.

[157] T. B. Nguyen, P. Retailleau, A. Almourabit, Org. Lett. 2013, 15, 5238 .

[158] T. B. Nguyen, L. Ermolenko, M. Corbin, A. Almourabit, Org. Chem. Front. 2014, 1, 1157.

[159] T. B. Nguyen, L. Ermolenko, A. Almourabit, Synthesis 2015, 47, 1741.

[160] T. B. Nguyen, J. Cheung-Lung, Eur. J. Org. Chem. 2018, 5815.

[161] H, Gan, Chem. Select 2020, 5, 717.

[162] T. B. Nguyen, L. P. A. Nguyen, T. T. T. Nguyen, $A d v$. Synth. Catal. 2019, 361, 1787.

[163] H. Gan, D. Yang, J. Saudi Chem. Soc. 2019, 23, 809.

[164] H. Gan, Chem. Select 2019, 4, 2858.

[165] M.-H. D. Dang, L. H. T. Nguyen, P. H. Tran, Synthesis 2020, 52, 1687. 
[166] S. Deng, H. Chen, X. Ma, Y. Zhou, K. Yang, Y. Lan, Q. Song, Chem. Sci. 2019, 10, 6828.

[167] T. Pavithra, E. S. Devi, S. Nagarajan, V. Sridharan, C. U. Maheswari, Eur. J. Org. Chem. 2019, 6884. 


\section{REVIEW}

Recent Advances in the Synthesis of Heterocycles via Reactions Involving Elemental Sulfur

Adv. Synth. Catal. Year, Volume, Page - Page

Thanh Binh Nguyen*

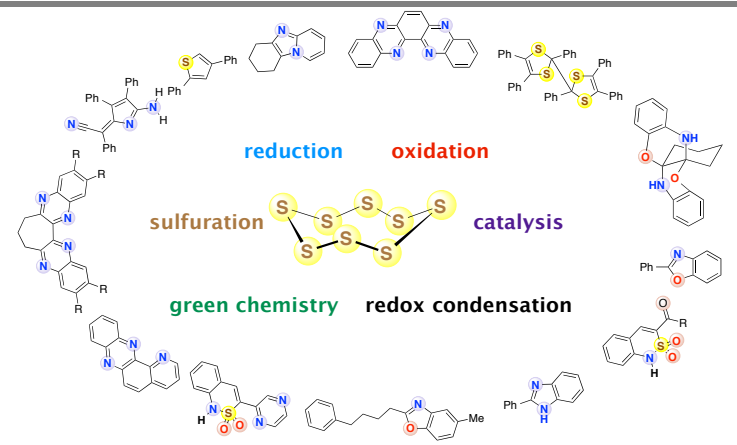

